\title{
Leading Canada's Sustainable Energy Transition: Does Gender Matter?
}

\author{
by
}

\author{
Silke Popescu
}

A thesis submitted to the Faculty of Graduate and Postdoctoral Affairs in partial fulfillment of the requirements for the degree of

Master of Arts

in

Sustainable Energy

Carleton University

Ottawa, Ontario

(C) 2021, Silke Popescu 


\begin{abstract}
Canada is failing to effectively address the slew of sustainability problems stemming from its energy sector, leading to a deterioration of its ecosystems and putting the health of Canadians and the long-term vitality of its economy at risk. In order to improve this situation, research suggests that a novel form of leadership is required. Through a review of literature and interviews with 18 leaders in Canadian energy sector firms, this thesis explores not only what kind of leadership Canada needs to address its contemporary sustainability problems, but also where this leadership can be found. The findings of this thesis suggest that women may be the sustainable energy transition leaders that Canada needs, and therefore supporting women so they can advance in Canadian energy sector firms will serve to facilitate Canada's sustainable energy transition. In short, I argue that gender matters when it comes to leading Canada's sustainable energy transition.
\end{abstract}

Keywords: Gender, Leadership, Sustainable Energy Transition 


\section{Acknowledgements}

I would like to thank my supervisors Professor Alexandra Mallett and Professor Lisa Mills for helping me throughout this process and being so supportive. I would also like to thank all of the participants in this research who took the time to speak with me and provide their insights and ideas. With support from leaders like them, we can work together to build a better future for Canada. 


\section{Table of Contents}

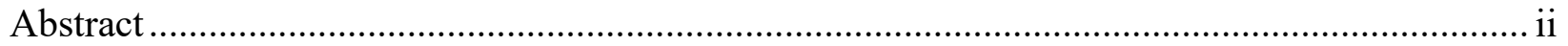

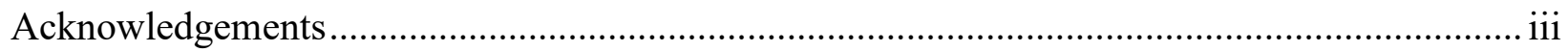

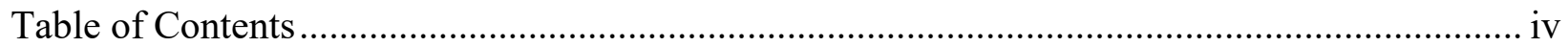

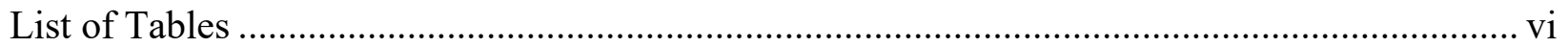

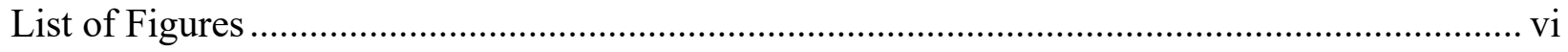

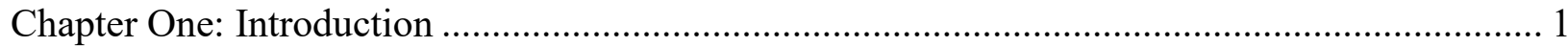

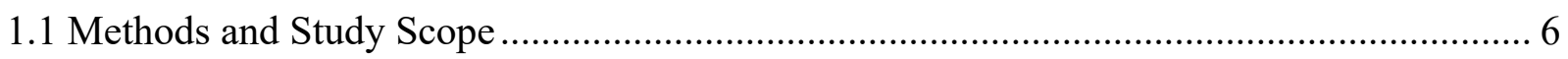

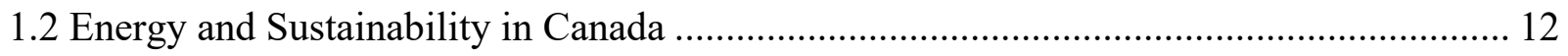

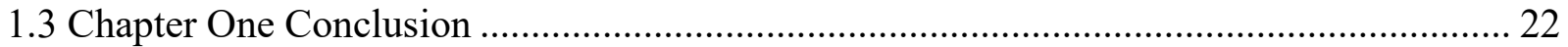

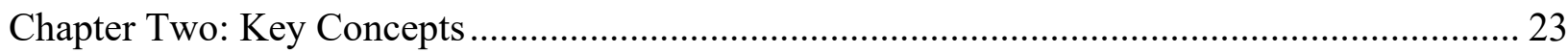

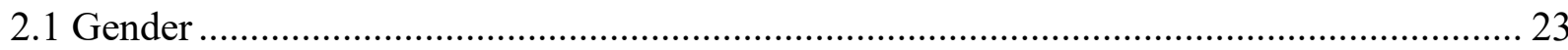

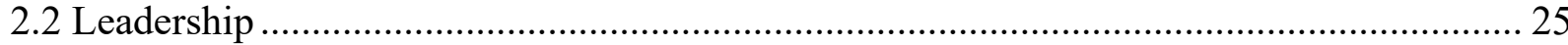

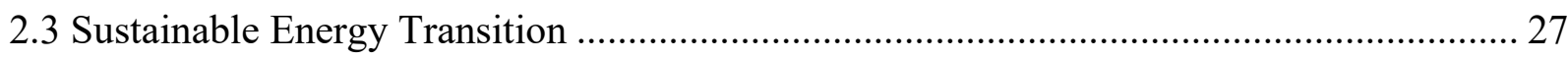

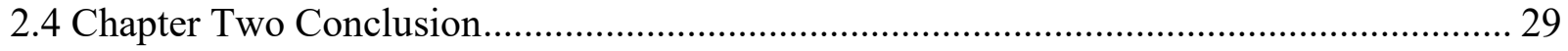

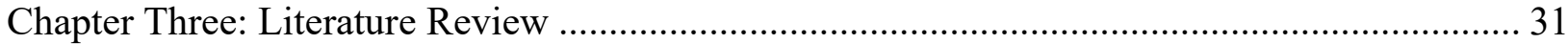

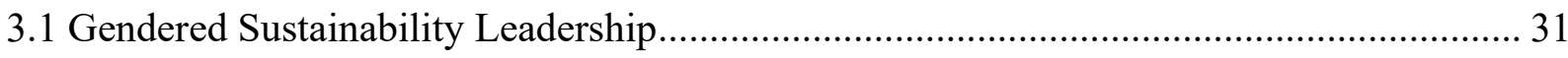

3.1.1 Sustainability leadership ........................................................................... 32

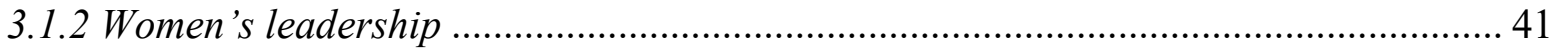

3.2 Barriers and Recommendations for Women Leaders ................................................... 53

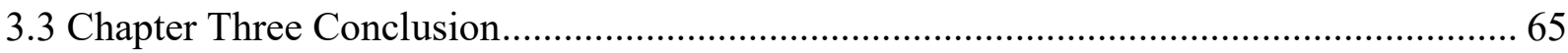

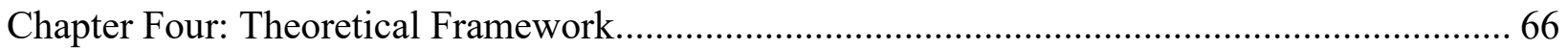

4.1 Women as Sustainable Energy Transition Leaders .................................................... 66

4.2 Situating Gender within Sociotechnical Transitions ................................................. 70

4.2.1 A new model for sociotechnical transitions ......................................................... 73

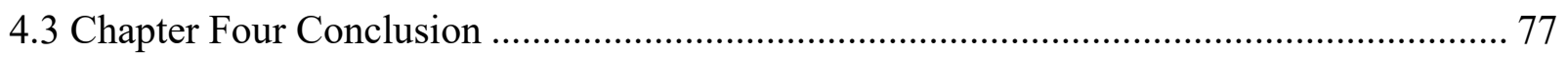

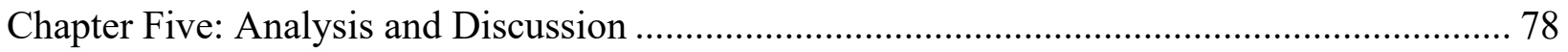

5.1 Evaluating Women as Sustainable Energy Transition Leaders ..................................... 78

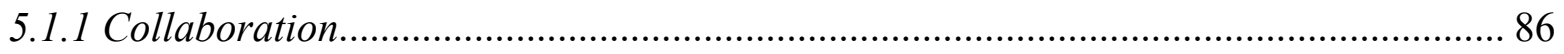

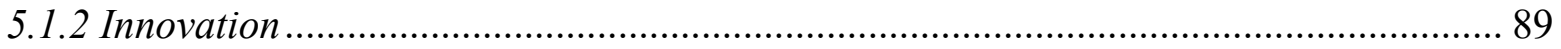


5.1.3 Transformational leadership ...................................................................... 92

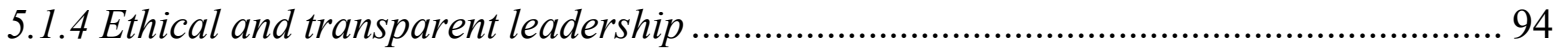

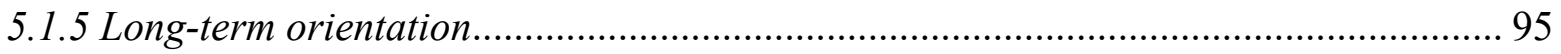

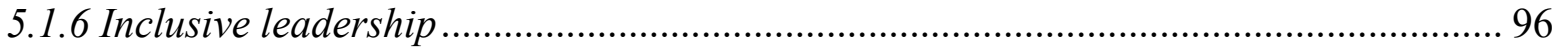

5.1.7 The ability to manage complexity ................................................................................ 98

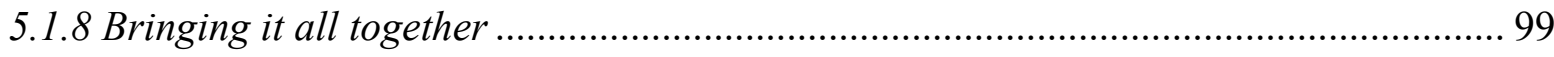

5.2 Revisiting Barriers and Recommendations for Women Leaders .................................. 101

5.2.1 A lack of flexibility and accommodation ................................................................ 107

5.2.2 Limited support and role models ................................................................... 108

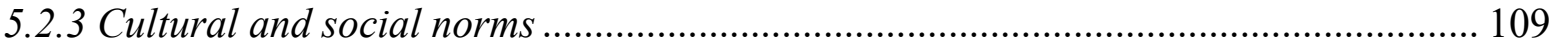

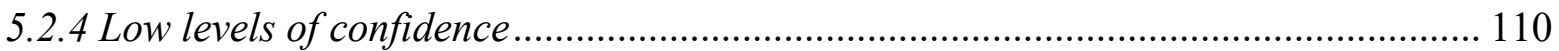

5.2.5 Improper/insufficient backgrounds and/or education .......................................... 112

5.2.6 Other barriers and recommendations ..................................................................... 113

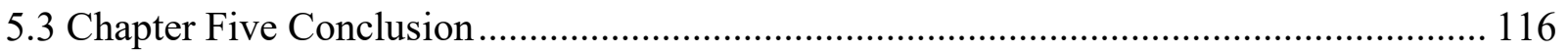

Chapter Six: Conclusion and Implications of Findings ................................................... 117

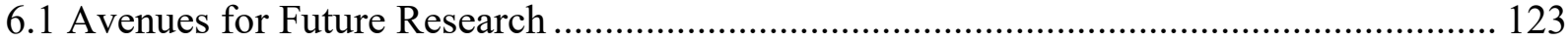

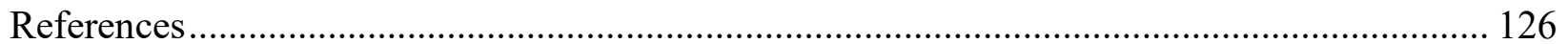

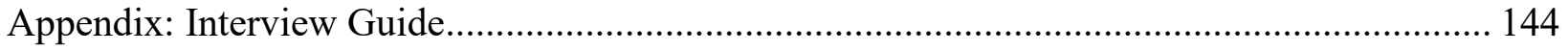




\section{List of Tables}

Table 1: Attributes for Private Sector Sustainability Leadership ................................................. 40

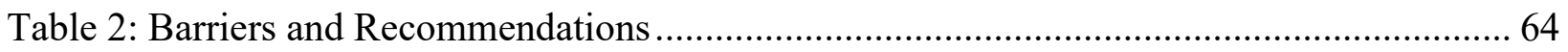

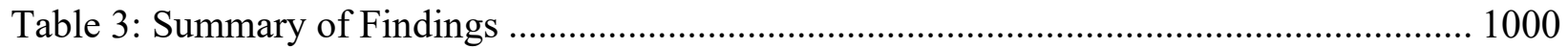

Table 4: Other Barriers and Recommendations Put Forward by Participants ......................... 1144

\section{List of Figures}

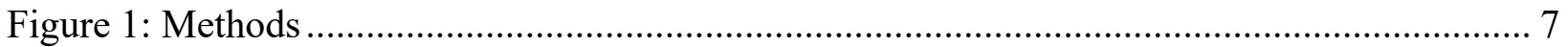

Figure 2: Canada's Primary Energy Production........................................................................ 14

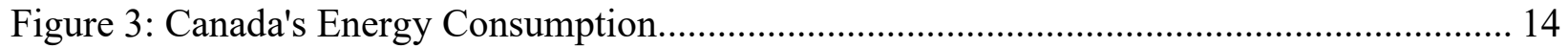

Figure 4: Sustainability Leadership Behavioural Competency Model ........................................... 35

Figure 5: The Cambridge Sustainability Leadership Model......................................................... 36

Figure 6: Model of Sociotechnical Transition ........................................................................ 77

Figure 7: Frequency of Themes Across Avenues of Questioning .............................................. 844

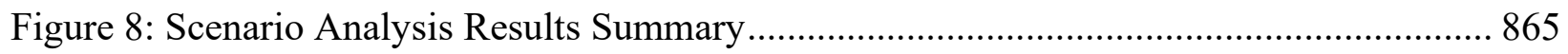

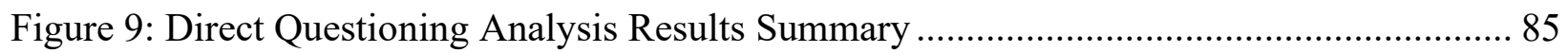

Figure 10: Barriers Women Face in Canadian Energy Sector Firms........................................ 1066

Figure 11: Recommendations to Better Support Women in Canadian Energy Sector Firms ... 1066 


\section{Chapter One: Introduction}

In the haste to save the planet it seems tempting to avoid gendered wars and potential misunderstandings. We do not have the time. But perhaps we have no other option.

(Marshall, 2011, p. 279)

Canada, along with the rest of the world, is facing a crisis of sustainability. The collective sum of humanity's exploitation of the Earth and its resources has reached a point where its impacts can no longer be ignored. Ozone depletion, drought and desertification, pollution of the land, air, and sea, biodiversity loss, a depletion of fresh water supplies, and climate change, are all making humanity's position on Earth increasingly perilous. These human-induced impacts are undermining the health, well-being, and livelihoods of people around the world.

This rhetoric, and the sentiment that change is needed, is hardly controversial. Stories of impending doom dominate the media, including headlines like: "Third of global food production at risk from climate crisis" (Harvey, 2021), "World running out of time to tackle climate crisis" (Millard, 2021), and "Water Stress: A Global Problem That's Getting Worse" (Felter \& Robinson, 2021). However, despite a general recognition that there is a problem, there is a lack of consensus regarding what to do. Unsurprisingly, coordinating a global or even national reorganization of technical, economic, and social systems to better protect the Earth and its inhabitants is not easy.

One key sector within these global reorganization efforts across a vast array of processes, practices, and technologies is that of the energy sector. This sector is particularly important in Canada (as will be further explored below in section 1.2). The energy sector contributes to many of the aforementioned sustainability challenges. For example, large amounts of fresh water are used in energy resource extraction, processing, and transportation, as well as in nuclear plants, hydroelectric facilities, and emissions scrubbing processes (Pate et al., 2007). Large swaths of land 
are also used in energy resource extraction and production, such as land that is drowned under reservoirs for hydroelectricity and used by roads and power lines to supply power plants (Dorber et al., 2018). For example, analysis by Bloomberg found that land use requirements of America's energy production system, which currently stands at 328 thousand square kilometres, could as much as quadruple by 2050 depending on the mix of energy sources (Merrill, 2021). Energy production and consumption is also the leading cause of human-caused air pollution and climate change in Canada (Government of Canada, 2017). In fact, the Canadian energy sector is responsible for $82 \%$ of national greenhouse gas (GHG) emissions, the leading cause of anthropogenic climate change (Natural Resources Canada [NRCan], 2020a). All of these sustainability challenges will be further explored in section 1.2, but what is important is that all of these issues must be addressed for Canada and Canadians to have a thriving, healthy, and prosperous future. The way that these sustainability challenges can be addressed is through a sustainable energy transition, ${ }^{1}$ which will be defined in section 2.3 .

These negative impacts originating in the Canadian energy sector primarily stem from the private sector, which holds the bulk of the capital available to unlock change or to support the existing unsustainable energy regime. Change is therefore desperately needed within Canadian energy sector firms: change which can be most effectively initiated from the top. Scholars within the field of sustainability leadership agree that leaders, particularly those within the private sector, are crucial linchpins for the attainment of sustainability (Campbell et al., 2018, p. 19; Hull et al., 2018; MacNeill, 2007). MacNeill (2007) goes so far as to argue that deep and enduring sustainability will not happen if those at the top are not committed to it (p. 21). Furthermore, Hull

\footnotetext{
${ }^{1}$ Though there is scholarly debate regarding terminology, this thesis will use the singular term 'transition' when describing Canada's movement towards a more sustainable energy system. However, despite being singular, this term is referring to changes across the economy and in various distinct energy systems, such as heating, transportation, and electricity systems.
} 
and colleagues (2018) point out that even when technological solutions exist which can ameliorate sustainability issues, a lack of leadership can lead to shortcomings or failure in implementation (p. 171).

Leaders within Canadian energy sector firms will therefore play a key role in creating a more sustainable future, yet little progress has thus far been made. For example, GHG emissions from oil and gas production in Canada increased by 23\% between 2000 and 2018 (NRCan, 2020a). Current leaders and their styles of leadership therefore simply have not sufficiently advanced sustainability in Canada. To improve this situation and more effectively promote sustainability within the Canadian energy sector, new leadership, with different priorities and styles of leadership, is needed. This research builds on a small body of literature which suggests that women, who are currently a minority in leadership positions in energy sector firms, may be the leaders needed to achieve more sustainable outcomes (Campbell et al., 2018; Lieu et al., 2020; Marshall, 2011).

The origin of this research can therefore be summarized by two questions: what kind of leadership does Canada need to facilitate its transition to a sustainable energy future? And where can we find it? $?^{2}$ There is no one answer or field of literature which responds to these questions, and, to the best of my knowledge, these questions have not yet been asked. This research will therefore be combining the field of literature exploring sustainability leadership with that which explores gendered leadership to provide insights into the following primary research question: does gender matter when it comes to leading Canada's sustainable energy transition? In other words, will promoting women's leadership in energy sector firms serve to facilitate Canada's sustainable energy transition?

\footnotetext{
${ }^{2}$ Similar to questions asked by Marshall, 2011, p. 264.
} 
However, action on this issue requires additional research. This is because regardless of the answer to this primary research question, the fact remains that, in general, women are simply not entering or advancing within Canadian energy sector firms. For example, in the Canadian oil and gas sector, women hold an average of $7 \%$ of board of director positions and $9 \%$ of executive positions (Catalyst, 2019). This suggests that even if women are in fact the sustainability leaders that Canada needs, they may be unable to attain leadership positions within energy sector firms. Thus, this primary research question leads into another equally important question: what barriers do women, and particularly women leaders, face in Canadian energy sector firms and how can these barriers be overcome? These two research questions are set out below.

Research Question 1: Will promoting women's leadership in energy sector firms serve to facilitate Canada's sustainable energy transition?

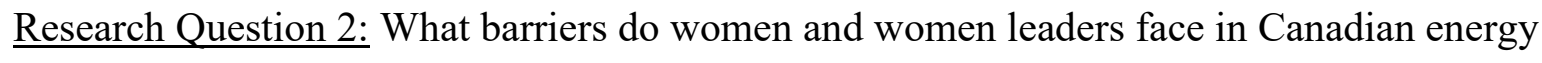
sector firms and how can these barriers be overcome?

In order to provide insights into these two research questions, this thesis will begin by laying the groundwork in subsequent sections of Chapter One. First, it will provide an overview of the research methods used and the scope of this study (section 1.1). Section 1.2 will then delve into the specifics of the Canadian energy sector and the sustainability challenges associated with it. Chapter Two will then provide additional background material through defining several key concepts used throughout this thesis. Namely, Chapter Two will define how the concepts of gender, leadership, and sustainable energy transition will be operationalized throughout this thesis.

Chapter Three will build on the foundation provided by the first two chapters through exploring existing literature relating to the two research questions presented above. More specifically, section 3.1 will explore research on sustainability leadership and gendered leadership 
(in response to the primary research question) while section 3.2 will examine the barriers that women in the energy sector face and the solutions that existing research recommends (in response to the secondary research question). Through this secondary research, section 3.1 will argue that leadership attributes which are integral for effective sustainability leadership are also leadership attributes associated with women's leadership, suggesting that women leaders may be more effective sustainability leaders. In response to the secondary research question of this thesis and through an exploration of existing research, section 3.2 will argue that there are a multitude of barriers that must be overcome to facilitate women's leadership in Canadian energy sector firms. However, there are also a number of realistic and effective solutions which could be implemented by firms, government actors, and advocacy groups which would ameliorate the situation.

Chapter Four will build on the secondary research performed in response to the primary research of this thesis in section 3.1. It will argue that women are not only sustainability leaders, but also sustainable energy transition leaders. Chapter Four will also lay out a theoretical framework for subsequent primary research. The framework was adapted from work done by Geels and colleagues (2017) on the Multi-Level Perspective (MLP). It suggests that women leaders, as niche actors uniquely equipped to lead sustainability initiatives, can help to facilitate Canada's sustainable energy transition if given the opportunity to do so.

This framework will be operationalized in Chapter Five, where primary research in response to both the primary and secondary research questions will be presented. In Chapter Five, section 5.1 will endeavor to provide evidence and insights into the primary research question while section 5.2 will seek to do the same for the secondary research question. Through a thematic analysis of interviews, section 5.1 will argue that women in Canadian energy sector firms are sustainability and sustainable energy transition leaders, as they demonstrate nearly all of the 
leadership attributes necessary for effective sustainability leadership. Section 5.2 will reiterate many of the conclusions of section 3.2, using evidence from interviews to argue that while there are a number of systematic barriers that women face in Canadian energy sector firms, there are also many solutions which could be pursued to improve the situation. Furthermore, if women are sustainability leaders as section 5.1 suggests, firms should implement these solutions as soon as possible to ensure their long-term success as a company.

Finally, Chapter Six will wrap up this thesis and provide additional insights into what the implications of these conclusions are for Canada's sustainable energy transition, Canadian energy sector firms, and women leaders in the energy sector. This concluding chapter will also point to several avenues for future research on the topic of gender, marginalized identities, and sociotechnical transitions like Canada's energy transition.

\subsection{Methods and Study Scope}

In order to provide insights into the two questions guiding this research, both primary and secondary research was conducted. The secondary research was conducted first and was used to frame and construct the subsequent primary research methods. This secondary research included in-depth literature reviews of sustainability leadership, gendered leadership, and barriers and solutions for women leaders in the Canadian energy sector. The results of this research can be found in Chapter Three.

This secondary research provided valuable insights, but much of the previous literature found is dated and/or not specific to the Canadian energy sector. Thus, primary research in the form of interviews was undertaken to build on this existing body of literature. This qualitative research complements many of the previously-conducted large-scale quantitative studies (such as Brammer et al., 2007; Dezsö \& Ross, 2012; Harrison \& Coombs, 2012; Miller \& Triana, 2009; 
Torchia et al., 2011 and many more studies referenced in Chapter Three) through providing

Canada-specific insights and a richness and level of detail which had not yet been explored. A

visual representation of the research methods used in this thesis can be found in Figure 1 below.

\section{Research Question 1: Will supporting women's leadership in energy sector firms serve to facilitate Canada's sustainable energy transition?}

\begin{tabular}{|c|c|}
\hline $\begin{array}{l}\text { Secondary } \\
\text { Research: } \\
\text { Literature } \\
\text { Reviews }\end{array}$ & $\begin{array}{l}\text { a). What leadership attributes are key to } \\
\text { sustainability leadership? (section 3.1.1) } \\
\text { b). What leadership attributes are associated } \\
\text { with women's leadership? (section 3.1.2) } \\
\text { c). How do these two bodies of literature line } \\
\text { up and what does it suggest? (section 4.1) }\end{array}$ \\
\hline & $\begin{array}{r}\text { This secondary research was used to } \\
\text { com }\end{array}$ \\
\hline $\begin{array}{l}\text { Primary } \\
\text { Research: } \\
\text { Interviews }\end{array}$ & $\begin{array}{l}\text { Content analysis of the interview transcripts } \\
\text { with the assistance of the software NVivo. } \\
\text { This analysis was used to either confirm or } \\
\text { refute findings of previous research. (section } \\
5.1 \text { ) } \\
\text { Avenues of questioning: scenarios, direct } \\
\text { questioning }\end{array}$ \\
\hline
\end{tabular}

\section{Research Question 2: What barriers do women, particularly women leaders, face in Canadian energy sector firms and how can these barriers be overcome?}

a). What barriers do women in Canadian energy sector firms face in terms of entry and advancement in the sector? (section 3.3)

b). How can these barriers be overcome? (section 3.3)

\section{Figure 1: Methods}

As can by seen in Figure 1 above, this thesis began with secondary research in the form of several literature reviews. Namely, reviews of literature exploring sustainability leadership attributes, women's leadership, and barriers and recommendations for women's entry and advancement in Canadian energy sector firms. This secondary research provided the foundation for the primary research, which built upon existing literature through providing additional evidence, more in-depth insights, and Canada-specific observations. 
The primary research component of this thesis consisted of qualitative research in the form of semi-structured interviews. This type of inquiry was chosen for several reasons. Much of the literature discussed previously is focused on quantitative data and statistical relationships between different variables (e.g., board diversity and environmental regulatory compliance). While this quantitative research is important, it is, by its very nature, limited in terms of the depth of understanding it can produce. Furthermore, this research is focused on abstract and intangible characteristics which cannot be easily captured by predetermined variables. A qualitative approach was therefore selected, which complements the previously-conducted quantitative work.

Since the goal of this research was to better understand leadership qualities and systemic barriers across gender identities, interviews were undertaken with both men and women working as leaders in the sector. However, participants had to be employed in the Canadian energy production sector in some leadership capacity, employed within the private sector, ${ }^{3}$ comfortable using computers to access the internet, at least 18 years old, and comfortable using the English language. The focus on energy production as opposed to energy sector firms as a whole, which could include everything from power-line technicians to electric vehicle manufacturers, was selected to guide this research. Though the energy sector includes energy production, transmission, distribution, and consumption, as well as the maintenance activities associated with these stages, many of the sustainability challenges associated with the sector stem from the energy production phase.

Between January and March of 2021, a total of 18 interviews were carried out with 4 participants who identified as men and 14 participants who identified as women. Men were included in this research to gain an understanding of their perspective on these issues and to

\footnotetext{
${ }^{3}$ Note that the private sector is simply defined as non-government and includes private companies and non-profits.
} 
compare their responses to those of women. While there are many more gender identities than simply men and women, this research focused on studying gender in binary terms and placed an emphasis on these two genders. This is because most research that has been done thus far on this topic has focused exclusively on this binary definition of gender. There are also methodological limitations to having a more open definition of gender identity. ${ }^{4}$

Of these 18 participants, 8 were employed in the renewable energy sector and 10 in the oil and gas sector. These interviews were conducted virtually through Zoom, Microsoft Teams, or on the telephone. They were recorded and, to ensure anonymity, transcribed using pseudonyms and without any identifying information such as their city or workplace. Informed consent was obtained in writing and reaffirmed verbally before interviews started.

Interviewees were recruited using several methods. To cast a wide net, all applicable companies from the Canadian Association of Petroleum Producers (CAPP) and Canadian Renewable Energy Association (CanREA) membership lists were contacted. Information regarding this study was also shared on LinkedIn and was distributed in the monthly newsletter of relevant advocacy organizations. Lastly, a snowball approach to participant recruitment was used.

Analysis of the qualitative data collected in these interviews was conducted using the software NVivo. Themes were identified across two different avenues of questioning: one which focused on revealed leadership attributes, and the other which focused on stated leadership

\footnotetext{
${ }^{4}$ A discussion of other gender identities and the intersection of gender with other variables, such as race, age, and socioeconomic status, can be found in section 6.2 of this thesis.
} 
attributes (see full interview guide in Appendix). ${ }^{5}$ The first way that themes were identified was through scenarios. This avenue of questioning focused only on responding to my primary research question and helped to identify leadership qualities in an implicit manner, through revealing participants' priorities and leadership styles in their responses to five scenarios. While scenarios as a form of research methodology is quite novel in the sphere of leadership literature, Ramirez and colleagues (2015) found that it is "a research mode that helps engaged scholars to make sense of and address complex and uncertain contexts and produce interesting findings" (p. 70). Since leadership, sustainability, and energy transition are all complex and uncertain, it was my hope that this method of questioning and including a study of revealed leadership attributes would produce more interesting and accurate responses than simply asking questions outright. It is likely that participants may be unwilling or unable to accurately portray their leadership attributes in a completely unbiased manner (whether consciously or unconsciously). This inclusion of revealed leadership attributes rather than only studying stated attributes is particularly important in light of women's tendency to under-sell themselves and men's tendency to over-sell their competencies and achievements (Zenger \& Folkman, 2019). For example, one attribute which was identified as being integral to sustainability leadership is having a long-term orientation. If participants were simply asked: "are you the kind of person who thinks about the long-term implications of a decision?", responses would likely be short and relatively similar. However, if instead they were asked about what they would do in a scenario where they had to make a decision about a project with long term implications, responses are often much longer and distinct.

\footnotetext{
${ }^{5}$ This is similar to research methods used in economic valuation: 'revealed preference' and 'stated preference' are common ways to value non-market goods. While revealed preference is generally deduced through participants' actions, stated preference focuses on participants' words and how they say they value a non-market good. For example, a remote public park can be valued through asking users of the park how much they spent to get to and use the park (e.g., flight, gas, and equipment costs as a method to uncover revealed preference) or users of the park could be asked how they would value the park (stated preference). In recent years, researchers have begun combining the two forms of research for a more comprehensive understanding of personal attributes (Haipeng \& Xuxuan, 2012).
} 
The second way by which themes were identified in the interviews was through direct questioning, which was done after all scenarios so as to not taint scenario responses. This order of questioning ensured that participants had already revealed their leadership attributes through scenario responses prior to explicitly discussing them. The questions falling under this method focused on explicitly asking participants about my research questions. This questioning therefore helped to provide insights into both my primary and secondary research questions: it unveiled participants' perceptions of gendered leadership qualities through directly asking them about their perceptions and experiences regarding gender and leadership and prompted participants to discuss what barriers women in the sector face and how these can be overcome.

There are several key methodological limitations to this research. In this research, I aimed to assess leadership attributes in the energy production sector across two gender identities: men and women. Though participants were quite evenly split between being members of the oil and gas sector and the renewable energy sector (10 and 8 participants respectively), many more women responded than men (14 and 4 respectively). This means that though themes can still be drawn from all interviews, comparisons between women's and men's responses may be inaccurate due to a skewed dataset. Furthermore, it is possible that the range of participants interviewed in this research is not representative of energy sector leaders: a dataset of 18 out of the hundreds or thousands of leaders in Canadian energy sector firms is hardly representative. Moreover, nearly all participants who responded to my inquiry were engaged with issues of sustainability, gender, and/or diversity in some manner, either in their private lives or in their workplaces. Thus, participants were likely more aware of these issues and their responses may not be reflective of leadership styles across the sector. Nonetheless, as leaders across Canadian energy sector firms, their responses still provide valuable insights into gendered leadership styles. Although the sample 
size may be small, interviews were in-depth and thus provided a degree of insight which would be difficult to attain with larger-scale quantitative interviews. The purpose of these interviews was not to gain any generalizable information through a representative sample. Instead, these interviews were meant to provide a deeper understanding of these issues in Canadian energy sector firms, and a snapshot of how different genders prioritize and lead. The primary outcome of these interviews was therefore to provide illustrations of the themes discussed in the literature as well as identify challenges and provide recommendations regarding how to support women as leaders within Canadian energy sector firms.

In order to better understand the problem at the root of this research, the following section will provide an overview of the Canadian energy sector and the sustainability challenges associated with it. This will include a discussion of what the Canadian energy sector consists of, why it is important, and what it must become in order to thrive in the coming years as sustainability issues continue to fester and grow.

\subsection{Energy and Sustainability in Canada}

Access to affordable, reliable, and abundant energy is necessary for modern life in a developed country like Canada. Though we may rarely think about it, energy systems drive everything from our modes of transportation to our long-distance communication networks, our workplaces, and our household and leisure activities. However, despite its key role in everyday life, research suggests that Canadians lack detailed knowledge about energy production and its impacts on the environment (Turcotte et al., 2012). Furthermore, Canadians tend to consider energy issues as a low priority compared to economic and social concerns (Eisler, 2016). However, energy and an energy system's sustainability are intimately linked to an economy's strength, resilience, and the health and well-being of its population and ecosystems. 
As the world's sixth largest producer of energy and fourth largest net exporter of energy, Canada is highly economically dependent on energy production (NRCan, 2020b). In 2019, the energy sector accounted for an estimated $10 \%$ of the national nominal Gross Domestic Product (GDP), with a total contribution of $\$ 219$ billion (NRCan, 2020b). ${ }^{6}$ That same year, the sector employed over 800,000 Canadians, 4.4\% of total employment in Canada (NRCan, 2020b). Energy is also an important source of government revenue: corporate income taxes, indirect taxes, royalties, and Crown land sales lead to an average annual revenue of $\$ 16.3$ billion, most of which ( $\$ 14$ billion) is from upstream oil and gas extraction (NRCan, 2020b). However, it is important to note that the Canadian energy sector also receives substantial subsidies. For example, though many vastly different estimates exist, the Canadian oil and gas sector received subsidies totalling anywhere from $\$ 600$ million to $\$ 4.8$ billion in 2019 (Corkal et al., 2020; Laan \& Corkal, 2020). ${ }^{7}$

Despite its dominance in contemporary discourse and policy, the energy sector in Canada consists of much more than oil and gas. It includes a variety of energy sources, including nuclear energy, coal, hydroelectricity, and a growing supply of renewable energy sources like wind and solar (see Figures 2 and 3 below). However, both energy production and energy consumption in Canada remain dominated by fossil fuels (65\% and over 77\% respectively) (Canada Energy Regulator [CER], 2020a; NRCan, 2020b).

\footnotetext{
${ }^{6}$ This includes the production and sale of petroleum products, electricity, and other energy products such as uranium. It also includes indirect energy products, such as energy services.

${ }^{7}$ A detailed national analysis of renewable energy subsidies has not yet been completed in Canada, but globally renewable energy subsidies are significantly lower than those for oil and gas (ratio of approximately 4:1) (Bridle et al., 2019; Corkal et al., 2020).
} 


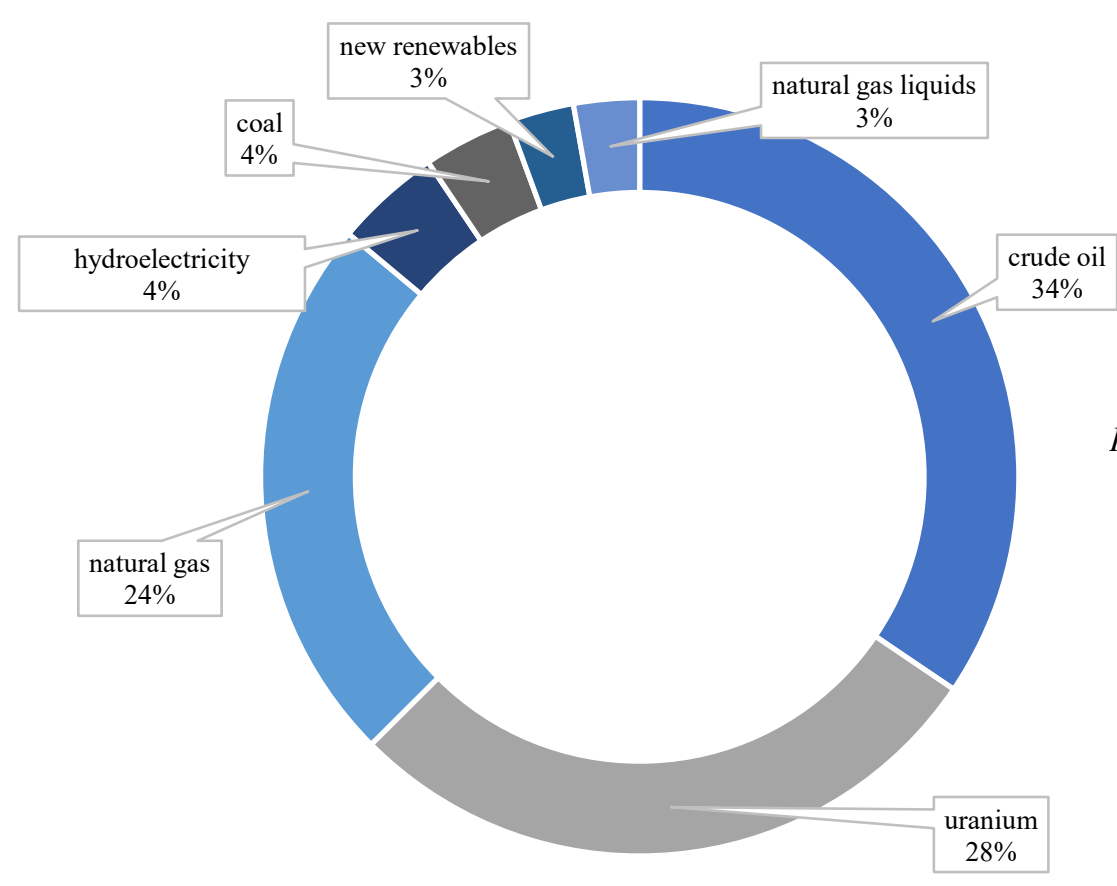

Figure 2: Canada's Primary Energy Production (2018)

Created based on data from NRCan, $2020 \mathrm{~b}$.

Note that new renewables refers to renewable energy production other than large-scale hydroelectricity such as wind and solar.

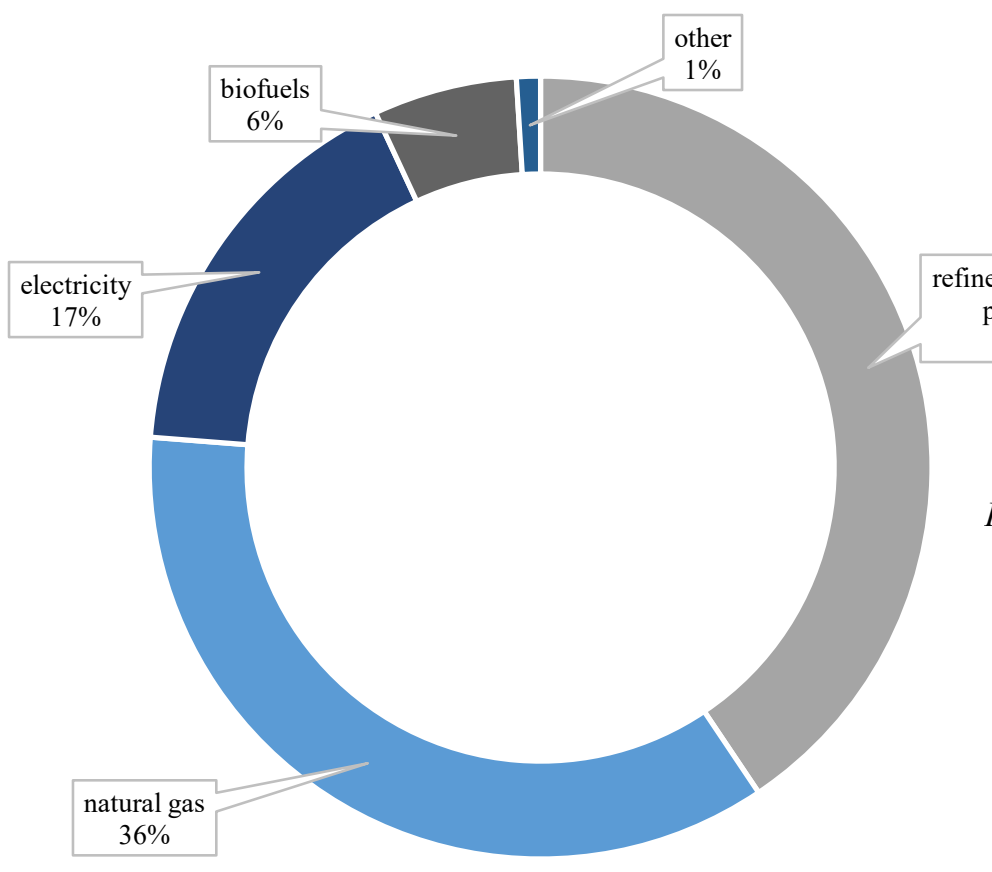

Figure 3: Canada's Energy Consumption (2017)

Created based on data from CER, 2020a.

Canada's electricity sector (17\% of total energy consumption) is dominated by hydroelectricity (62\%), nuclear (15\%), and natural gas (9\%). Thus, though there are emissions associated with Canada's electricity, it is less fossil fuel intensive than other forms of energy consumption (CER, 2020a). 
While energy production has therefore had positive economic impacts, Canada remains overly reliant upon fossil fuels in its energy production and consumption activities. This ongoing reliance has led to an exacerbation of many of the previously-mentioned sustainability challenges, including climate change, air pollution, water pollution, wildlife and habitat loss, and noise and light pollution. The situation is so bad that Canada risks becoming an "[energy] superpolluter" instead of the "energy superpower" that many leaders push it to be (Richardson, 2007, p. 1). Although advocacy organizations and non-profits have long pushed for action on the issue, these sustainability challenges have only recently been recognized and acted upon in any real way by government and industry actors. Unfortunately, resulting actions in Canada have thus far been insufficient.

What these actors consider in discussions of sustainability varies. Environmental sustainability issues often dominate rhetoric surrounding Canada's energy sector, and this thesis will follow this trend by also focusing on environmental sustainability. This focus was chosen to ensure the parameters of this research are manageable. However, sustainability challenges include not only environmental, but also social and economic elements. In terms of social sustainability, energy-related challenges include poverty and social vulnerability, widening inequalities, poor working conditions, unemployment, and financial volatility (Savaget et al., 2019, p. 879). These social and the previously-mentioned environmental issues are associated with negative effects on human, flora, and fauna health and wellbeing as well as, ultimately, a negative impact on the longterm vitality of the Canadian economy due to a deterioration of the resources on which we rely for industrial processes and everyday life. Key environmental sustainability challenges associated with the Canadian energy sector, as well as their impact on human health and the local ecology, are discussed below. 
The most commonly cited sustainability issue stemming from Canada's current energy system is that of GHG emissions. Since almost all of Canada's GHG emissions (82\%) are energyrelated, climate change is inexorably intertwined with energy systems (CER, 2020b). Globally, Canada generates $1.7 \%$ of total emissions, but it is one of the most emissions-intensive countries in the world (CER, 2020c). In fact, Canada has been ranked in last place compared to 17 similar Organisation for Economic Co-operation and Development (OECD) nations in terms of its energy and emissions intensity per capita (CER, 2020c). These GHG emissions from energy production and consumption are exacerbating the already-concerning phenomenon of climate change and the host of issues that it brings, including increased flooding, fires, extreme storms, vector-borne diseases, drought, and the spread of pests such as ticks and pine beetles. For example, climate change-induced flooding across Quebec in 2019 caused over \$127 million in insured damage (Insurance Board of Canada, 2019). Due to rising temperatures, such catastrophic flooding incidents are expected to become increasingly common (Eschner, 2019).

The oil and gas sector is often pointed to as a key source of the GHG emissions contributing to such catastrophes, but there are GHG emissions associated with renewable energy production as well. That being said, the difference in terms of lifecycle emissions of the two forms of energy is staggering: while coal and oil produce approximately 888 and 733 tonnes of carbon dioxide equivalent $(\mathrm{CO} 2 \mathrm{e})^{8}$ per Gigawatt-hour (GWh) respectively, solar, wind, and hydroelectricity each produce 85, 26, and 26 tonnes of CO2e per GWh (World Nuclear Association, 2011). ${ }^{9}$ Renewable

\footnotetext{
${ }^{8} \mathrm{CO} 2 \mathrm{e}$ is a commonly-used unit for measuring carbon footprints. It expresses emissions in terms of the amount of $\mathrm{CO} 2$ required to produce the same amount of warming. For example, even though methane produces $25 \mathrm{x}$ the warming that $\mathrm{CO} 2$ does, the two forms of air pollution can be expressed in one unit (e.g., $5 \mathrm{CO} 2+1$ methane $=30 \mathrm{CO} 2 \mathrm{e})$ (Brander, 2012).

${ }^{9}$ Lifecycle emissions refers to emissions produced throughout the production of the technology, its use, and its disposal. Thus, while wind turbines may not produce any emissions while they are operational, their production, transportation, and disposal may.
} 
energy sources therefore produce just $3-10 \%$ of the GHG emissions that these fossil fuels do over their lifetime.

Despite its dominance in contemporary discussions, energy-related sustainability concerns go far beyond GHG emissions. Present-day energy production and consumption is also the largest contributor to air pollution around the world (Prasad et al., 2019, p. 178). The burning of fossil fuels leads to several harmful emissions, including carbon monoxide, volatile organic compounds, nitrous oxides, sulfur dioxide, and particulate matter (Prasad et al., 2019, p. 178). These air pollutants are estimated to lead to 6.5 million deaths each year globally and create acid rain which destroys ecosystems and leads to decreased soil and water quality (International Energy Agency [IEA], 2016). Though renewable energy production does not directly produce any air pollution, it is quite likely that, in our current fossil fuel intensive energy system, the manufacturing and transportation of the technology and/or parts does lead to air pollution. No estimates regarding the magnitude of these ancillary air pollution emissions could be found, but it is reasonable to assume that they are a fraction of the emissions stemming from the production and consumption of fossil fuels.

Water pollution is yet another sustainability challenge associated with Canada's energy production system. Energy production with fossil fuels depends heavily on water (Folk, 2019). For example, the combustion of fuels such as gas or coal creates heat that boils water, emitting steam which spins turbines to generate electricity. Many refinement processes also require the use of water (Folk, 2019). Once the water is used for these energy-related processes, it is often pumped back to its source (with varying amounts of treatment) (Folk, 2019). Even if there are no toxins in the water which is released back into the environment, it is often considerably warmer, causing thermal pollution. This heat can decrease the fertility of marine wildlife and lead to lower levels 
of oxygen in the water (Folk, 2019). For example, the Bay Shore coal plant in Ohio faced backlash in 2010 when damning reports emerged, showing that the plant's operations were killing 46 million adult fish and over 2.4 billion eggs, larvae and young fish in Lake Erie each year (Hawthorne, 2011).

The volume of water consumed by the energy industry is substantial. Ali (2018) estimated that in 2009, 358 million metres squared $\left(\mathrm{m}^{3}\right)$ of water was withdrawn and used by the energy production sector in Alberta, mostly from the Athabasca River (p. 104). Furthermore, he estimated that this water use increases at an annual growth rate of $9 \%$ (Ali, 2018, p. 104). No recent studies on the volume of toxic water pollution from the Canadian energy production sector could be found, but a 2013 study estimated that 11 million litres of toxic waste from the oil sands in Alberta leak into the watershed daily (Environmental Defence).

Oil and gas activities are not the only source of energy-related water pollution; nuclear power plants and hydroelectric power plants are also water-intensive processes (Ali, 2018, p. 105). Nuclear power plants consume and pollute water the same way that fossil fuel combustion does, through using the heat of nuclear reactions to boil water, create steam, and run a turbine to produce electricity. Nuclear plants in Canada also use heavy water to cool the nuclear reactors so they do not overheat, which further contaminates water waste. Hydroelectricity processes consume water through evaporation from reservoirs (Lee et al., 2016) and can lead to a lack of oxygen in deep water, algae growth and therefore a hypoxic environment, thermal pollution, and mercury pollution (Goodfellow et al., 2018).

Wildlife and habitat loss are issues stemming from the sustainability issues discussed above. GHG emissions, air pollution, and water pollution all destroy ecosystems and harm wildlife. However, wildlife and habitats are also impacted by the energy sector in other ways. In the oil and 
gas sector, large-scale production, pipelines, and marine shipping for the transportation of fuels lead to deteriorated, destroyed, and/or fragmented habitats (Fluker, 2019). In Canada, specific concerns have been raised regarding the impact that increased marine vessel traffic from the construction of the Trans Mountain Pipeline expansion project would have on the endangered southern killer whales (Fluker, 2019). The woodland caribou populations have also been severely negatively impacted by energy projects in northern Alberta (Fluker, 2019). Lastly, reserve pits and evaporation ponds used to store the by-products of drilling lead to avian fatalities as birds fly into unprotected pits and cannot get out (U.S. Fish and Wildlife Service, 2018).

In the renewable energy sector, the impacts of energy production are also considerable. Increasing the use of large-scale wind turbines, solar panels, and hydropower will require massive amounts of land, which will lead to the degradation and fragmentation of wildlife habitats across the country (World Wildlife Fund, 2016). Analysis by Bloomberg has shown that if wind and solar were to provide $98 \%$ of America's electric power by 2050 , land use by the energy production sector would quadruple (Merrill, 2021). Furthermore, many post-use parts from renewable energy production technologies take up large amounts of space in landfills. For example, the composite materials used to manufacture wind turbine blades cannot currently be reused or recycled. ${ }^{10}$ These turbines therefore end up in landfills after their 20 to 25-year lifetime (Kelley, 2017). Due to their massive size (average rotor diameter of 114 metres), this landfill build-up will become increasingly concerning as wind energy continues to grow in Canada (CER, 2019). Lastly, wind turbines have also been linked to bird and bat death through hitting the turbines or barotrauma (when the

\footnotetext{
${ }^{10}$ However, this is quickly changing as wind turbine producers push for $100 \%$ recyclability of their products. For example, Vestas, a Danish wind turbine manufacturer, has committed to producing products which are fully recyclable (Corbley, 2021).
} 
movement of the blades causes a drop in air pressure, which damages bats' lungs) (Lafleur, 2019). ${ }^{11}$

Noise and light pollution are an often-overlooked energy-related sustainability challenge. These forms of pollution are a source of disturbance for humans and other animals, contributing to wildlife displacement and masking visual and auditory traits which are essential to the survival and reproduction of many animals (Jones et al., 2015, p. 296). In the oil and gas sector, noise pollution stems from drill rigs, fracking, pumps, compressors, generators, and vehicle traffic (Jones et al., 2015, p. 296). Light pollution from oil and gas fields includes gas flares and vehicle headlights (Jones et al., 2015, p. 297). In the renewable energy sector, most concerns regarding noise pollution are related to wind turbines, which produce aerodynamic noise as the blades pass through the air (Rogers et al., 2006). Wind turbines are also required to be lit at night due to air safety concerns (Jones et al., 2015, p. 297). The impact of this noise and light pollution is often difficult to detect or define empirically.

The cumulative impact of these sustainability challenges is becoming increasingly difficult to ignore. Governments across Canada have therefore increasingly made sustainability a key goal in the energy sector. Much of this work stems from the Pan-Canadian Framework on Clean Growth and Climate Change (PCF), Canada's collective plan for economic growth and addressing climate change. Private sector actors are also increasingly recognizing and acting upon energyrelated sustainability challenges. Research by PricewaterhouseCoopers has shown that

\footnotetext{
${ }^{11}$ There have been many notable efforts to mitigate these negative effects that wind turbines can have on fauna, and many are promising. For example, research has shown that painting one turbine blade black can reduce the number of birds hitting the turbines by $70 \%$ (Kinver, 2020). However, as the number of wind turbines increase in the coming years, there will need to be a concerted effort to ensure that these bird and bat deaths are addressed.
} 
sustainability (defined as Environmental Social and Governance $[E S G]^{12}$ actions) has become a leading factor in guiding investment decisions (Crutchfield \& Asghar, 2020). For example, in April of 2021, one of the largest U.S. public pension funds pulled out its stake in the Canadian oil sands because of a desire to transition its investments to net-zero (Thurton, 2021). This means that a lack of awareness and action regarding sustainability in Canadian energy sector firms may very well mean a lack of investment and ultimately economic failure.

Firms within the energy sector are not oblivious to this growing sensitivity to sustainability; even a brief overview of the websites of a few large energy companies reveals an awareness of how important sustainability is becoming. While recognizing that reality and tangible actions are very different from what a company may present on its website, even the homepage of ExxonMobil, the world's largest energy company, states that: “...ExxonMobil scientists and engineers are pioneering new research and pursuing new technologies to reduce emissions while creating more efficient fuels. We're committed to responsibly meeting the world's energy needs" (Exxonmobil, 2021). This quote, which is displayed in the centre of the company's homepage, indicates that, at least at a rhetorical level, even the world's largest oil and gas company recognizes the importance of addressing the pressing sustainability challenges associated with the energy sector.

This sentiment and the prominence of sustainability rhetoric on the websites of energy companies is relatively common in 2021. In fact, many oil and gas companies have committed to

\footnotetext{
${ }^{12}$ ESG has come to be the most commonly-used concept used to refer to and gauge sustainability efforts within the private sector. ESG is a set of targets and standards for a company's operations that address their environmental, social, and governance impacts and processes. ESG criteria has become a popular standard used by investors to determine socially conscious investments (Chen, 2021).
} 
having net-zero GHG emissions by $2050 .{ }^{13}$ However, the question is whether or not this sustainability rhetoric and these targets will translate into sufficient tangible action, and whether or not this action will be enough to attain a truly sustainable energy future. This research seeks to help energy companies in this endeavor and suggests a solution by which they could more efficiently and effectively achieve these sustainability goals. If gender does matter when it comes to sustainability leadership, then energy companies could use this research to make a case for increased attention to the promotion of women leaders, which would ultimately support their attainment of sustainability goals and thus their long-term success as a company.

\subsection{Chapter One Conclusion}

In this thesis, I will argue that gender does matter when it comes to sustainability leadership, and therefore supporting women so that they can overcome the systematic barriers preventing them from achieving leadership positions in Canadian energy sector firms will serve to facilitate Canada's sustainable energy transition. Chapter One began laying the foundation for this argument, setting out the methods, study scope, and the many sustainability problems that lie at the root of this research. Chapter Two will continue laying the foundation for this research through exploring and defining several key concepts.

\footnotetext{
${ }^{13}$ For a private company, achieving net-zero means "achieving a state in which the business model of the company results in no net impact on the climate" (Pineda \& Faria, 2019, p. 16). Companies which have made a net-zero commitment include BP, Shell, Repsol, and Equinor (Murray, 2020).
} 


\section{Chapter Two: Key Concepts}

The main argument of this thesis, that gender matters when it comes to sustainability leadership and Canada's sustainable energy transition, makes use of several ambiguous concepts. Therefore, prior to delving into the question of whether or not women are sustainable energy transition leaders, several key concepts must be explored. This chapter will explore and set out how the concepts of gender, leadership, and sustainable energy transition will be operationalized throughout this thesis.

\subsection{Gender}

Gender shapes our societal structures, institutions, and interactions in a fundamental way. As stated by Aikhenval'd (2016) in her book How Gender Shapes the World: "the multifaceted notion of 'gender' pervades every aspect of life and of living. Gender differences form the basis for family life, patterns of socialization, distribution of tasks, spheres of responsibility, and occupational predilections" (p. 1). However, despite its prominent role in everyday life, 'gender' can be difficult to define.

Though controversial when it was first suggested by psychologist Robert Stroller in 1968, the distinction between gender and sex has come to be widely accepted (Mikkola, 2017). When the concept of gender first emerged and became popularized, the distinction between gender and sex was viewed as relatively straightforward: while sex referred to biological features to denote differences between men and women, gender was used to recognize that many differences are the result of cultural and social factors (Editors of Salem Press, 2011, p. 42; Mikkola, 2017). Thus, gender was often overlaid over biological sex. However, since the 1990s this conception of gender has been shifting, recognizing the complexity of gender and gender relations. More recent scholarship emphasizes the role of power, hegemony, and intersectionality in shaping gender 
identity and relations (Posca, 2018, p. 241; Swigonski \& Raheim, 2011, p. 14). This literature also acknowledges the variability of gender, its fluidity, and its non-binary diverse nature (Siltanen \& Doucet, 2008). Furthermore, rather than viewing gender as something that people have, it is conceived as "something that people do as they practice or perform the routine and recurrent tasks and accomplishments of daily life" (Swigonski \& Raheim, 2011, p. 14).

The most prominent scholar with this performance-based conception of gender is Judith Butler. And, though there are many different definitions of gender, each providing unique insights, the articulation of gender by Butler (1988) is the most applicable for this research. Butler's articulation is built on Simone de Beauvoir's famous claim that "one is not born, but, rather, becomes a woman" (Beauvoir, 1973, p. 301). It is this active articulation of gender that will provide the theoretical foundations of this research. Rather than conceiving of gender as a set of norms or social constructions unilaterally forced upon women, this research will define gender as "an identity instituted through a stylized repetition of acts," something that is performed rather than innate (Butler, 1988, p. 519). This definition recognizes the inherent instability of gender and the agency of individuals.

The study of how gender is performed and changes over time has increasingly come to the forefront of both academia and public discourse. Scholarship on gender differences suggests that societal structures and power dynamics encourage different behaviours in women and men. For example, Gilligan (1982) points out that women are rewarded for altruistic behaviour much more than men. These structures have implications for how people of different genders perceive themselves, act around others, and prioritize when making decisions. It therefore has implications for how they lead, which will be the focus of this research. 


\subsection{Leadership}

A common perception of leaders in the private sector is that they must be a solo, assertive, rational, and charismatic individual who does not let their emotions get in the way (Petit, 2014). Though it is an extreme example, Jordan Belfort, the inspiration for the 2013 film The Wolf of Wall Street, epitomizes many of these characteristics. In the film adaptation, he is charismatic, inspiring his staff with his (rather unethical) speeches, he leads by example, and he encourages his staff to "leave [their] emotions at the door" (Scorsese, 2013). These stereotypes surrounding leaders are primarily masculine, meaning people tend to perceive good leadership as something associated with masculinity and male stereotypes (Koenig et al., 2011). However, in reality leaders come in a variety of shapes and sizes, and often do not conform to these traditional stereotypes.

Leaders and leadership therefore vary, but all share a defining characteristic. Namely, they are distinct from managers, who deal with operational efficiencies. Instead, leaders are concerned with inspiring change, and moving towards a desirable future for the given company. The following definition of a leader put forward by Visser and Courtice (2011) will be used in this research: "a leader is someone who can craft a vision and inspire people to act collectively to make it happen, responding to whatever changes and challenges arise along the way" (p. 2).

This definition points to another important characteristic of leadership and leaders: what is considered 'leadership' is determined by the needs of any given circumstance (Redekop \& Olson, 2010, p. 6). Leadership is therefore socially constructed and situational: "change the context and leadership changes, as does what is sought and whether specific leadership patterns are considered effective" (Osborn et al., 2002, p. 797-798). For example, a hunter-gatherer community would look for different forms of leadership and leadership qualities than a settlement facing a Mongol raid, which would in turn look for different leadership than a modern business struggling to reduce its carbon footprint. This fluidity and reactionary nature of leadership is a key foundation of this 
research. When leadership is defined in this manner, as a reaction to changing circumstances, it becomes evident that modern sustainability and energy transition problems require a modern and novel form of leadership. What used to count as good leadership in the twentieth century (what Rost [1991] dubbed the "industrial paradigm" of leadership) is no longer relevant and will not help to solve contemporary sustainability and energy transition problems. For example, Rost (1991) argues that the new "post-industrial" style of leadership must move away from an emphasis on authority and towards a recognition of the importance of values, ethics, and influence. He asserts that only through changing leadership in this way can society properly address the issues that it faced in the late twentieth century.

These conclusions that Rost reached in the early 1990s are perhaps even more relevant to leadership in 2021 and moving forward. Societal expectations, business structures, and the problems businesses face have all changed, meaning leadership structures must change as well. This sentiment can be found in reports by prominent companies like Deloitte (2019) and work by business professors Moldoveanu and Narayandas, who, in a 2019 article stated that "companies of all sorts realize that to survive in today's volatile, uncertain, complex, and ambiguous environment, they need leadership skills and organizational capabilities different from those that helped them succeed in the past" (para. 1). Yet even though the shortcomings of dominant leadership styles and structures have been broadly recognized, no clear alternative has emerged to take its place (Davenport, 2001). This research endeavors to address this gap and demonstrate what kind of leadership Canada needs to address these contemporary challenges, specifically challenges relating to sustainability in energy sector firms. 


\subsection{Sustainable Energy Transition}

In order to address the multitude of energy-related sustainability challenges that Canada and the world are facing, a sustainable energy transition must take place. In fact, many believe that the negative effects of the incumbent energy system are already causing firms and countries to initiate energy transitions (International Renewable Energy Agency [IRENA], 2020; Smith \& Coady, 2018, p. 4). These transitions are characterized by increased attention to environmental and healthrelated impacts of the energy system as well as the rapid uptake of renewable and low-carbon energy technologies such as solar panels, wind turbines, lithium-ion batteries, and clean hydrogen. ${ }^{14}$ In fact, over the past decade renewable energy has been the only form of energy that has grown at a rate in the double digits, with global consumption growing at an average rate of 13.7\% each year (Rapier, 2020).

The sustainable energy transition that Canada and the world is facing is not the first energy transition that the world has made, but it is distinct from previous transitions. The world has already transitioned from an energy system primarily supplied by wood, to one driven by coal during the Industrial Revolution, and then later still to one driven by oil in the mid-to-late 1900s (CER, 2020d). However, these previous transitions were not driven by external landscape factors (e.g., sustainability challenges) but by the emergence of a more efficient, effective, and/or affordable energy source. Furthermore, these past transitions occurred gradually over a long period of time. Canada's current energy transition is also occurring gradually, but it will need to speed up in the coming years if the effects of the accelerating environmental and socio-economic degradation previously discussed are to be effectively mitigated. Canada and the world thus do not have the

\footnotetext{
${ }^{14}$ Clean hydrogen refers to hydrogen produced either through electrolysis or through the typical steam-methane
} reforming process but with carbon capture to make the process carbon neutral. 
luxury of waiting for a gradual and perhaps more natural energy transition towards more sustainable production (Huberty \& Zysman, 2010, p. 2027).

Despite progress in this regard, this transition has only just begun. For example, estimates suggest that renewable energy makes up $24 \%$ of the total global energy supply and only $16 \%$ of the energy supply in Canada (NRCan, 2020c). However, in the Intergovernmental Panel on Climate Change's (IPCC's) Special Report on Global Warming of 1.5 degrees Celsius, experts predicted that renewable energy must contribute approximately $70-85 \%$ of total energy supply by 2050 to limit warming to 1.5 degrees (IPCC, 2018, p. 132). While addressing climate change is only one facet of sustainability, this suggests that while a transition is underway, further action is needed.

A sustainable energy transition is also much larger than adopting renewable energy technologies. Though the definitions overlap, renewable energy is not synonymous with sustainable energy or a sustainable energy system. As demonstrated in section 1.2, many sustainability challenges associated with the oil and gas sector are also present in the renewable energy sector, though often to a lesser extent. For example, though renewable energy technologies such as wind turbines may not produce GHG emissions, the production of these technologies and/or their transportation likely will, and their use and disposal can lead to other sustainability challenges such as wildlife and habitat loss and landfill build-up. Because these sustainability challenges therefore apply to the breadth of energy production in Canada, a main goal of this research is to explore how private sector leaders can accelerate the transition to a more sustainable energy system as a whole. This includes promoting sustainability in the oil and gas sector, as well as a greater awareness of sustainability challenges associated with renewable energy technologies. While encouraging further uptake of renewable energy is critical to addressing climate change, 
having a narrow focus on the adoption of renewable energy technologies will not effectively address contemporary sustainability challenges. Beyond the limitations of the technologies themselves, the manner by which this new infrastructure is constructed, the materials that are used, their location, and the level of attentiveness to the impact on local ecology will all impact the overall sustainability of renewable energy installations. If these additional factors are not accounted for, renewable energy infrastructure can have negative effects on sustainability through reducing biodiversity, increasing mining of rare earth metals, and creating landfill waste from old infrastructure that cannot be recycled (Spillias et al., 2020). Since they often require large amounts of land, renewable energy projects can also have negative social impacts such as leading to conflict with Indigenous peoples through threatening local land rights and cultural heritage (Spillias et al., 2020).

Thus, while increasing the uptake of renewable energy technology is one goal, transitioning to a sustainable energy system requires a much more holistic mindset. This research will therefore define 'sustainable energy transition' as the collective sum of actions promoting sustainability in the energy sector, which includes increased attention to climate change, biodiversity, water, air, and soil pollution, habitat loss, and human health and wellbeing. This open-ended definition of sustainable energy transition can include actions across the energy sector, so long as they address Canada's many sustainability challenges.

\subsection{Chapter Two Conclusion}

In this thesis, I will argue that gender matters when it comes to sustainability leadership and promoting Canada's sustainable energy transition. In short, women are sustainable energy transition leaders and supporting them in energy sector firms so that they can attain leadership positions will benefit the firms and Canada as a whole. Chapter Two built on Chapter One 
through completing the foundation for this research. This chapter defined the key concepts of gender, leadership, and sustainable energy transition, which will be used throughout the rest of this thesis. Having established this foundation, the next step is to begin the secondary research component of this thesis through a review of the literature. 


\section{Chapter Three: Literature Review}

There is evidence in existing literature supporting the main argument of this thesis, namely, that gender is a relevant factor in sustainability leadership and sustainable energy transition leadership. However, since this topic currently contains only a sparse amount of literature, research must be drawn from a variety of fields in order to respond to the research questions guiding this thesis. Thus, the following literature review is split into two sections: the first will address the primary research question, and the second will address the secondary research question. Since the primary research question of this thesis (will promoting women's leadership in energy sector firms serve to facilitate Canada's sustainable energy transition?) cannot be answered by one body of literature, this secondary research will include a review of research in the fields of both sustainability leadership and gendered leadership. These two bodies of literature will be analyzed and compared in order to provide evidence that women are in fact sustainability leaders. The second section of this literature review will provide an overview of the literature relevant to the secondary research question: what barriers do women and women leaders face in Canadian energy sector firms and how can these barriers be overcome? This secondary research will then be used to structure and conduct the primary research component of this thesis (Chapter Five).

\subsection{Gendered Sustainability Leadership}

The first section of this literature review explores research related to the primary research question of this thesis and can be broken down into two parts. The initial focus is on sustainability leadership, and includes an exploration of the field of literature which has responded to the question: what kind of leadership does Canada need to address contemporary sustainability challenges? The second part of this literature review ties in gender, and responds to the question: where can we find this leadership that previous research suggests we need? It reviews the field of 
literature on women's leadership, tying leadership attributes associated with women leaders with leadership attributes necessary for sustainability leadership. Through combining these two fields of literature, this secondary research will provide insights into the primary research question guiding this thesis.

\subsubsection{Sustainability leadership}

There is a distinct need for novel leadership in order to effectively address contemporary sustainability problems. As discussed in section 2.2, traditional leadership structures and attributes are ill-equipped for such problems. Yet surprisingly little research has been done on the topic of leadership for sustainability (Redekop \& Olson, 2010, p. 2). In the field of leadership studies, few scholarly texts discuss this topic in any depth, but rather refer to it as an "emerging issue" of interest for future studies (Antonakis et al., 2004; Gill, 2006; Redekop \& Olson, 2010, p. 2). The one thing that scholars agree on is that effective leadership is essential to the attainment of sustainability (Hull et al., 2018; MacNeill, 2007). Furthermore, though leadership for sustainability is needed in all walks of life, the private sector is one sphere in which this form of leadership is particularly lacking, despite it being absolutely critical to achieving sustainability (Campbell et al., 2018, p. 19). Since the private sector is responsible for the vast majority (85\%) of all investments around the world, ensuring their actions and funds are supporting rather than undermining sustainability is key (Climate Action Network, 2013). In fact, in advanced economies such as Canada, state-owned energy investments made up only 9\% of total energy investments in 2019 (IEA, 2020). In short, private sector sustainability leadership matters now more than ever. These leaders can not only drive change within their own businesses, but they can also catalyze more systematic changes through influencing policy, partners, and investors (World Business Council for Sustainable Development [WBCSD], 2011, p. 2). 
Since problems of sustainability require a distinct form of leadership and leadership attributes, the next step of this research is to describe a framework for identifying effective private sector sustainability leaders. In other words, what leadership attributes are conducive to sustainability leadership in private sector companies? There are only a handful of articles from which to pull in order to respond to this question. However, this literature is relatively consistent in terms of what it shows to be integral for sustainability leadership.

When it comes to private sector sustainability, corporate social responsibility (CSR) ${ }^{15}$ and ESG are key motifs across the literature. Metcalf and Benn (2013) build on this and identify key attributes for private sector leaders to enable the efficient and effective enactment of CSR initiatives. The authors identify several leadership attributes which are key to the attainment of these CSR efforts. They present the ability to understand and address complexities as being a key attribute, while also recognizing the important role that collaboration, ethical leadership, and transformational leadership play:

We argue that the complex and dynamic nature of interpreting just how and in what way an organisation is to be sustainable means that leadership for sustainability requires leaders of extraordinary abilities. These are proposed to be leaders who can think through complex problems, engage groups in dynamic organisational change and have high emotional intelligence (EI) to deal with the personal emotions associated with complexity. (p. 370)

Hull and colleagues (2018) also recognize the exceptional challenge posed by modern sustainability problems, and the "specialized leadership competencies" necessary to effectively enact sustainability initiatives in the private sector (p. 171). Much like Metcalf and Benn (2013), Hull and colleagues (2018) highlight the complexity of addressing sustainability, and how leaders must be able to manage this complexity and uncertainty through collaboration and shared

\footnotetext{
${ }^{15} \mathrm{CSR}$ is a business model which encourages companies to be conscious of and take action to mitigate any negative impacts their processes and practices have on society, including environmental and social impacts. For example, one CSR target that the coffee company Starbucks has had in recent years is to attain $99 \%$ ethically sourced coffee (Starbucks, 2020, p. 5).
} 
leadership (p. 172). For example, they bring up how most sustainability challenges (e.g., climate change) can only be addressed through changing complex interconnected global systems. Since no one leader has authority over or will even interact with all stakeholders involved, addressing these sustainability challenges will require working with others, sharing power, and managing complex systems and relationships (Hull et al., 2018, p. 172).

Work by the World Business Council for Sustainable Development (WBCSD) highlights similar leadership attributes for modern sustainability problems. Drawing on research and evidence collected from its 200 member companies, the WBCSD identified six attributes for modern sustainability leaders: understanding the context, managing complexity, systems thinking, working with stakeholders and non-traditional approaches, inspiring and leading change, and enabling innovation through moving away from restrictive hierarchies (WBCSD, 2011, p. 6). Much like previously mentioned research, this work once again emphasizes the importance of working with others and managing a complex process. 
While also recognizing that sustainability problems are complex, the conclusions of Knight and Paterson (2017) are distinct from the previous studies in that they argue that the "skills identified as most critical for sustainability leaders are familiar and learnable" (p. 573). Thus, there is less of an emphasis on the exceptional requirements necessary for individuals to become sustainability leaders in the private sector, though there is still a recognition that sustainability leadership is distinct. These authors create a model for sustainability leadership (see Figure 4) based on the contributions of 97 participants, finding that five leadership attributes are key to success: having an ethical orientation, and being inclusive, a change agent, visionary, and results driven (Knight \& Paterson, 2017, p. 565). These authors therefore bring a few new things to the table, including inclusivity and being visionary, which they argue are key to successful sustainability leadership.

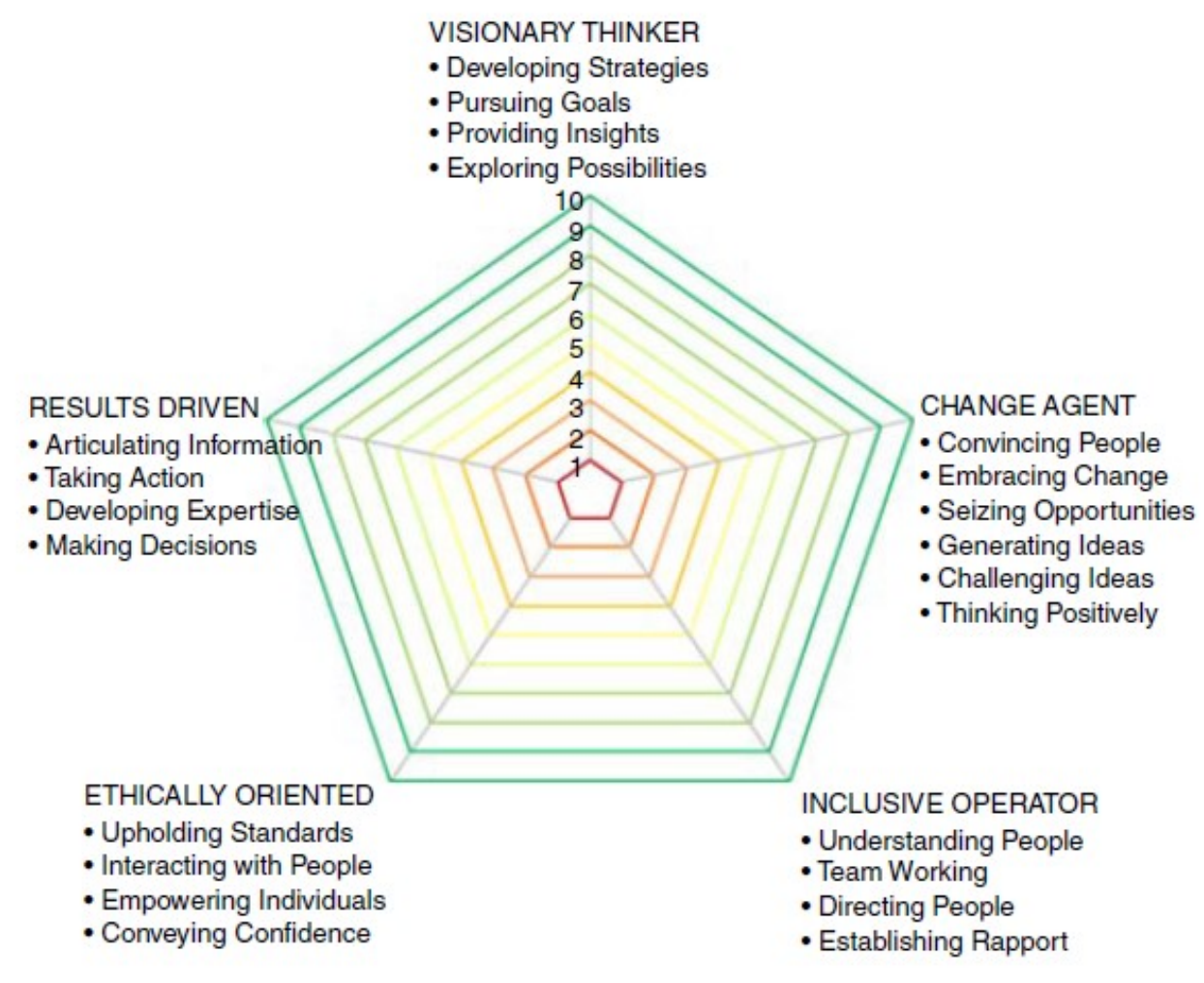

Figure 4: Sustainability Leadership Behavioural Competency Model (Knight \& Paterson, 2017, p. 565) 
The works of Metcalf and Benn (2013), Hull and colleagues (2018), the WBCSD (2011), and Knight and Paterson (2017) therefore have many similarities. The importance of being able to effectively manage complexities, working collaboratively, being ethical and inclusive, facilitating innovation, and being a transformational leader are all attributes identified across this literature. However, other academics have gone beyond personal leadership attributes and put forward more comprehensive frameworks for identifying sustainability leaders in the private sector. Visser and Courtice's (2011) model includes a variety of aspects including leadership traits, styles, skills, internal and external actions that are conducive to sustainability leadership (see Figure 5 below). This model includes many attributes listed by other authors, including being inclusive, innovative, collaborative, and able to manage complexity.

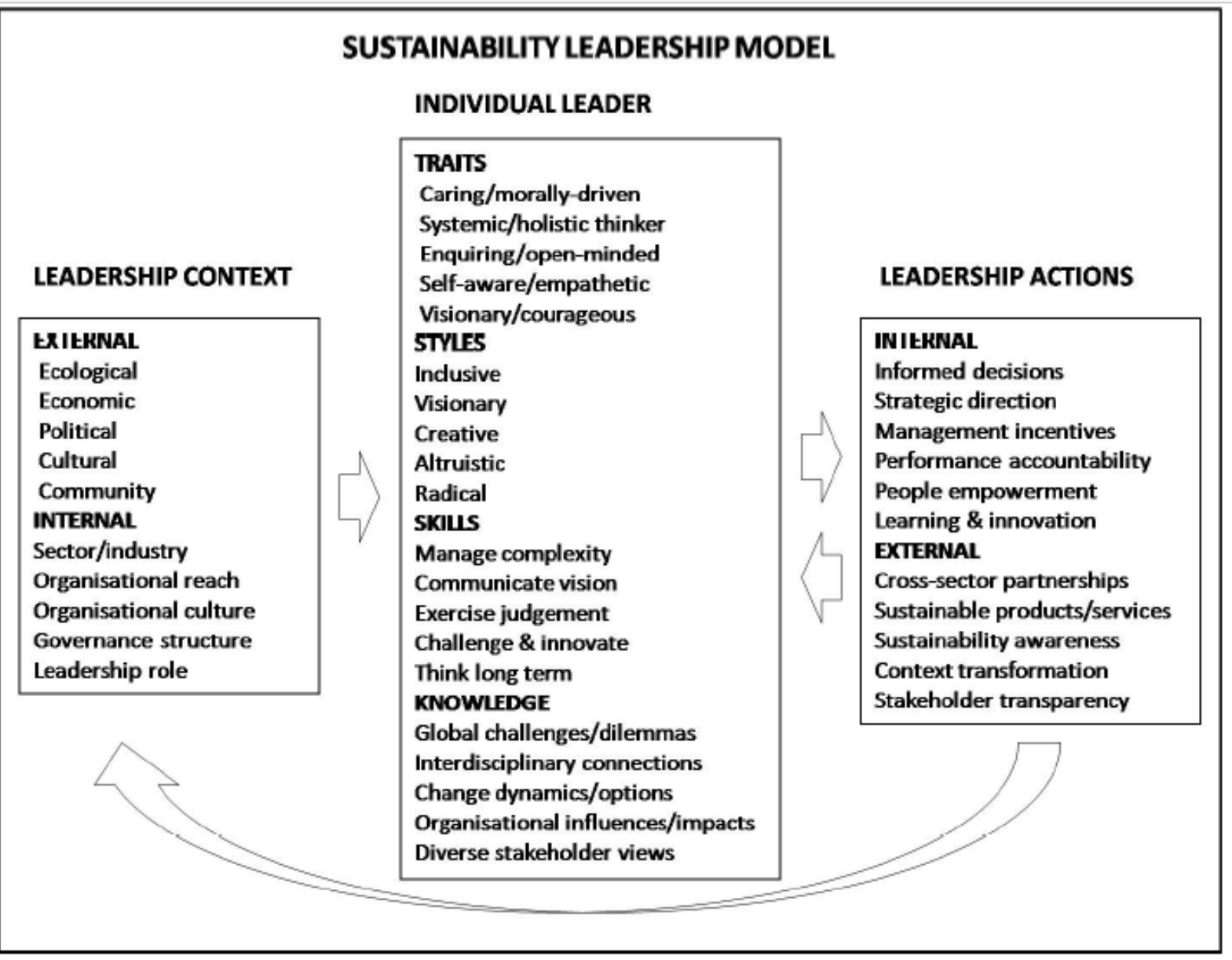

Figure 5: The Cambridge Sustainability Leadership Model (Visser \& Courtice, 2011, p. 5) 
The leadership models discussed above all focus on private sector sustainability leadership in the context of addressing modern sustainability problems. However, another field of literature focuses explicitly on private sector leadership for the attainment of the Sustainable Development Goals (SDGs). ${ }^{16}$ Despite having a different focus, the work within this second sphere of scholarship has similar conclusions. For example, Sørensen and Handcock (2020) conducted interviews with 55 private sector sustainability leaders to gain an understanding of what attributes are key to sustainability leadership and the attainment of the SDGs (p. 2). They conclude that four leadership attributes are key to this: the ability to address complexity through multilevel systems thinking, stakeholder inclusion and collaboration skills, innovation and creative orientation, and long-term thinking (p. 11). The work of Campbell and colleagues (2018) also focuses on private sector leadership for the attainment of the SDGs. These authors identify six leadership attributes which are critical to attaining private sector sustainability: long-term thinking, innovation, collaboration, transparency, environmental management (leaders that recognize and prioritize environmental issues), and social inclusiveness (p. 10). Many of these are similar if not identical to what previous research concluded.

These conclusions of previous research studies are interesting for a couple of reasons. Their consistency, despite the fact that they were done with different populations and across a nine-year timespan, is remarkable. This suggests that no matter where you may be and whatever your sustainability goal (whether it be related to CSR initiatives or the SDGs), certain leadership attributes will be more effective than others in attaining that goal. For example, one theme which consistently emerged was collaboration and looser hierarchies. This form of leadership may not

\footnotetext{
${ }^{16}$ First adopted in 2015, the SDGs are a blueprint for all United Nations Member States for a better future for all people and our planet. They are a global partnership calling for the realization of 17 goals by 2030, including an end to poverty, improving health and education, reducing inequality, and tackling our modern environmental challenges (United Nations, 2021).
} 
always be the answer: if a leader is dealing with an emergency that needs to be addressed right away or managing a niche problem irrelevant to others, a collaborative approach would likely not be the most effective. However, this literature review suggests that when leading sustainability efforts, collaboration is key.

Another interesting take-away from this review is that these leadership attributes which the literature has identified as being key to sustainability leadership are notably absent from the stereotype of a traditionally masculine leader and the attributes that they should possess. Rather than the traditional stereotype of a solo, assertive, rational, and charismatic individual, this literature suggests that sustainability leaders must be collaborative, encouraging, ethical, and inclusive. This not only reinforces my previous suggestion that modern sustainability problems require a distinct form of modern sustainability leadership, but also suggests that effective sustainability leadership is decidedly non-masculine. Instead, leadership attributes such as collaboration and inclusivity are consistently tied to femininity and women's leadership (as will be discussed in section 3.1.2 below).

Lastly, it is important to note the place that these attributes which existing literature identifies as being key to sustainability leadership have in institutional structures and norms surrounding leadership and promotions. While things are changing, in a traditional company setting many of these are not leadership attributes which will typically get an individual promoted. For example, individuals who work well with others in a collaborative manner and showcase group success as opposed to individual success are often overlooked for promotions. Instead, research suggests that loud narcissists are more likely to step into positions of power (Brunell et al., 2008; Campbell \& Crist, 2020). This failure is systematic: currently, many private sector companies are set up with structures and norms which prioritize self-aggrandizing behaviour (Campbell \& Crist, 2020). 
However, if individuals with these sustainability leadership qualities (e.g., ethical and collaborative) are not promoted to leadership positions, the sustainability of a company will suffer as a result of leaders ill-suited for issues of sustainability. In light of the global trend towards increasing awareness of sustainability challenges and the key role it is now playing in investment decisions, continuing to promote leaders who are ill-suited to sustainability problems could lead to the downfall of a company in the long term.

A comprehensive summary of what attributes this literature review has pointed to as being critical for private sector sustainability leadership can be found in Table 1 below. While there is no discussion in the literature of how these leadership attributes rank in terms of their importance in effective sustainability leadership, some leadership attributes do appear to be more important than others. For example, the importance of a collaborative leadership style in leading sustainability initiatives emerges in six different articles, more than any other attribute. Collaboration is also a component of other sustainability leadership attributes, such as innovation, transformational leadership, and inclusive leadership. Similarly, the ability to manage complexity is referenced many times (in five articles) and is tied to several other attributes. Like collaboration, the ability to manage complexity is inherently linked to other sustainability leadership attributes. This is because if a leader is not good at managing complexity, it is unlikely that they will be able to be collaborative, innovative, ethical, inclusive, and think long-term all at once. 
Table 1: Attributes for Private Sector Sustainability Leadership

\begin{tabular}{|c|c|}
\hline Attribute & Scholarship \\
\hline $\begin{array}{l}\text { Collaborative } \\
\text { Collaboration as a leadership attribute means that a leader focuses on } \\
\text { team building, working together, looser hierarchical structures, and } \\
\text { moving away from silos. }\end{array}$ & $\begin{array}{l}\text { Metcalf and Benn (2013) } \\
\text { Hull et al. (2018) } \\
\text { WBCSD (2011) } \\
\text { Visser and Courtice (2011) } \\
\text { Sørensen and Handcock (2020) } \\
\text { Campbell et al. (2018) }\end{array}$ \\
\hline $\begin{array}{l}\text { Innovative } \\
\text { Innovation as a leadership attribute contributes to sustainability as a } \\
\text { personal attribute and as a leadership style. As a leadership style, } \\
\text { innovation consists of encouraging others to share new ideas and be } \\
\text { creative. }\end{array}$ & $\begin{array}{l}\text { WBCSD (2011) } \\
\text { Knight and Paterson (2017) } \\
\text { Visser and Courtice (2011) } \\
\text { Sørensen and Handcock (2020) }\end{array}$ \\
\hline $\begin{array}{l}\text { Transformational leadership } \\
\text { A transformational leader is the opposite of a transactional leader. They } \\
\text { are less about giving orders than they are about encouraging, inspiring, } \\
\text { and motivating employees for change. }\end{array}$ & $\begin{array}{l}\text { Metcalf and Benn (2013) } \\
\text { WBCSD (2011) } \\
\text { Knight and Paterson (2017) } \\
\text { Visser and Courtice (2011) }\end{array}$ \\
\hline $\begin{array}{l}\text { Ethical and transparent leadership } \\
\text { Leaders who are ethical and transparent will push for more honest } \\
\text { business practices, such as increased disclosure of risks to stakeholders. }\end{array}$ & $\begin{array}{l}\text { Metcalf and Benn (2013) } \\
\text { Knight and Paterson (2017) } \\
\text { Visser and Courtice (2011) } \\
\text { Campbell et al. (2018) }\end{array}$ \\
\hline $\begin{array}{l}\text { Environmental management } \\
\text { The leadership attribute of environmental management refers to leaders } \\
\text { that recognize and prioritize environmental issues. This refers to both } \\
\text { personal convictions and their willingness to act on those convictions } \\
\text { and push their firm towards greater environmental protection. }\end{array}$ & Campbell et al. (2018) \\
\hline $\begin{array}{l}\text { Long-term orientation } \\
\text { A leader who thinks in the longer-term will consider and prioritize } \\
\text { future risks and benefits to a greater extent. This is not always easy in an } \\
\text { economic structure which prioritizes short-term gains for shareholders. }\end{array}$ & $\begin{array}{l}\text { Visser and Courtice (2011) } \\
\text { Sørensen and Handcock (2020) } \\
\text { Campbell et al. (2018) }\end{array}$ \\
\hline $\begin{array}{l}\text { Inclusive leadership } \\
\text { Inclusive leadership as a leadership attribute refers to leaders who } \\
\text { promote better working conditions for employees and a more welcoming } \\
\text { environment. }\end{array}$ & $\begin{array}{l}\text { Knight and Paterson (2017) } \\
\text { Visser and Courtice (2011) } \\
\text { Campbell et al. (2018) }\end{array}$ \\
\hline $\begin{array}{l}\text { The ability to manage complexity } \\
\text { Leading an energy company in the midst of an energy transition is } \\
\text { extremely complex, there are a multitude of players, systems, and } \\
\text { economic considerations which must be taken into account. The ability } \\
\text { to navigate these complexities is key to effective sustainability } \\
\text { leadership, }\end{array}$ & $\begin{array}{l}\text { Metcalf and Benn (2013) } \\
\text { Hull et al. (2018) } \\
\text { WBCSD (2011) } \\
\text { Visser and Courtice (2011) } \\
\text { Sørensen and Handcock (2020) }\end{array}$ \\
\hline
\end{tabular}




\subsubsection{Women's leadership}

Having established what leadership attributes are key to sustainability initiatives, the next step is to identify where leaders demonstrating these attributes can be found. One recommendation put forward by a handful of academics is that women are sustainability leaders, and the promotion of women leaders can lead to the achievement of more sustainable outcomes (Campbell et al., 2018; Lieu et al., 2020; Marshall, 2011). This second literature review will scrutinize this suggestion and assess the literature on women's leadership. More specifically, it will evaluate whether or not previously conducted research studies suggest an alignment between the leadership attributes which are key to sustainability (see Table 1 above) and the leadership attributes associated with women's leadership.

Prior to delving into this literature, a brief review of the issues surrounding women's leadership is warranted. In recent years, there has been increased public interest in promoting women to leadership positions. Unfortunately, many suggested solutions and initiatives that have been pursued are founded on the conception that to succeed, women ought to emulate men (Miner, 1993). This means taking up qualities typically associated with men, such as assertiveness (Koenig et al., 2011). For example, Hennig and Jardim's book The Managerial Woman (1977) recommends studying football in order to better understand the male conceptualization of strategy. Similarly, research by Höpfl and Matilal (2007) demonstrates how women are encouraged to give up their womanhood in leadership roles in an "annihilation of the feminine" (p. 201). They state that "it seems almost as inevitable as it is pervasive to hear women's 'success' described in terms of their ability to demonstrate male behaviour...to succeed requires that a woman perform as a man" ( $p$. 199).

More recent scholarship recognizes the shortcomings of this traditional approach to leadership and how to best elevate women to leadership positions (Eagly \& Carli, 2003, p. 810). 
Since the 1990s, a "post-heroic" style of leadership for the so-called "twenty-first century leader" has been promoted in a growing number of books, courses, and leadership training programmes (Huey, 1994; Sandmann \& Vandenberg, 1995). This new style of leadership is characterized by several attributes which are notably not-traditionally-masculine, such as focusing on communities and a non-authoritarian leadership style (Hesselbein et al., 1998; Hirschorn, 1997; McFarland et al., 1994). At a rhetorical level, many private sector actors have embraced this new style of leadership. However, in practice traditional leadership attributes are still privileged in determinations of what makes for an effective leader (e.g., loud, self-aggrandizing behaviour) (Höpfl \& Matilal, 2007, p. 200). The point of this research is to question this practice and theorize that for modern sustainability problems in Canadian energy sector firms, a new form of leadership is required. Furthermore, this form of leadership does not conform to traditional masculine stereotypes of what leadership is and what it requires to be a leader.

Beyond issues stemming from a system which tells women to take on traditionally male leadership attributes in order to succeed, another issue surrounding women's leadership is that of stereotypes. I have found this issue difficult to navigate in my research and writing. Because of stereotyping and the host of controversies that it brings, the literature on women and leadership is a minefield for feminists (Höpfl \& Matilal, 2007, p. 202). On the one hand, there is a recognition that gender is largely socially constructed, but at the same time any argument presented regarding women's leadership abilities is predicated upon a difference between men and women. Thus, any argument must not only recognize that any leadership qualities particular to women are the result of social constructs and gendered socialization, but also must assume a level of continuity in the social construction of gender (or the argument would be rendered null). It is for this reason that Butler's active definition of gender has been adopted for this research; gender as being something 
that is performed leaves more room for inconsistency and individual agency. For example, one leadership attribute which is associated with women's leadership is collaboration. Though not all women leaders lead in a collaborative way, societal pressures and structures are such that women are encouraged to take on a more collaborative leadership style. In other words, one aspect of 'performing' womanhood, is leading collaboratively (at least to a greater extent than men).

Despite the perhaps awkward nature of this field of literature, there is significant research pointing to a difference between the leadership attributes typically associated with men compared to those typically associated with women. While not all women are the same, and thus this research cannot be assumed to apply to all women, the following literature review will provide an overview of key trends in this research. It is however important to keep in mind these gender differences in terms of leadership attributes are the result of gendered social structures and power dynamics (see section 2.1). These structures are not homogenous, and every individual responds to them in their own unique way, meaning that while on average women may have certain attributes to a larger extent than men (or vice versa), there are many exceptions.

Lastly, prior to delving into this literature, another important distinction must be made between women's representation in leadership roles and their ability to participate and contribute to decisions. Research has shown that putting a lone woman at the top of business hierarchies does not lead to system-wide change, as lone women are much less likely to exhibit the characteristics associated with women's leadership (Glass et al., 2016, p. 507; Noland et al., 2016, p. 3). Rather, when alone, women leaders often take on traditionally masculine leadership attributes, especially when they are not supported by other women and/or human resource policies. The critical threshold at which women do exhibit these stereotypically feminine leadership attributes and can actually make a difference in an organization has been found to be 30\% (Carter \& Wagner, 2011; 
IRENA, 2019; Noland et al., 2016) or at least three women (Konrad et al., 2008; Post et al., 2011; Torchia et al., 2011; Joecks et al., 2013). Initiatives like the 30\% Club, a global campaign led by private sector leaders, are working to attain this goal of having women represented in at least $30 \%$ of board of directors and executive teams (30\% Club, 2021).

Women leaders: what does the literature say?

As "a stylized repetition of acts," gender can be seen being performed when women and men are in leadership positions (Butler, 1988, p. 519). These performances lead to distinct styles of leadership and leadership attributes. An overview of key attributes associated with women's leadership is presented below. In an effort to maintain coherency, rather than presenting all literature relating to women's leadership, only literature focusing on the attributes presented in Table 1 (sustainability leadership attributes) will be reviewed.

Literature on sustainability leadership consistently suggests that a collaborative approach is key when leading sustainability initiatives. This leadership attribute is also associated with women's leadership: research shows that women's leadership tends to be far more collaborative than their male counterparts (Gould \& Hosey, 2007, p. 3). For example, Rosener (1995) points out that women's leadership is typically characterized as more empowering, interactive, and collaborative, while men's is more assertive and command-and-control. Similarly, other studies have shown that women are better at balancing multiple stakeholders' interests and reaching an outcome that all parties support (Benko \& Pelster, 2013, p. 81; Brammer et al., 2007; Harrison \& Coombs, 2012). This style of leadership that women leaders often exhibit can also be described as transformational leadership, which is characterized by less rigid hierarchies and more encouragement and inspirational leadership (Bass \& Avolio, 1994, p. 549; Eagly \& Carli, 2003; Eagly et al., 2003). 
This more collaborative approach that women leaders often exhibit has several key benefits. First, there is a link between increased collaboration and higher levels of innovation (which will be explored below). Furthermore, in our post-industrial society, successful leaders are those who share power and work to establish collaborative relationships (Lipman-Blumen, 1996). Thus, in the modern age, good leadership is less about strict hierarchies and authority than it is about encouraging collaboration and empowering employees (Hammer \& Champy, 1994; Senge, 1994). For example, research by Deloitte demonstrated that a successful executive team in the twentyfirst century can no longer afford to operate in silos, but rather must work together as a collaborative team (Lahiri et al., 2018). This means that research, training modules, and leadership books are increasingly proposing more collaborative forms of leadership.

A second key trend in the sustainability leadership literature is that being an innovative leader is important to the successful achievement of sustainability goals. When reviewing the literature on women's leadership, the fact that women's leadership leads to increased innovation emerged as the most commonly cited reason to include more women in leadership positions within the private sector. There are many examples of research which support this theory. Dezsö and Ross (2012) tested data from 1500 firms over 15 years and found that female representation in leadership roles is associated with increased firm innovation, which was represented by the ratio of research and development (R\&D) expenses to assets (p. 1072). ${ }^{17}$ Torchia and colleagues (2011) have similar findings, concluding that having at least three women on a company's board of directors substantially increases the level of firm innovation (p. 299). Similarly, in an analysis of Fortune

\footnotetext{
${ }^{17}$ Since there is no source for a statistical data collection of innovation activity at a firm, R\&D expenses are commonly used a proxy. While this is not a perfect metric for innovation, it has been used as a metric for innovation for several decades (Mohnen, 2019, p. 3).
} 
500 firms, Miller and Triana (2009) found that increased board gender diversity increases R\&D expenses and thus firm innovation (p. 755).

There are two proposed reasons for this link between innovation and gender diversity: women as individuals bring new ideas and perspectives to the table, and women's leadership style tends to boost innovation among employees through encouraging new ideas and collaboration. This first reason can be summarized by the popular saying that 'two heads are better than one'. In other words, gender diversity brings increased cognitive conflict (Torchia et al., 2018, p. 215). As stated by Pellegrino and colleagues (2011), when faced with complex problems and innovation, "a diverse group of competent performers almost always outperforms a homogenous group of star performers by a substantial margin" (p. 10). In fact, there is evidence that homogenous groups may serve to hamper innovation through a lack of critical evaluation of alternatives and points of view (Janis, 1972). Beyond this, evidence has also shown that women leaders are more likely to question traditional practices and instead pursue unorthodox initiatives (Adams \& Funk, 2012; Eagly et al., 2003).

In terms of their leadership style, research has consistently shown that women leaders overall are more innovative and supportive of new ideas and collaborative efforts (Adams \& Funk, 2012; Eagly et al., 2003; Torchia et al., 2011). This is important because this leadership style is key to encouraging group innovation. For example, Hewlett and colleagues (2013) point to six specific leadership behaviours which unlock innovation in teams, all of which are associated with a collaborative leadership style: encouraging new ideas, ensuring that people are heard, distributing decision-making authority (less hierarchical), sharing credit, giving feedback, and implementing any feedback received from the team (p. 2). Similarly, Woolley and colleagues (2010) found that when teams are less willing to engage in turn-taking and sharing ideas equally, collective group 
intelligence decreases (p. 688). Thus, the more collaborative leadership style typically associated with women's leadership can have a substantial positive impact on innovation.

There is an important caveat to these findings. Lyngisie and Foss (2017) reach similar conclusions, finding that the presence of more women leaders positively impacts levels of firm innovation. However, the authors also find that adding more women is not necessarily going to have this impact: in industries and firms which already have high levels of women in the workforce, adding additional women in leadership roles has little impact on firm innovation (Lyngsie \& Foss, 2017, p. 487). This is because when women leaders dominate a firm or industry, they are no longer outsiders challenging the status quo and bringing novel ideas (Lyngsie \& Foss, 2017, p. 500). In such cases, the marginal impact of adding one more woman is often small. However, since women leaders are currently a minority in Canadian energy sector firms, this should not be a concern.

A third leadership attribute which the literature on sustainability leadership points to is the importance of ethical and transparent leadership. Like collaboration and innovation, this sustainability leadership attribute is also associated with women's leadership (at least to a greater extent than their male counterparts). ${ }^{18}$ Women's higher level of attention to ethics and transparency in leadership positions has been demonstrated in a variety of ways. Boulouta (2013) performed research studying the impact of women leaders on corporate social performance (i.e., the number of ethical issues). Her research, based on analysis of 126 firms over five years, found that increased gender diversity led to fewer corporate scandals (p. 193). Greater gender diversity in private firms is also associated with increased transparency and social and environmental reporting (Brown et

\footnotetext{
${ }^{18}$ Note that most studies which demonstrate women's leadership and an increase in ethical and transparent behaviour in firms deal with correlations rather than causations. Thus, even though the two are correlated, the manner by which they interact is unclear. For example, women may simply be attracted to more ethical firms rather than women's actions making the firm more ethical.
} 
al., 2002; Frias-Aceituno et al., 2013; McElhaney \& Mobasseri, 2012, p. 4) and fewer large-scale environmental lawsuits and controversies (McElhaney \& Mobasseri, 2012, p. 4). Furthermore, in countries with higher levels of gender diversity in private sector leadership positions, the levels of transparency and CSR reporting are higher (Fernandez-Feijoo et al., 2014, p. 351).

Research also suggests that women leaders are, on average, more ethical at a personal level. Women leaders are more driven by their moral compass, by a desire to contribute to a purpose and shape organizational culture in a positive way (Orr \& Stevenson, 2017). For example, Franke and colleagues (1997) performed a meta-analysis of gender differences in ethical decision making, finding that women are more sensitive to ethical dilemmas than men (p. 920). Borkowski and Ugras' (1998) study of business students had similar findings: female students exhibited more ethical behaviour than men. Likewise, Smith and Rogers (2000) found that in uncertain and undefined situations, women are more likely to act ethically. Since ethical and transparent leadership is key to sustainability leadership, this suggests that women leaders may be more effective sustainability leaders.

The fifth attribute identified in the sustainability leadership literature is environmental management, which essentially refers to leaders' recognition and prioritization of environmental issues. In industrialized countries like Canada, research shows that women tend to be more concerned about environmental issues than men (Albaum \& Peterson, 2006; Burton \& Hegarty, 1999; Forte, 2004; Kennedy \& Dzialo, 2015; McCright \& Xiao, 2014). The reason which is often given for this is that women are socialized to be more socially responsible and community-oriented than men (Liu, 2018, p. 119; Zelezny et al., 2000, p. 443). They are also less overconfident than their male colleagues (Chen et al., 2016; Huang \& Kisgen, 2013; Levi et al., 2014) and more riskaverse (Bord \& O'Connor, 1997). This translates into more careful decision-making when it comes 
to making decisions which may have negative consequences down the road, as is often the case with sustainability issues.

The result of this is an association between environmental management and the number of women in leadership positions: firms with more women on their board of directors perform better environmentally than those without (Glass et al., 2016; Kassinis et al., 2016, p. 399; Post et al., 2011). In fact, Arbogast and Thornton (2010) identify leadership diversity as one of the top reasons as to why some private companies are more successful in achieving sustainability than others. Using data from firms, the authors developed a regression model to explain the variability in sustainability metrics and found that leadership diversity as an independent variable had a notable impact on firm sustainability (Arbogast \& Thornton, 2010, p. 7). Evidence also suggests that women's presence on boards is associated with increased CSR performance (Bear et al., 2010; Harjoto et al., 2015; Landry et al., 2016; Larkin et al., 2013; McGuinness et al., 2017) and fewer corporate environmental violations (Liu, 2018).

The positive relationship between women's leadership and environmental management has also been demonstrated in the energy sector: in an analysis of over 1500 companies, McElhaney and Mobasseri (2012) demonstrated that companies with more women on their boards are also more likely to invest in renewable power, integrate and account for climate change in their business practices, and try to reduce waste and preserve biodiversity (p. 3-4). Based on an even wider pool of 3389 firms, Xie and colleagues (2020) demonstrated that including women on boards contributes to the implementation of proactive environmental strategies (p. 2044). This all points to a direct positive relationship between environmental management of a private company and the number of women in leadership positions. 
A sixth leadership attribute identified in sustainability leadership literature is having a longterm orientation. Though there is less research on the topic, studies have suggested that women as leaders have a longer-term orientation (Silverman, 2003). For example, McElhaney and Mobasseri (2012) demonstrate that businesses with more women leaders are more likely to focus on longer-term growth goals rather than short-term profits. Likewise, boards of directors which include women are more likely to make decisions prioritizing longer-term rewards (Adams \& Ferreira, 2009). At a personal level, women also typically have lower personal implicit discount rates than men, meaning that they value future costs and benefits more than men do (Coller \& Williams, 1999; Kirby \& Marakovic, 1996).

Inclusive leadership is the seventh attribute which has shown to be important for sustainability leaders. Inclusiveness as a leadership style is related to several attributes discussed above, such as collaboration and innovation. However, beyond this openness to discussion and new ideas, inclusive leadership is also concerned with better working conditions for employees and a more welcoming environment, both of which have also been tied to women's leadership (McElhaney \& Mobasseri, 2012, p. 4). This link between women and social inclusiveness has also been shown to extend beyond internal affairs, as companies with more women leaders are more likely to prioritize and protect their social license to operate through efforts to provide benefits to local communities (McElhaney \& Mobasseri, 2012, p. 4).

The eighth and final attribute identified in sustainability leadership literature is the ability to manage complexity. Unlike previous attributes, no literature which explores whether or not the ability to manage complexity varies by gender could be found. However, based on the literature which has already been discussed, it is possible to conclude that women leaders may be more effective in complex systems for a couple of reasons. 
Due to the ubiquitous nature of energy, energy systems are extremely complex. Energy system transitions are even more complex, as they occur in a variety of spheres (political, economic, technical, social), and are non-linear in terms of their progression. Unsurprisingly, literature suggests that leadership within complex systems like this is particularly challenging (Ercetin, 2016; Uhl-Bien et al., 2007). In order to overcome these barriers and successfully lead through complexity, McKelvey and Boisot (2003) put forward the Law of Requisite Complexity, which states that only complex organizations and approaches can address complex systems or problems. This suggests that loose hierarchies and encouraging innovation and unorthodoxy may be more effective as an organizational structure and leadership strategy when it comes to energy transitions (Uhl-Bien et al., 2007, p. 301). Similarly, Uhl-Bien and colleagues (2007) suggest that to be effective, leadership in complex systems should focus on enabling learning, creativity, informal network dynamics, and adaptive capacity among organizations (p. 298, 302). Thus, since leadership qualities for managing complexity, such as looser hierarchies, innovation, challenging the status-quo, and encouraging creativity, are all characteristic of women's leadership style, women leaders may also be better able to manage complexity.

This literature review suggests that the eight leadership attributes which literature on sustainability leadership found to be crucial (see Table 1) are also characteristic of women's leadership. Collaboration, innovation, transformational leadership, ethical and transparent leadership, environmental management, having a long-term orientation, inclusive leadership, and the ability to manage complexity are both crucial leadership attributes to the attainment of sustainability and associated with women's leadership. However, many of the studies referenced are dated and most were not conducted in Canada or in the energy sector. Many also rely on correlations rather than causations, meaning it is impossible to say whether or not, for example, 
women cause a firm to be more ethical or if women are simply attracted to more ethical firms. These conclusions are also generalizations and cannot be assumed to apply to all women leaders. Lastly, there is also some evidence to the contrary: though most research on gender and leadership suggests that there is a difference between men and women's leadership, not all does. For example, research by Andersen and Hansson (2011) found no statistically significant difference in leadership behaviours between men and women leaders.

Another point which requires further discussion is whether these generalizations that I am making are harmful to women leaders. When discussing women's leadership and the stereotypes associated with it, there are two sides: one which suggests that the solution is to celebrate how these stereotypes can help women and should be more widely adopted by all gender identities, and the other which suggests that the solution is to stop stereotyping and take gender out of discussions of leadership attributes. This thesis is obviously ascribing to the former and seeks to present these stereotypes as something positive and beneficial for both women and, ultimately, the world (as these stereotypes suggests women are sustainability leaders). However, other work proposes that doing this and reiterating stereotypes like 'women leaders are more collaborative' is harming women and their advancement (Chan, 2021; Deloitte, 2011). This side of the discussion presents these stereotypes, even if they are positive, as a form of "benevolent sexism" that ultimately hurts women and their position in the workforce (Chan, 2021). While I recognize that assuming an individual necessarily has or does not have a certain attribute because of their gender may be harmful, this research recognizes that these are stereotypes and thus do not apply to all individuals. I also believe that this is an opportunity to celebrate women leaders and promote change in a system which currently prioritizes a form of leadership ill-suited for sustainability issues. As discussed at the beginning of this section (3.1.2), a lot of literature on leadership as it relates to 
women has, in the past (and to an extent even now), been concerned with telling women what to do. Essentially, it presents women as the problem, and encourages them to conform to a system which does not recognize the merits of these more stereotypically-feminine leadership attributes. This thesis aims to turn this notion on its head, and present women leaders as a solution to contemporary sustainability challenges and the system which does not recognize them as such as the problem.

This section (3.1) has reviewed the literature on sustainability leadership and gendered leadership to respond to the primary research question of this thesis: whether or not promoting women's leadership will facilitate Canada's sustainable energy transition. This review demonstrated that these two fields of literature line up, and the attributes necessary for sustainability leadership are also associated with women's leadership. These conclusions suggest that the answer to this primary research question is yes, women's leadership can facilitate an energy transition towards sustainability. While this question will be further explored in subsequent chapters, the following section will focus on the secondary research question of this thesis: what are the barriers for women and women leaders in Canadian energy sector firms and how can they be overcome? Previous research responding to this question will be reviewed and evaluated below.

\subsection{Barriers and Recommendations for Women Leaders}

The literature reviewed in section 3.1 above suggests that promoting women's leadership within the Canadian energy sector may serve to facilitate a sustainable energy transition. However, actually getting women into these leadership positions is an entirely different question. As previously mentioned, the Canadian energy sector currently has a distinct lack of women in the workforce, particularly in leadership positions. Though different estimates exist, at a global level, research suggests that women account for $8-22 \%$ of the oil and gas workforce and $14-32 \%$ of the 
renewable energy workforce (Airswift \& Energy Jobline, 2019; IRENA, 2019, p. 10). Furthermore, as in many other industries, the higher up the organizational hierarchy you go, the fewer women you typically find. In the Canadian oil and gas sector, women hold an average of $7 \%$ of board of director positions and $9 \%$ of executive positions (Catalyst, 2019). Data regarding women in leadership positions within the Canadian renewable energy sector could not be found, though Electricity Human Resources Canada (EHRC) did find that women hold fewer than 1\% of jobs in top management positions in the clean energy sector in industrialized nations (EHRC, 2017). ${ }^{19}$ The question therefore is: what barriers are these women facing and what can be done to promote more women into leadership positions? While there is a mountain of research on this topic in general, the following literature review will focus on research done within the energy sector specifically, and within Canada or a similar industrialized country.

\subsubsection{A lack of gender-disaggregated data}

A review of the literature reveals that there are a variety of challenges that women in the Canadian energy sector face, but one of the most basic challenges identified in past studies is a lack of gender-disaggregated data on employment within the energy sector (Barua \& Gaudet, 2018; Pearl-Martinez \& Stephens, 2016, p. 2; Smet, 2018). This lack of information makes analysis and tracking progress challenging to impossible. A lack of data also limits the visibility of the issue, and with no visibility it is much harder to galvanize support for and action on the issue of gender and diversity within the sector. In a society as data-driven as ours this has drastic consequences: "what has not been counted, does not count" (Pearl-Martinez \& Stephens, 2016, p.

2).

\footnotetext{
${ }^{19}$ The clean energy sector includes a range of policies, technologies, and services which accelerate a shift to a carbonfree energy system. Examples include energy efficiency, renewable energy, smart grids, and energy storage technologies such as batteries (EHRC, 2017).
} 
This lack of data is a barrier that I faced in determining a baseline for this research. Though many companies do collect gender-disaggregated employee data, often for ESG reporting, this information is not always publicly available or shared ${ }^{20}$ The Canadian government also does not consistently collect this information, meaning there is no centralized database or platform where one can learn about this issue. Data that I was able to find was often dated and/or pulled from studies which looked at the energy sector around the globe, rather than in Canada specifically. For example, the International Renewable Energy Agency (IRENA) conducted a study exploring this issue, resulting in its 2019 publication titled Renewable Energy: A Gender Perspective. IRENA's research was conducted through an online survey in 2018, collecting over 1500 responses from 144 different countries (IRENA, 2019, p. 21). While the conclusions of this study are definitely interesting, its applicability to the Canadian context is dubious. While some issues are global, women in Africa and China likely have different experiences in the energy sector than women in Canada. For example, the survey conducted by IRENA found perceptions of gender roles to be the most commonly-cited barrier to entry for women in the energy sector (IRENA, 2019, p. 11). Though it is likely that this is still a barrier in Canada, the extent to which this is an issue and the way it may manifest likely varies. In a country like Canada, more explicit forms of gendered bias are often less common than unconscious bias and prejudice.

The solution to this dilemma is clear: Canada needs to start collecting gender-disaggregated data on employment within the sector. Any number of governmental or nongovernmental bodies could initiate these efforts. At a company level, increased transparency in terms of diversity in the

\footnotetext{
${ }^{20}$ This data can be on annual reports or ESG reports, which are sometimes be publicly-available. There are also voluntary standards for ESG reporting, such as through the Sustainability Accounting Standards Board (SASB). New legislation on this issue has emerged, and as of January 2020, companies under the Canada Business Corporations Act (CBCA) must disclose gender diversity on boards (Tardif \& Stanley, 2020). However, even when this information is publicly available, it is not compiled anywhere and no national and/or provincial statistics are taken.
} 
workforce as well as holding leaders accountable could go a long way to improve the situation. At a wider scale, advocacy group initiatives like Equal by 30 and the IEA's Gender Diversity Initiative are pushing this issue into the spotlight and strengthening data collection at a global and national scale (Cision, 2021, Johnstone \& Silva, 2020). While these efforts are commendable, further data collection in Canada specifically is needed. For example, a report recently conducted by Canadabased Diversio in support of the Equal by 30 campaign provided updated data on this issue, but data is global rather than country-specific (Cision, 2021). While useful, a more convincing narrative would be based on purely Canadian data and would be more granular in nature (e.g., not just the percentage of women in the workforce, but also their role in the company).

\subsubsection{Cultural and social norms}

Other critical challenges which women face stem from the culture of the energy sector. Research on women in the energy sector has identified cultural and social norms, such as the perception of the energy sector as an "old boys' network," as one of the top perceived barriers to women's entry and advancement in the sector (Baruah \& Biskupski-Mujanovic, 2018, p. 5; Boyd et al., 2019, p. 30; EHRC, 2017, p. 22; IRENA, 2019, p. 11-12; 2020, p. 25, 27). Even in the absence of deliberate and conscious bias, a lack of awareness of and attention to the challenges that women face leads to issues. Unconscious bias in both men and women is a notable challenge to creating a more inclusive and diverse workforce (Boyd et al., 2019, p. 50). ${ }^{21}$ Because of these biases and the culture engrained within the sector, research has shown that women in technical fields need more experience or superior qualifications to be treated as equals with male colleagues (Smet, 2018).

\footnotetext{
${ }^{21}$ While conscious bias is attitudes, perceptions, and actions about a group or identity that an individual is aware of, unconscious bias are attitudes which an individual may not be aware of. However, not being consciously aware of a bias does not mean it will not impact a person's actions and words. Unconscious bias is therefore a more insidious form of bias, and it can be difficult to convince someone that they hold biased beliefs if they are not aware of it.
} 
Addressing this challenge will take time and a concerted effort by companies and the government. One key aspect of this cultural shift that needs to take place is starting to have the difficult conversations and making people aware of the biases that they hold (Baruah \& BiskupskiMujanovic, 2018, p. 3). This must happen both at companies throughout the energy sector and in Canadian society more generally. A second important initiative which would serve to initiate this cultural shift is providing unconscious bias and diversity training to personnel (Boyd et al., 2019, p. 66; Equal by 30, 2021). At a societal level, these efforts could take the form of public information campaigns seeking to draw attention to unconscious bias and harmful stereotypes (Park et al., 2019). These public information campaigns could also be incorporated into school curriculums, both at the K-12 and postsecondary education levels. Ensuring that young people are more aware of conscious and unconscious bias, even if it is not specific to the energy sector, could help to transform the sector in the longer term as the older generation is replaced with younger workers. Lastly, hiring an inclusion and/or diversity officer of some kind could help to bolster and ratify these efforts (Equal by 30, 2021). This officer would not only solidify a company's commitment and hold it accountable to targets, but it would also signal to investors that it is a forward-looking company.

\subsubsection{Unfair practices}

A third challenge that women in the energy sector face stems from this culture and the biases engrained in the sector. These biases lead to unfair practices, specifically as they relate to recruitment and promotions. Recruitment practices often skew the playing field through allowing unconscious bias to impact decision-making (Boyd et al., 2019, p. 58; Park et al., 2019, p. 58). Similarly, research shows that women are simply not promoted as often and do not receive the same level of support from managers (Boyd et al., 2019, p. 32; MacDougall et al., 2020). Women 
may be passed over in recruitment and promotions in favour of men because of a phenomenon called homosocial reproduction. This means that, in a male-dominated industry like the energy sector, it is often men who are making the hiring/promotion decisions, and people are predisposed to hire individuals similar to themselves (Furst \& Reeves, 2008, p. 373). These decision-makers often hire and promote based on 'fit', but when most top managers and leaders are men, 'fitting in' often means being a man and/or displaying masculine attributes and liking traditionally masculine hobbies (Morrison \& Von Glinow, 1990; Powell, 1999).

There are a couple of changes companies could make to their recruitment and promotion practices which could address this challenge. Making a conscious effort to attract diverse candidates and making it an attractive industry to work in as well as implementing diversity quotas and/or targets would go a long way to change the sector (EHRC, 2017, p. 3). ${ }^{22}$ Bias could also be reduced from hiring processes through using inclusive language in job descriptions and any advertisements as well using standardized rubric-based interviews (Boyd et al., 2019, p. 75-76). Similarly, bias can be minimized in performance reviews and promotions through creating clear guidelines and standards for decision-making, thus ensuring decisions are as objective as possible (Park et al., 2019).

\footnotetext{
${ }^{22}$ Advocates of quotas for women in the workforce argue that it is impossible to remove all bias from the workplace, so quotas are necessary to equal the playing field (Boyd et al., 2019, p. 53). There are however many people resistant to the concept of quotas. There two main reasons as to why people oppose quotas: 1) they argue that it is undemocratic, and 2) they argue that it places under-skilled women in positions of power in lieu of qualified men. Both of these arguments can be refuted. The first assumes that the current system is democratic, which it clearly is not. Instead, as demonstrated above, the system currently favours men. Research also indicates that the second argument may not hold water. Research in Sweden demonstrated that the implementation of quotas for women simply served to weed out mediocre men and replace them with competent women, thus supporting rather than undermining a meritocratic system (Besley et al., 2017). Yet even despite the fact that opposition to quotas is often not warranted, there are many women who do not want to feel as if they got a job because of a quota (Boyd et al., 2019, p. 54). Women also may face stigma and further hardships in the workplace if they received a job under a quota system. Thus, quotas are a nonperfect solution for a non-perfect world, and though they may be well-suited in some contexts and situations, they may not always be appropriate.
} 


\subsubsection{A lack of flexibility}

A fourth challenge that women in the energy sector face is a lack of flexibility in the workplace. This is a hurdle which is not at all specific to the energy sector, but rather applies to women in the workforce across Canada. It is also not a challenge specific to women; many men also struggle to manage familial obligations when there is a lack of flexibility in their workplaces (EHRC, 2017, p. 1-2). However, women face additional barriers if they go through pregnancy: research shows that women are more likely to have their commitment to work questioned and be taken less seriously by their superiors following parental leave, whereas men who return from parental leave are often "valorized for their commitment to parenting" and welcomed back with open arms (Clean Energy, Education, and Empowerment [C3E], 2019, p. 14).

Transitioning towards a more flexible workplace requires a cultural change as well as specific initiatives such as implementing mandatory parental leave, leave for caring, flexible scheduling, and on-site childcare (Boyd et al., 2019, p. 75-76; Park et al., 2019). These kinds of initiatives make it easier for all employees to balance their work and personal lives and would serve to make work-life balance more of a norm rather than the exception. For example, with mandatory parental leave, all personnel would take time off to care for young children, meaning women would not be seen as any more of a "risk" in terms of hiring and promotions in their childbearing years (as is currently the case at many companies) (Becker et al., 2019).

\subsubsection{Sexual harassment}

A fifth barrier that women in the energy sector face is sexual harassment in the workplace (Boyd et al., 2019, p. 32; Catalyst, 2020; Devillard et al., 2019, p. 8; EHRC, 2017, p. 2). Though this barrier unfortunately applies to women in all walks of life, research shows that women in male-dominated industries like the energy sector experience significantly higher levels of sexual 
harassment than those in other industries (Women's Initiative, 2018). For example, a study by Kabat-Farr and Cortina (2014) found that women working with almost all men are nearly twice as likely to experience harassment than women working in a gender-balanced group (p. 68). Though this issue would need to be reviewed on a firm-by-firm basis, this research suggests that the gender make-up of a group plays a role in the level of sexual harassment faced by women. Since women make up a minority of the energy sector workforce, particularly in leadership positions, they likely also face a higher incidence of sexual harassment. To ameliorate this, human resource policies may need to be reviewed with a gender-focused lens. Ensuring that workplaces are safe through enforcing a zero-tolerance policy on sexual harassment is key to overcoming this challenge (Boyd et al., 2019, p. 75-76).

\subsubsection{Limited role models and support}

Working in a male-dominated sector does not only lead to a higher incidence of sexual harassment for women, but it also means that women have few role models to look to (EHRC, 2017, p. 2). They also do not have access to much of the additional support systems and networks that men do (Catalyst, 2020; IRENA, 2019, p. 12; MacDougall et al., 2020). This is particularly important because many jobs in the energy sector require apprenticeships, which, due to a lack of mentorship and support, women have difficulty accessing (Smet, 2018). In fact, many of these apprenticeships are obtained through "FBI networks" (friends, brothers, and in-laws), which limits women's access: often these close-knit networks are less willing to facilitate a young women's training than a young man's due to conscious and unconscious biases (Baruah \& BiskupskiMujanovic, 2018, p. 3). This lack of role models, mentoring, skills training, and career development opportunities limits women's entry and advancement in the sector. These issues can be addressed through encouraging mentorship and sponsorship programs for women in the energy 
sector as well as highlighting women in the sector (Boyd et al., 2019, p. 54; EHRC, 2017, p. 3; Equal by 30, 2021).

\subsubsection{Low levels of confidence among women}

Beyond external barriers and biases which constrain women's advancement, women also face internalized barriers in the workforce. The most notable of these is low levels of confidence among women. Though there are a variety of reasons why this phenomenon may emerge, research indicates that societal pressures and self-perceptions prevent women from "feeling bold" and pushing their career forward in non-traditional roles, such as in leadership positions in the energy sector (EHRC, 2017, p. 1-2). Young women in particular tend to be far more competent than they perceive themselves to be in self-assessments, while men are often "overconfident and assuming they are more competent than they are" (Zenger \& Folkman, 2019).

There are two sides to this issue: the fact that women are often not confident enough, and the fact that men can be too confident. In response to scenarios such as this, there are typically two suggested solutions, each focusing on one of these two sides. The first solution focuses on women and suggests that women need to speak up more and be more confident in advocating for themselves. The second solution focuses more on systematic change and suggests altering the system so it no longer prioritizes the promotion of people who are extremely vocal and (over)confident over those who may be quieter but equally or even more competent. This sentiment is expressed in a blog by Tomas Chamorro-Premuzic and Cindy Gallop (2020), who state that “...the real problem is not a lack of competent females; it is too few obstacles for incompetent males, which explains the surplus of overconfident, narcissistic, and unethical people in charge."

The most effective solution to this challenge is likely a combination of these two. On one hand, women should be encouraged to showcase their knowledge and expertise. In the energy 
sector, this could be facilitated through increasing mentorship and sponsorship programs for women, as well as highlighting women in the energy sector. These initiatives could help show women that they can and should strive for the top if they so desire. On the other hand, systematic change to better facilitate diverse leaders, rather than just vocal and (over)confident ones, is also desperately needed.

\subsubsection{A lack of understanding of jobs and opportunities within the energy sector}

While many women may be interested in the energy sector but be unable to enter the sector or progress due to the variety of challenges already discussed, others may not even consider it as a career opportunity due a lack of understanding of what the sector consists of and the range of jobs and career paths available. This is relatively common: Canadians in general are not aware of what exactly the energy sector looks like, making it much more difficult to attract interest (Baruah \& Biskupski-Mujanovic, 2018, p. 5; EHRC, 2017, p. 1-2). This is a particular challenge for women, who may avoid the sector due to a perception of it being simply a male-dominated technical sector with little else to offer. However, in reality the sector includes a wide range of technical and non-technical opportunities, including sustainability experts, financial roles, communications jobs, and project management, as well as engineering and construction positions.

Addressing this challenge requires a more conscious effort to spread information regarding employment in the Canadian energy sector, particularly to women and with inclusive language and imagery (C3E, 2019, p. 13). For example, an advertisement for a company which showcases a woman and/or people of other diverse backgrounds would likely encourage more diverse applicants. These information campaigns could be pursued by both companies and government actors. 


\subsubsection{Women having insufficient and improper backgrounds/education (whether perceived or real)}

The final challenge that women face is the perception or reality that women have insufficient or improper backgrounds and education for the energy sector. As was mentioned previously, the energy sector consists of a much wider range of jobs than many Canadians think, so many women may actually be well-equipped for the sector and simply not know it. However, in other cases this perception is more of a reality. Fewer women than men hold science, technology, engineering, and mathematics (STEM) degrees, with women making up approximately 34\% of STEM-degree graduates in Canada (Wall, 2019). The difference between men and women graduates is therefore notable, but not huge. However, many more women than men leave their respective STEM fields in the years following graduation (Frank, 2019). This indicates that pointing to the educational backgrounds of women is not a comprehensive picture of the issue: women are leaving their technical fields, often due to a lack of support and mentorship as well as bias that they face in the workplace.

Addressing this challenge therefore must include a suite of initiatives. Encouraging mentorship and sponsorship programs, highlighting women in the energy sector, changing recruitment and promotion practices, and promoting women in STEM would all encourage women to consider the energy sector as a career and support them so that they can thrive in the sector. Companies, advocacy groups, and government actors all have a key role in realizing these initiatives.

This literature review has provided an overview of key barriers and recommendations for women's advancement in Canadian energy sector firms, which are summarized in Table 2 below. While many barriers exist, such as cultural and social norms and sexual harassment, there are solutions which could be implemented by companies, government actors, and/or advocacy groups. 
These solutions include collecting gender-disaggregated data on employment within the Canadian energy sector, initiating a cultural shift, changing recruitment and promotion practices, and increasing the flexibility of work for all employees.

Table 2: Barriers and Recommendations

\begin{tabular}{|c|c|c|}
\hline Barriers & Recommendations & $\begin{array}{l}\text { Actor(s) implementing } \\
\text { suggested recommendation }\end{array}$ \\
\hline $\begin{array}{l}\text { A lack of gender-disaggregated } \\
\text { data on employment within the } \\
\text { Canadian energy sector }\end{array}$ & $\begin{array}{l}\text { Collect gender-disaggregated data on } \\
\text { employment within the Canadian } \\
\text { energy sector }\end{array}$ & $\begin{array}{l}\text { - Companies } \\
\text { - Government } \\
\text { - Advocacy groups }\end{array}$ \\
\hline $\begin{array}{l}\text { Cultural and social norms } \\
\text { - Lack of awareness of the } \\
\text { challenges that women } \\
\text { face } \\
\text { - Conscious and } \\
\text { unconscious bias }\end{array}$ & $\begin{array}{l}\text { Initiate a cultural shift } \\
\text { - Start having the difficult } \\
\text { conversations } \\
\text { - Provide unconscious bias and } \\
\text { diversity training } \\
\text { - Hire an inclusion and/or } \\
\text { diversity officer }\end{array}$ & $\begin{array}{l}\text { - Companies } \\
\text { - } \text { Government } \\
\text { - Advocacy groups }\end{array}$ \\
\hline $\begin{array}{l}\text { Unfair practices } \\
\text { - Recruitment/promotion } \\
\text { practices which perpetuate } \\
\text { the predominance of men } \\
\text { in the energy sector }\end{array}$ & $\begin{array}{l}\text { Change recruitment and promotion } \\
\text { practices } \\
\text { - Actively try to attract diverse } \\
\text { candidates } \\
\text { - Implement diversity quotas } \\
\text { or targets } \\
\text { - Use inclusive language in } \\
\text { advertisements and job } \\
\text { descriptions } \\
\text { - Ensure performance reviews } \\
\text { and promotions are bias-free }\end{array}$ & - Companies \\
\hline $\begin{array}{l}\text { A lack of flexibility and } \\
\text { accommodation in the workplace }\end{array}$ & $\begin{array}{l}\text { Increase the flexibility of work and } \\
\text { improve work-life balance for all } \\
\text { employees } \\
\text { - Mandatory parental leave } \\
\text { - Leave for caring } \\
\text { - Flexible scheduling } \\
\text { - On-site childcare } \\
\end{array}$ & $\begin{array}{ll}\text { - } & \text { Companies } \\
\text { - } & \text { Government }\end{array}$ \\
\hline $\begin{array}{l}\text { Women face sexual harassment in } \\
\text { the workplace }\end{array}$ & $\begin{array}{l}\text { Improve human resource policies to } \\
\text { be more inclusive } \\
\text { - Zero-tolerance for sexual } \\
\text { harassment }\end{array}$ & $\begin{array}{ll} & \text { Companies } \\
\text { - } & \text { Government }\end{array}$ \\
\hline $\begin{array}{l}\text { Limited support and role models } \\
\text { for women }\end{array}$ & $\begin{array}{l}\text { Encourage mentorship and } \\
\text { sponsorship programs, highlight } \\
\text { women in the energy sector }\end{array}$ & $\begin{array}{l}\text { - Companies } \\
\text { - Government } \\
\text { - Advocacy groups }\end{array}$ \\
\hline
\end{tabular}




\begin{tabular}{|l|l|l|}
\hline $\begin{array}{l}\text { Low levels of confidence among } \\
\text { women }\end{array}$ & $\begin{array}{l}\text { Encourage mentorship and } \\
\text { sponsorship programs, highlight } \\
\text { women in the energy sector, change } \\
\text { recruitment and promotion practices }\end{array}$ & $\begin{array}{l}\text { Companies } \\
\text { Government }\end{array}$ \\
\hline $\begin{array}{l}\text { A lack of understanding of jobs } \\
\text { and opportunities within the } \\
\text { energy sector }\end{array}$ & $\begin{array}{l}\text { Spread awareness of the energy } \\
\text { sector and its wide range of jobs }\end{array}$ & $\begin{array}{l}\text { C Government } \\
\text { - Advocacy groups }\end{array}$ \\
\hline $\begin{array}{l}\text { Women having insufficient and } \\
\text { improper backgrounds/education } \\
\text { for the energy sector (perceived or } \\
\text { real) }\end{array}$ & $\begin{array}{l}\text { Encourage mentorship and } \\
\text { sponsorship programs, highlight } \\
\text { women in the energy sector, change } \\
\text { recruitment and promotion practices, } \\
\text { promote women in STEM }\end{array}$ & $\bullet$ Gompanies \\
\hline
\end{tabular}

\subsection{Chapter Three Conclusion}

This chapter has provided an overview of existing literature responding to the two research questions guiding this thesis. Section 3.1 responded to the primary research question, arguing that previous research suggests that women are sustainability leaders because they often demonstrate all leadership attributes necessary for effective sustainability leadership. This secondary research therefore provides evidence supporting the main argument of this thesis, that gender matters when it comes to leading Canada's sustainable energy transition.

Section 3.2 responded to the secondary research question of this thesis, focusing on existing research exploring the barriers that women in the energy sector face and solutions to ameliorate the situation. While this section found that there are many systemic barriers that must be overcome, there are also a variety of realistic solutions which could be pursued by companies, government actors, and/or advocacy groups. Thus, this chapter provided not only a review of evidence as to why women's leadership should be supported (3.1), but also recommendations as to how this could be achieved (3.2). 


\section{Chapter Four: Theoretical Framework}

In this thesis, I am arguing that gender matters when it comes to sustainability leadership and sustainable energy transition leadership. In section 3.1 above, Chapter Three provided a review of existing research supporting this argument, demonstrating an alignment between sustainability leadership attributes and women's leadership. However, this review focused on women as sustainability leaders rather than sustainable energy transition leaders. Therefore, this chapter will expand on the secondary research in Chapter Three and will present evidence as to why women are the sustainable energy transition leaders that Canada needs to mitigate contemporary sustainability problems. It will also situate gender within sociotechnical transitions like Canada's energy transition and present a theoretical framework which will set the groundwork for the subsequent primary research analysis.

\subsection{Women as Sustainable Energy Transition Leaders}

This paper has reviewed what the literature points to as being important for sustainability leadership in the private sector and what women's leadership generally looks like. While topics have varying amounts of research, all attributes identified as being important for sustainability leadership (see Table 1) were identified as being leadership attributes typically associated with women's leadership. This suggests that sustainability leadership is gendered, and that women leaders perform gender in a way that better addresses modern sustainability challenges.

However, does the fact that women may be more effective sustainability leaders mean that they are also more effective sustainable energy transition leaders? While the former is concerned with the efficient and successful attainment of sustainability goals and initiatives, the latter deals with a global and multi-faceted transition over which no one actor or group has control. I posit that it does: these attributes identified as being key to effective sustainability leadership are also key to 
sustainable energy transition leadership. This is because this research views sustainable energy transition as the culmination of sustainability efforts by both renewable and oil and gas energy companies (see section 2.3). Thus, as both sectors become more aware of sustainability challenges and increasingly move to address those challenges, Canada will move towards a more sustainable energy future. Since this research has shown that women may be more effective leaders for the attainment of sustainability at an individual company level in the private sector, and the aggregate of these successful sustainability efforts is an indication of a sustainable energy transition, women may very well be the sustainable energy transition leaders that Canada and the world needs.

There are other reasons why I believe women may be sustainable energy transition leaders. There is a field of literature which posits both women and the environment as an 'other'. This parallel oppression of nature and women is a key tenet of ecofeminist literature, but it has found its way into the realm of women's sustainability leadership. Marshall $(2007 ; 2011)$ is one of the most prominent academics to make this argument, pointing out that private sector initiatives to attain sustainability (e.g., through CSR) treat the environment as an 'other' just like women are an 'other' to the private corporate world (Marshall, 2011, p. 266, 269). In short, since women are not embedded in power structures, they can more effectively critique dominant practices; practices which often prioritize profits at the expense of environmental and community well-being. For example, the energy production centre of Canada is the oil sands in western Canada. This sector has the reputation of being a "boy's club" (Amnesty International, 2016). Unequal hiring practices, sexual harassment, and multiple barriers to advancement for women has led to a lack of gender diversity in the sector, leading to major blind spots (Lieu et al., 2020, p. 5). Since most leaders in the industry have similar academic and professional backgrounds and demographic features, they are less likely to challenge the status quo and critically evaluate alternatives. The promotion of 
new voices in the sector with new ideas and perspectives could help the industry make the necessary changes to adapt to a sustainable energy future. This suggests that women leaders could be more effective sustainable energy transition leaders, since they may be more willing to move towards change and transition than their male counterparts.

This idea that women bring something unique and important to the table as a result of their status as a form of 'outsiders' can be found in feminist literature as well. Standpoint theory is a concept within feminist literature which posits that all knowledge is situated, and "those belonging to marginalized groups are situated in ways that allow them to see more than those who are not" (Halpern, 2019, p. 2). Thus, like Marshall (2011) and Lieu and colleagues (2020), standpoint theory suggests that bringing more women into a sector dominated by men, such as the energy sector, may serve to instigate positive change through new perspectives and ideas.

These conclusions point to another important reason as to why women leaders are needed in the energy sector: including women in leadership positions will lead to a more holistic understanding. Including women's voices in energy transition efforts will help solutions benefit a larger segment of society. Since dominant discourses surrounding energy transition exclude women, they also exclude the impact that certain solutions and efforts have on women (Lieu et al., 2020). Thus, a lack of consideration of gender means that efforts are often disconnected from local needs and realities and lack public support and buy-in, leading to a slower and less effective sustainable energy transition (Lieu et al., 2020, p. 1).

Finally, energy transition may also be the perfect opportunity for women to emerge as leaders within the energy sector. The concept of the glass ceiling is a recurring theme in feminist literature. The glass ceiling is a metaphor based on the idea that demographic features (such as one's gender) prevent people from rising beyond a certain rank in an organization or hierarchy. In 
the case of women in the private energy sector, the glass ceiling can be seen in the extremely low representation of women in CEO, board of directors, and executive management positions. Furst and Reeves (2008) present a unique solution to this phenomenon: using Schumpeter's concept of "creative destruction," 23 the authors argue that at times of transition and turbulence, women are seen as especially attractive candidates for leadership positions due to their unique leadership style (p. 372). Women's leadership is typically characterized as more open, inclusive, transparent, innovative, and collaborative, which is a style that can more effectively facilitate change and manage uncertainty (Furst \& Reeves, 2008, p. 372). For example, a recent study on leadership during the COVID-19 pandemic demonstrated that cases and deaths were systematically lower in countries which were led by women (Garikipati \& Kambhampati, 2021). The authors of the study suggest that these better outcomes can be, at least to some extent, explained by the policy actions taken by the female leaders, such as the timing of lockdowns (Garikipati \& Kambhampati, 2021). Therefore, times of transition like Canada's sustainable energy transition may be an opportunity for women to attain leadership positions.

There is therefore ample reason to believe that women are sustainable energy transition leaders and can achieve and thrive in these positions if given the proper support. The following section will expand on this idea and situate the issue of women leaders within the wider arena of sociotechnical transitions, specifically, Canada's energy transition. It will also provide a framework, constructed from the conclusions of the literature review, which will be used in the subsequent primary research analysis.

\footnotetext{
${ }^{23}$ Political economist Joseph Schumpeter proposed the idea of 'creative destruction' in 1942 to describe the process through which new market leaders and innovations emerge in capitalist market economies (Furst \& Reeves, 2008 , p. 374). He argued that new innovations destroy or dismantle long-standing practices and processes, thus making way for improvements in terms of their efficiency, cost, and/or productivity. This dynamic reinvention is, according to Schumpeter, central to capitalist economies.
} 


\subsection{Situating Gender within Sociotechnical Transitions}

Addressing the multitude of sustainability challenges that Canada is facing (see section 1.2) will require profound change to Canada's energy system; a sociotechnical transition which will reorient the energy system in a direction which recognizes and addresses these challenges. Sociotechnical transitions are multi-dimensional transformations of sociotechnical systems, which involves changes in technologies, regulations, infrastructure, and supply networks (Geels, 2005). Canada's sustainable energy transition can be dubbed 'sociotechnical' because of the ubiquitous nature of energy, meaning that a transition will impact technologies, markets, regulations, infrastructure, organizations, policies, and everyday life. This calls attention to an important point: despite the importance of technology, energy transitions are about much more than simply adopting new energy sources. Energy systems consist of energy production technology, energy consumption technology, physical infrastructure, behaviours, and institutional and policy frameworks (Lieu et al., 2020, p. 2). This is why most transitions literature dubs energy transitions as "sociotechnical" or "techno-economic" transitions, thus recognizing that a new energy system has implications for social interactions, policy frameworks, our economic system, and public discourse as well as technology (Bolwig et al., 2020; Verbong \& Geels, 2007). Since this research is focusing on a specific kind of transition, a sustainability transition, this sociotechnical transition can be viewed as "long-term, multi-dimensional, and fundamental transformation processes through which established socio-technical [energy] systems shift to more sustainable modes of production and consumption" (Markard et al., 2012, p. 956)

An example of the multifaceted nature of sociotechnical transitions is the global energy transition from wood to coal between the eighteenth and late nineteenth century. This transition 
led to the emergence of new livelihoods, new building designs, ${ }^{24}$ new methods of manufacturing, and the creation of new policies to limit collusion among emerging coal powers (Huberty \& Zysman, 2010, p. 1027). One such policy was the New Law (1710), which, in response to rising coal prices, made collusion among coal producers and traders illegal in what was then Great Britain (Biswas, 2016; Sweezy, 1938).

The non-technical impacts of a sociotechnical energy transition are so great that Miller and colleagues (2013) go so far as to suggest that the key choice in energy transitions is not one between different forms of energy production, but "between different forms of social, economic, and political arrangements built in combination with new energy technologies" (p. 139). In this way, energy transitions can be a harbinger for a new era in global human history (Miller et al., 2013, p. 146). This social element to energy transitions has been recognized by academics, though energy transitions literature is still dominated by technology-focused literature. Furthermore, besides broad discussions of energy justice and just transition, this social dimension is rarely addressed in any real way in government policy. ${ }^{25}$

An aspect of energy transitions that has received even less attention is the fact that energy transitions are deeply gendered (Lieu et al., 2020, p. 1). Some fields of research which explore the intersection of gender with a specific topic or theme have grown considerably in the twentieth and twenty-first century. For example, gender and the environment has received a great deal of attention since the emergence of ecofeminism in France in the 1970s. However, research on the intersection of gender and energy, especially energy transitions, has proven to be far less popular

\footnotetext{
${ }^{24}$ This change in building design can be seen in the present-day sociotechnical transition as well, in the trend towards passive and net-zero buildings. These buildings are constructed using novel architecture, materials, and with different goals in mind.

${ }^{25}$ However, this is rapidly changing. For example, BC Hydro's Energy Conservation Assistance Program offers home energy-saving kits and assessments for free to low-income households (CleanBC, 2021).
} 
(Pearl-Martinez \& Stephens, 2016, p. 2). The research that does explore women and energy is dominated by work looking at either women's lack of access to energy (Dutta et al., 2017; Groot et al., 2017; Johnson et al., 2019; Oparaocha \& Dutta, 2011; Pueyo \& Maestre, 2019; Winther et al., 2018) or the disproportionate harm that the dominant fossil-fuel energy system inflicts upon women (Altson \& Whittenbury, 2013; MacGregor, 2009). Both of these topics are mostly researched under the umbrella of development studies in the Global South and primarily paint women as passive victims (Bell et al., 2020, p. 2). In the few cases where women have agency, they are portrayed as grassroots activists standing outside of traditional institutions; an enigmatic 'other'. This has led to a limited understanding of gender and energy transitions, particularly in the Global North and within more conventional institutional and organizational structures (Milne, 2003, p. 57).

Lieu and colleagues (2020) point out that incorporating gender concerns into energy transitions literature is so difficult in large part due to entrenched power structures (p. 1). Energy transitions literature is dominated by male voices, and thus there is an exclusion of women's voices and input (Lieu et al., p. 2). The result of this is a perpetuation of the dominant perspectives, norms, and practices in the sociotechnical energy transitions literature, just as there is a perpetuation of these same male perspectives in the energy sector itself. ${ }^{26}$

The extremely limited recognition of the gendered nature of energy transitions matters for several reasons. The first reason is that incorporating gender as a relevant factor to energy transitions will lead to more equitable outcomes in our future energy system. For example, if

\footnotetext{
${ }^{26}$ This is however changing. Though energy transition literature has traditionally been dominated by men, the value that women bring to the table is increasingly being recognized. For example, the Global Women's Network for the Energy Transition (GWNET) brings academics and experts in the field together and provides access to networking, training, and mentoring for women (GWNET, 2021). Global movements and celebrations like the \#MeToo movement or International Women's Day have also made ignoring gender issues increasingly difficult.
} 
gender is not accounted for in energy policy planning, changes could disproportionately hurt women. Furthermore, many see energy transitions and the emerging renewable energy system as an opportunity to build a more equitable workforce (IRENA, 2019; Pearl-Martinez \& Stephens, 2016). While attaining more equitable outcomes and a more gender-balanced energy sector workforce within energy sector firms is an important goal of this research, this research suggests that the inclusion of women leaders in the energy sector can do much more. Namely, women leaders within energy sector firms may bring leadership attributes which are key to sustainability leadership, meaning promoting the inclusion of women leaders in the sector may serve to facilitate a transition towards a more sustainable energy future.

\subsubsection{A new model for sociotechnical transitions}

There has been substantial research into how a sociotechnical system, like an energy system, can be steered to address sustainability challenges. Sustainability transitions theory focuses on how sustainability innovations and their proponents can overcome the prevailing unsustainable alternatives and the structure of institutionalized processes supporting them (Savaget et al., 2019, p. 879). Though there are variations within this field of literature, the consensus is that the unsustainable characteristics of the dominant sociotechnical system are difficult to change. This resistance to change stems from the fact that sociotechnical systems consist of mutuallyreinforcing practices and institutions, including technology, infrastructure, behaviour, and policies (Savaget et al., 2019, p. 879). For example, Canada's transportation system is currently dominated by petroleum vehicles. This transportation system includes infrastructure which is not easily adapted to a more sustainable alternative like electric vehicles (EVs), maintenance systems and personnel who are not trained to care for EVs, and people who may be resistant to changing their 
behaviour to adapt to EVs (e.g., taking 30 minutes to charge your vehicle instead of 5 minutes to fill its gasoline tank) (Geotab, 2021). ${ }^{27}$

There are several frameworks which help us better understand the complexity of sociotechnical transitions and how these entrenched structures and practices can be overcome, but this research will focus on the Multi-level Perspective (MLP). This framework is dominant within this sphere of literature and is particularly useful for this research because of the way it structures actors within sociotechnical transitions. In short, the MLP leaves space for niche actors (which, as will be argued below, could be interpreted as women) to promote change in a system which opposes them.

The MLP describes sociotechnical transitions as the product of interactions between three levels: regimes, niches, and landscapes (Geels \& Schot, 2007, p. 399). A regime is the current dominant stable socioeconomic system. In the case of sustainable energy transitions, the regime is the dominant energy system which is characterized by a lack of sustainability and diversity. These (primarily male) actors within the regime are ill-equipped to address modern sustainability challenges because they have "cognitive routines" that make them blind to new developments outside of their focus and traditional practices (Geels \& Schot, 2007, p. 400; Geels, 2019, p. 189). In this way, the regime is inherently an embedded system, dealing with institutionalized technologies and approaches, which makes it resistant to change (Upham et al., 2018, p. 164).

Niches, however, are where novelties and innovations emerge. Outsiders or fringe actors develop and/or nurture these innovations within the niche (Geels \& Schot, 2007, p. 400). Unlike regime actors, these outsiders are not dominant or powerful within the existing system. Rather they

\footnotetext{
${ }^{27}$ However, it is worth noting that a transition from fossil-fuel vehicles to EVs would be easier than a complete overhaul of our transportation system through emphasizing active transport (e.g., walking, biking) and public transportation.
} 
are actors who are working on innovations which do not conform to the regime and its trajectory. Although the MLP is sometimes critiqued for its lack of consideration for the agency of actors (Geels \& Schot, 2007, p. 400), many view the successful diffusion of sustainability innovations as being highly dependent upon the agency of different actors within this framework (Savaget et al., 2019 , p. 886). One sphere of actors which the literature on sociotechnical transitions has deemed to be particularly important is actors within private companies, as they have a central role as change agents in their ability to enable or hinder the diffusion of innovations (Geels et al., 2017, p. 1243; Lundvall et al., 2009; Savaget et al., 2019, p. 886). Examining this diffusion of innovations that private sector companies can promote is important because it is through these innovative technologies and approaches that sustainability will be achieved.

In the adapted MLP framework I am proposing for a sustainable energy transition, niche actors are women leaders in the private sector, and their innovation is their unique approach to leadership and sustainability challenges (namely, the eight leadership attributes discussed above, see Table 1). Since women leaders are a minority and are external to the dominant energy system (the regime), they are more willing to question prevailing practices and facilitate a transition to sustainability. This idea that women as external actors have unique and important contributions is similar to arguments put forward by Marshall (2011), Halpern (2019), and Lieu and colleagues (2020) (see section 4.1).

The sociotechnical landscape is the third component of the MLP. The landscape is the exogenous environment, which includes macroeconomics, demographics, and cultural patterns. The landscape therefore forms the arena in which regime and niche actors operate. According to the MLP framework, sociotechnical transitions most commonly occur when niches have built up internal momentum, the landscape is putting pressure on the existing regime, and the regime is 
destabilized, creating a window of opportunity for niche innovations (Geels \& Schot, 2007, p. 400). Thus, one key factor which can trigger sociotechnical change is a shock to the landscape. For example, an economic crisis can cause drastic changes to entrenched market structures around the world (Geels et al., 2017, p. 1242). Changes to the sociotechnical landscape do not determine any particular structural change, but it does make certain actions and paths forward easier than others (Geels \& Schot, 2007, p. 403). In the model proposed for this research, the shock in the dominant energy system is that of the growing sustainability crisis, which is increasingly putting pressure on the (unsustainable) dominant energy system and destabilizing it. This sustainability crisis provides the opportunity for the emergence of niche actors (women) and their innovations (sustainability leadership attributes).

This adapted MLP model for a sociotechnical transition to a more sustainable energy future is illustrated in Figure 6 below. While this model is by no means the only path by which this transition can occur, it presents the theoretical foundations of a model by which this transition could be facilitated. In the Figure, the specific niche innovation that women bring is their unique form of leadership. More specifically, women leaders' innovation is the eight leadership attributes which research has shown to by key to sustainability leadership and are also characteristic of women's leadership (see section 3.1). These leadership attributes are collaboration, innovation, transformational leadership, ethical and transparent leadership, environmental management, having a long-term orientation, inclusive leadership, and the ability to manage complexity. 
Women leaders in the private energy sector, who bring a novel approach to sustainability challenges through a unique form of leadership, increasingly rise

Niche innovations to leadership positions.

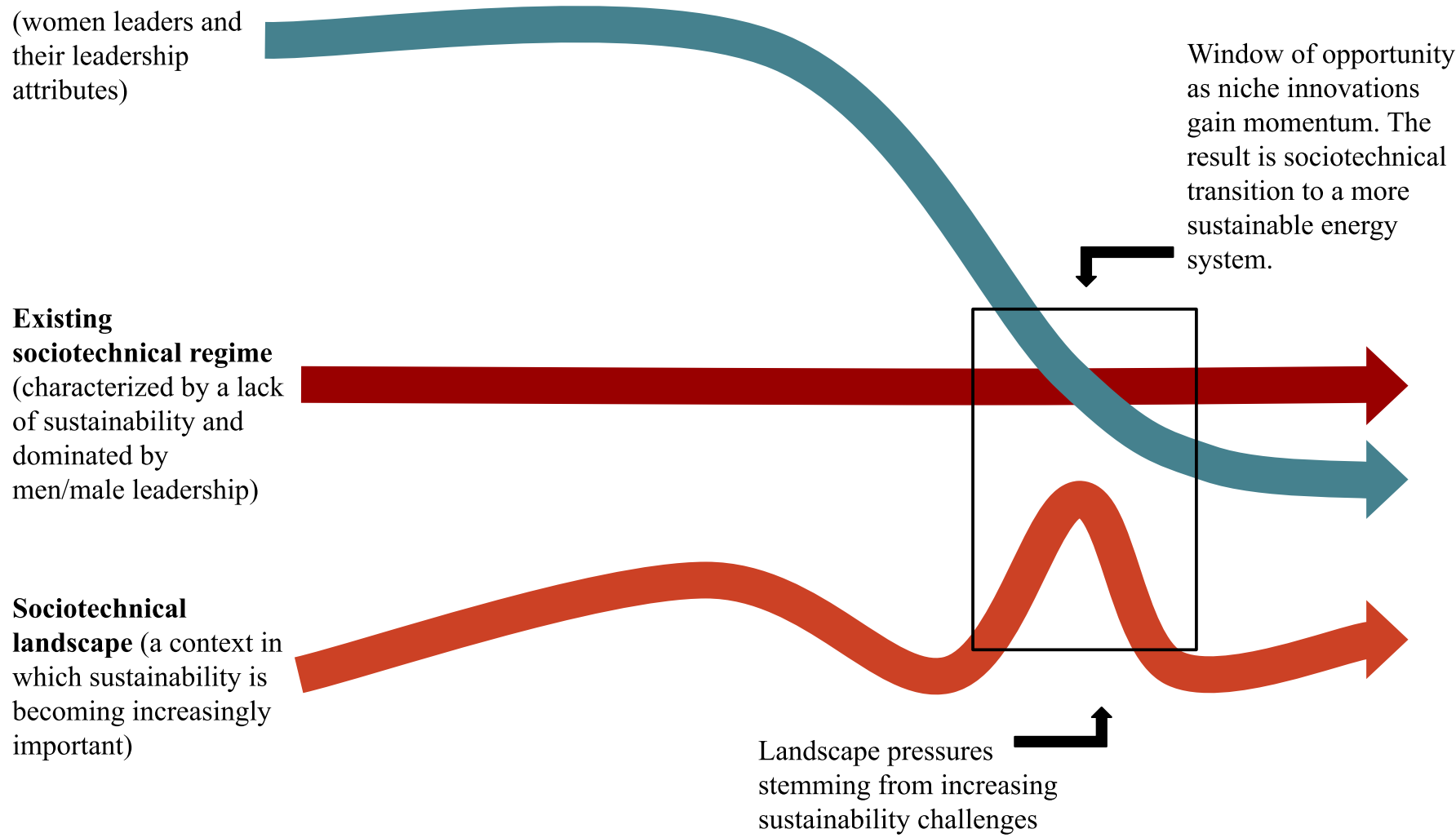

Figure 6: Model of Sociotechnical Transition (adapted from Geels et al., 2017)

\subsection{Chapter Four Conclusion}

This chapter built on the previous literature review through establishing that there is evidence suggesting that women are not only sustainability leaders, but also sustainable energy transition leaders. Chapter Four also mapped out an adapted MLP framework which sets out the manner by which women leaders can influence and encourage Canada's sustainable energy transition. This work bolstered previous evidence set out in Chapter Three which supported the main argument of this thesis: that gender matters when it comes to leading Canada's sustainable energy transition. 


\section{Chapter Five: Analysis and Discussion}

In this thesis, I am arguing that women leaders are sustainability and sustainable energy transition leaders, and thus gender matters when it comes to leading Canada's sustainable energy transition. Chapters Three and Four provided secondary research supporting this argument. In the following Chapter, these conclusions will be revisited using data from primary research (see section 1.1). The first part of Chapter Five will provide further insights into the primary research question of this thesis, arguing that women leaders in Canadian energy sector firms display sustainability leadership attributes and that supporting women's leadership may serve to facilitate Canada's sustainable energy transition. Though previous research suggested that women leaders do demonstrate sustainability leadership attributes and may be sustainable energy transition leaders (sections 3.1 and 4.1), more research was needed to verify these findings and explore their applicability to the Canadian energy transition. The second part of Chapter Five will return to the secondary research question of this thesis, and explore the barriers and solutions discussed by participants and how their insights line up with the literature (section 3.2).

\subsection{Evaluating Women as Sustainable Energy Transition Leaders}

Based on existing literature, this research hypothesized that promoting women's leadership in energy sector firms will serve to facilitate Canada's transition towards a sustainable energy future. Eight leadership attributes were identified as being key to sustainability leadership, and the literature review demonstrated that all eight attributes are also characteristic of women's leadership. The purpose of the primary research, which took the form of interviews, was to further interrogate these findings (see section 1.1). Thus, the main argument of this research can be broken down into eight themes, each of which corresponds to the eight leadership attributes identified in the literature. These themes are as follows: collaboration, innovation, transformational leadership, 
ethical and transparent leadership, environmental management, long-term orientation, inclusive leadership, and the ability to manage complexity. The question that this primary research will respond to is whether the responses of leaders in Canadian energy sector firms who were interviewed demonstrate these attributes, and whether or not women participants demonstrated them to a greater extent than men. However, prior to delving into each theme, an important starting point for this research was understanding how participants understood gendered leadership and sustainable energy transition. This information framed subsequent analyses.

Understanding participants' perceptions of gendered leadership was achieved through direct questioning. In other words, they were asked outright if they perceived women's leadership to be in any way distinct from men's. In their responses, all participants indicated that they perceived women's leadership to be distinct from men's leadership, though they identified a variety of reasons why they believed it to be the case. Several participants added caveats to this statement, recognizing the heterogeneity of men and women leaders. For example, when asked if women's leadership is distinct from men's, Stephanie emphasized that women leaders sometimes take on leadership attributes associated with male leadership:

Yes, yes, absolutely and it's [women's distinct leadership] proven right, it's been proven by many, many different tomes of research that have been done and just look at Catalyst ${ }^{28}$ as an example. But yes, we [women] do lead differently. And there are women who have morphed themselves into male-like clones, but there have been women who have said 'okay, I want to be me, but I also want to be able to lead through my innate strengths.'

This sentiment that women's leadership is distinct, but not always due to a pressure for women leaders to emulate men, was reflected in the responses of a total of seven participants (six women, one man). All of these participants also indicated that this pressure was to the detriment of women leaders, emphasizing the importance of "authentic leadership" and the benefits of leadership

\footnotetext{
${ }^{28}$ Catalyst is a global non-profit that supports women in the workforce. The organization publishes a range of research relating to women's issues, equity, and inclusion.
} 
attributes typically associated with women's leadership. This trend supports the goal of this thesis. As discussed in section 3.1.2, a lot of literature on women's leadership is concerned with telling women what to do. A main goal of this research was to demonstrate the merits of these more stereotypically-feminine leadership attributes through assessing their potential to contribute to sustainability and sustainable energy transition. Through emphasizing the importance of authentic leadership, participants echoed this same rhetoric. Rather than toeing the line of 'women should take on this or that attribute to be better leaders', participants were more intent on women being authentic, meaning they should be genuine, self-aware of their strengths and weaknesses, and transparent, rather than simply taking up more traditional and masculine leadership attributes.

The importance of authentic leadership has come to be recognized in a small body of literature on leadership. This literature indicates that being an authentic leader is more difficult for women leaders than men (Hopkins \& O'Neil, 2015). However, research by Jensen and Luthans (2006) found that a leader's authenticity is key to leadership success: these authors found leadership authenticity to be the strongest predictor of employee happiness, satisfaction, and commitment. Thus, though societal pressures are such that being authentic is often more difficult for women leaders, pushing through and being authentic is crucial to leadership success.

An important caveat to this is that though being authentic as a woman leader may mean demonstrating the eight leadership attributes discussed in this research, this may not always be the case. Because women and women's circumstances are heterogenous, being authentic also may mean demonstrating more traditional and masculine leadership attributes. Though the focus of this research is facilitating the former, women who demonstrate the latter should also be encouraged to be their authentic selves. This is related to a 'damned if you do, damned if you don't' dilemma that many women in leadership positions face. On one hand, women are encouraged to take up 
traditionally masculine leadership qualities, yet when they emulate men and take on these qualities, women leaders are often less well-liked and seen as "cold" (Fiske, 2012, p. 33; Shinbrot et al., 2019). Thus, women leaders can either be seen as cold and capable or warm and unqualified for leadership roles. The focus of this research is to overcome the second barrier referenced in this statement: women leaders should not be penalized and viewed as unqualified when they demonstrate stereotypically feminine leadership qualities. Rather, this research seeks to emphasize how women leaders who demonstrate these attributes are a strength in contemporary energy companies and can facilitate a sustainable energy transition.

Having established that participants were all in agreement regarding the distinctness of women's leadership, the other key motif framing this analysis was how participants envisioned sustainable energy transition. The multi-faceted and complex nature of transitions and the multitude of sustainability challenges associated with the Canadian energy sector were already discussed (see section 1.2), but not everyone in the energy sector envisions this issue the same way. Though all participants recognized the importance of a sustainable energy transition, there were a variety of different definitions of what this transition entails. Unsurprisingly, participants focused on energy production and specifically incorporating more renewable energy sources into our energy system (61\% of participants). Similarly, many focused on decarbonization as a key aspect, rather than other aspects of sustainability ( $44 \%$ of participants). While this is not entirely surprising considering how discussions of climate change dominate contemporary sustainable energy transition rhetoric, a sustainable energy transition consists of much more than renewable energy and decarbonization. Though these two aspects were by far the most common, several participants did indicate a more holistic understanding of this transition. Interestingly, more women than men indicated that sustainable energy transition consisted of more than renewable 
energy and decarbonization: while $57 \%$ of women included considerations beyond these two aspects, only $25 \%$ of men did (eight women, one man). These additional considerations included consumer education, energy system resilience, economic sustainability, and just transition. For example, Michael, who works in the renewable energy sector and was the only male participant who indicated a more holistic definition of sustainable energy transition, defined this transition as follows:

First thing that comes to mind is decarbonisation. The second thing is probably equal opportunity and when I say that I look at Indigenous communities, northern communities, communities that have been very dependent... very energy dependent on fossil fuels and are looking for more independence and that independence could be from fossil fuels or from Crown corporations that typically generate and distribute power. You know I think the other component, that is obvious, and that is independence for all .... so beyond First Nations, it could be communities, it could be individuals.

Thus, while he still recognizes the importance of decarbonization, Michael's response indicates an understanding of the potential social ramifications of an energy transition. In particular, how this transition could change power dynamics and empower citizens and communities. Similarly, Tracy and Anna also had distinct conceptions of sustainable energy transition and what it includes:

What comes to mind right away [when asked about what sustainable energy transition is] is education. I think education is key because we're talking ... we're throwing all these different terms around right: climate change, green recovery, windfarms, hydrogen, cleantech, you know and those are really broad topics and I think most people ... most people when they flip the switch on, they don't think about what happens to the grid or understand what sustainability means. (Tracy)

I would picture [a sustainable energy transition as] moving away from traditional energy like oil and gas and moving towards more sustainable or green energy, and that includes energy efficiency. And I also think a big part of that is a just transition, ensuring no one gets left behind. (Anna)

As can be seen in these quotes, while both Tracy and Anna also mentioned the more traditional technical aspects of a sustainable energy transition (e.g., "windfarms" and "green energy"), they also emphasized the importance of other aspects. While Tracy emphasized the key role that 
education will play in this transition, Anna emphasized just transition, and how this transition must be inclusive and leave no one behind.

These perceptions of gendered leadership and sustainable energy transition lay the groundwork for an analysis of the main themes identified in the interviews. Though other themes were identified as they emerged (for example, women leaders emulating men, as discussed above), the focus of this analysis was addressing the eight themes listed above, each of which focuses on a different leadership attribute. As discussed in section 1.1, themes were identified across two different avenues of questioning, scenarios and direct questioning.

Though the scenarios were structured and written in order to facilitate responses which either confirmed or refuted my hypotheses that women leaders in Canadian energy sector firms tend to demonstrate these eight attributes to a greater extent than men, not all themes were identified in scenario responses. Likewise, not all themes were identified in direct questioning (which was expected as these questions were left open-ended). Alternatively, some themes were identified across both scenario responses and direct questioning. Ultimately, all themes except for environmental management were identified in scenario responses, came out in direct questioning, or both. However, neither gender indicated that they perceived one gender identity to be more environmentally conscious or risk averse when in leadership positions (direct questioning) and the scenarios failed to prompt responses which indicated participants' ability to recognize and prioritize environmental issues. Since neither avenue of questioning prompted responses which included this theme of environmental management, this theme is not included in the following analysis.

Results of this analysis are presented in Figures 7, 8, and 9 below. Figure 7 illustrates the frequency of themes in the responses of all participants across both avenues of questioning. 
Though there were only 18 participants, some themes were identified multiple times in the responses of a single individual. For example, the theme of 'collaboration' was identified as many as seven times in the responses of one participant. As can be seen in the graph, the theme of 'collaboration' emerged the most frequently, a total of 62 times. Other common themes were innovation (32 times), ethical and transparent leadership (24 times), and inclusive leadership (22 times). In Figure 7, themes are not disaggregated by gender, meaning that this simply demonstrates that themes which emerged more frequently, like collaboration and innovation, emerged as more common leadership attributes in this research (regardless of gender).

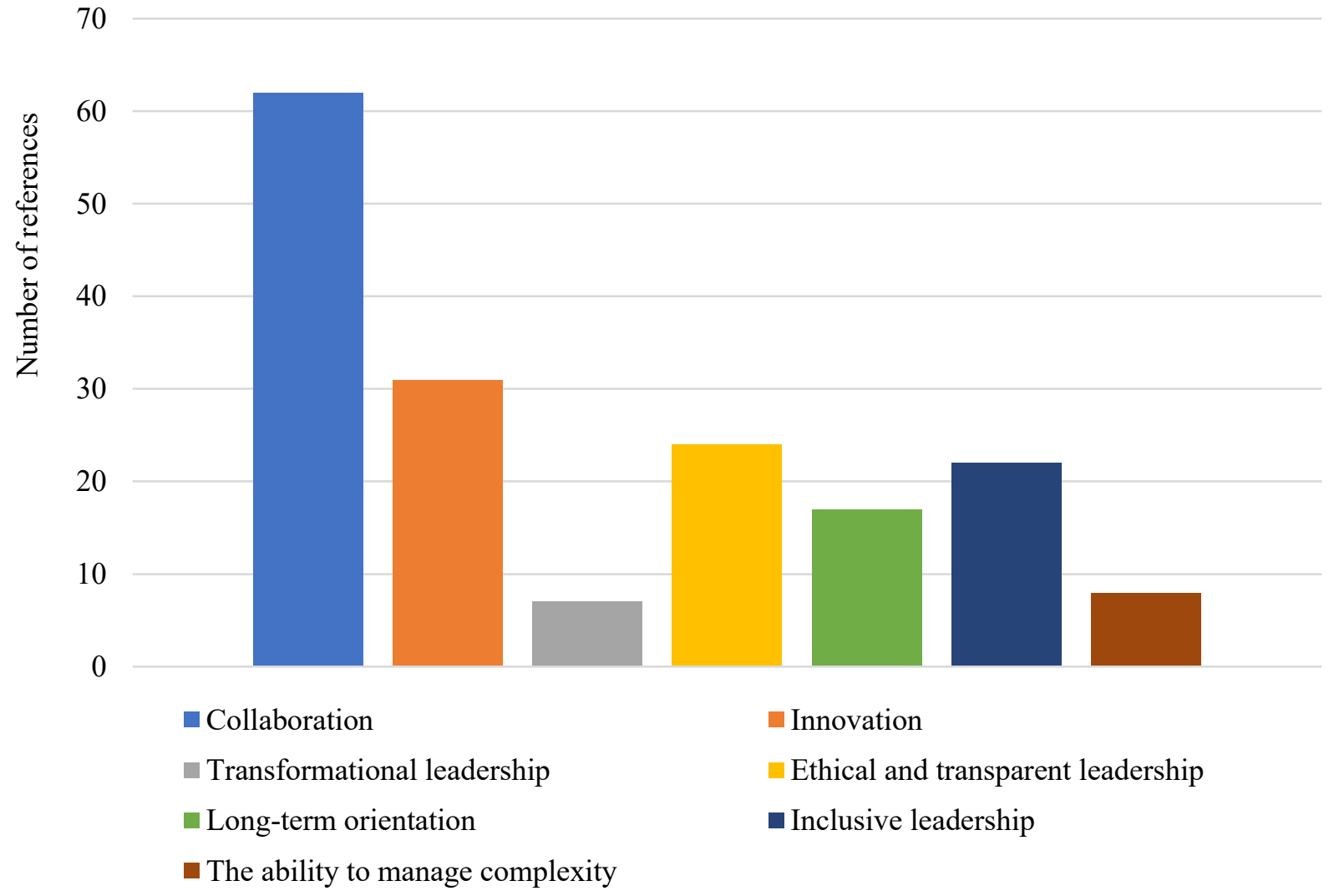

Figure 7: Frequency of Themes Across Avenues of Questioning 
In Figures 8 and 9, results are further disaggregated: data is organized by not only theme, but also by gender identity and the avenue of questioning. Results are also counted by participant, rather than counting all references to a particular theme. In this way, the graphs below only demonstrate whether or not a theme emerged in the responses of a participant, regardless of the number of times that theme emerged. ${ }^{29}$ Figure 8 demonstrates the frequency of each theme in participants' responses to scenarios. Figure 9 demonstrates the frequency of each theme in participants' descriptions of women's leadership. Gaps demonstrate a lack of data, meaning that this analysis did not identify that theme. These gaps do not necessarily mean that either gender does not have that particular leadership attribute, rather, it is reflective of the ability of the questions to draw out particular responses.

\section{Scenario Analysis}

$(\mathrm{n}=18)$

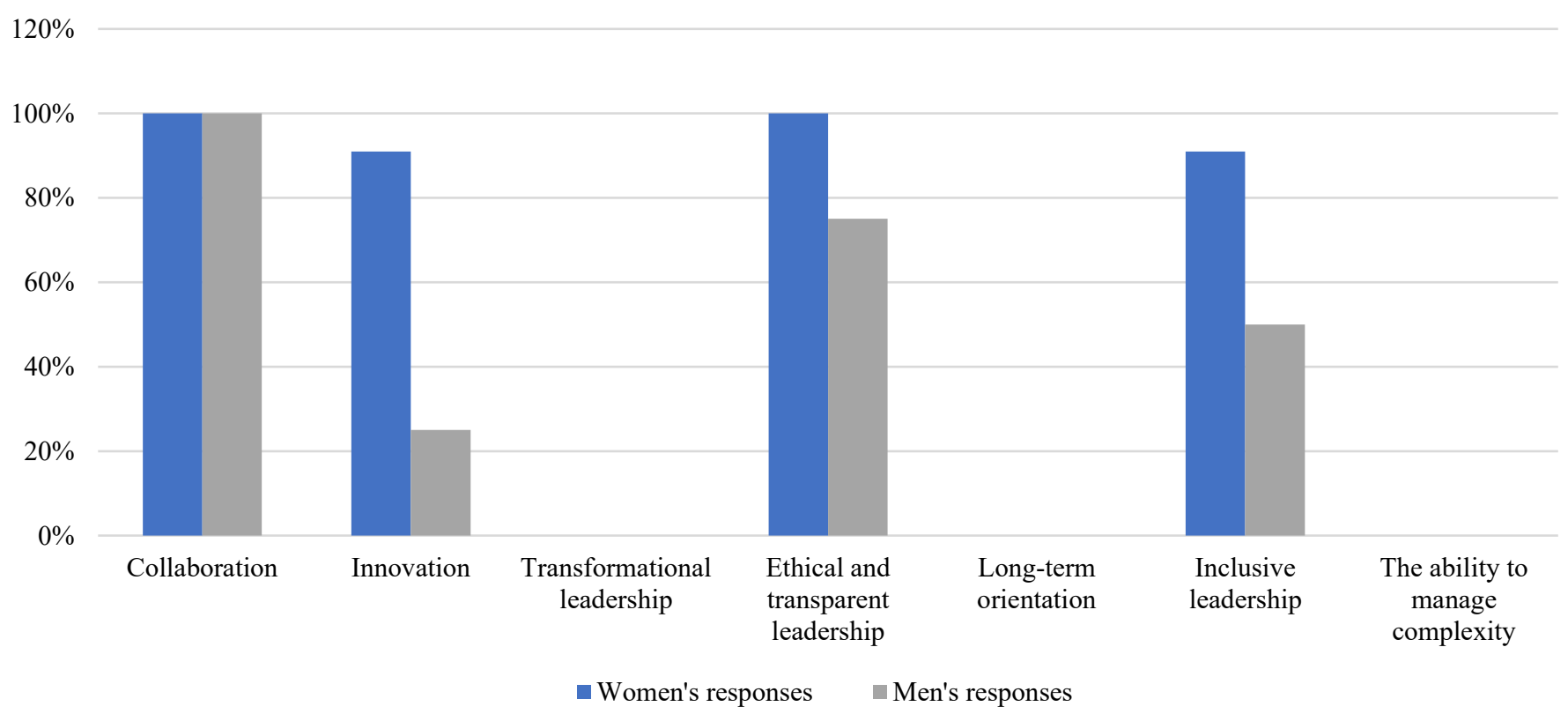

Figure 8: Scenario Analysis Results Summary

\footnotetext{
${ }^{29}$ Results are also presented by percentages in the graphs, though the text that follows includes exact numbers. Percentages were used in large part because not all respondents had the time to respond to all of my questions. Three women participants did not have time for the full interview, so were unable to respond to all scenarios. Thus, percentages demonstrate the results as a percent of the total number of participants who responded to the given question(s).
} 


\section{Direct Questioning Analysis \\ $(n=18)$}

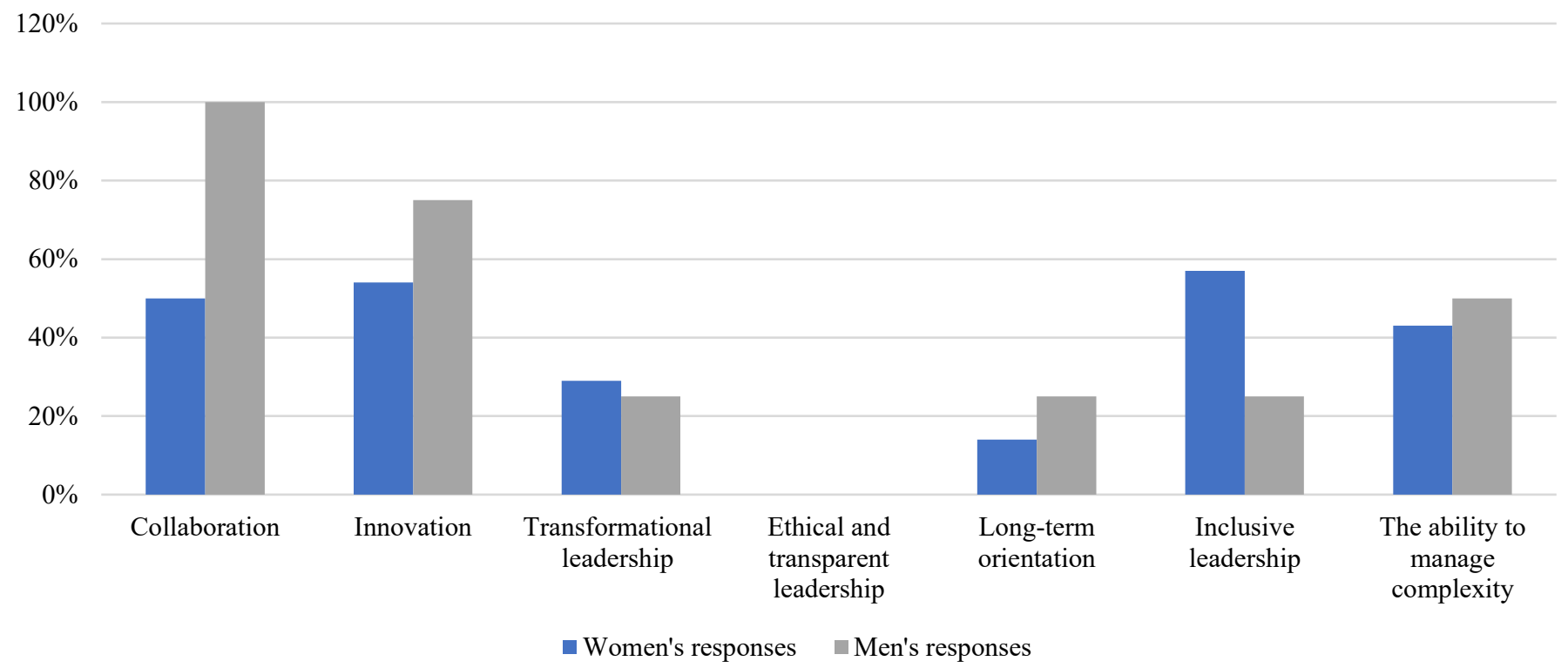

Figure 9: Direct Questioning Analysis Results Summary

\subsubsection{Collaboration}

Existing research on sustainability leadership indicates that a collaborative approach to sustainability problems and initiatives is key. This is because sustainability is a complex and multifaceted issue, and collaborative leaders are better able to manage this complexity and uncertainty through improved information sharing, communication, and group performance (Hull et al., 2018, p. 172). Research on women's leadership also indicates that women perform gender such that they lead in a more collaborative fashion than men, suggesting that women may be more effective at leading sustainability initiatives (Gould \& Hosey, 2007, p. 3). In their responses to scenarios, both men and women demonstrated collaborative leadership. In fact, this theme appeared more than any other theme, and was identified in the scenario responses of all participants. For example, Ashley, who works in the oil and gas sector, displayed a particular enthusiasm for this style of leadership: 
I think diverse perspectives are important and that's something we foster as well in the organization not just within my team that I work with, but more broadly. And there have been times when we had different perspectives on a particular approach or topic, etc. I think, comes down to having a conversation, to give everyone the respect to hear them out and hearing their perspective. And I think that there are always ways and opportunities to come to some kind of, I would say compromise. You may not always agree but there's always a way, I think... find a way to compromise and look at a scenario, or whatever the case in multiple ways, but I think the best place to start would be having an open and respectful conversation and giving everybody the opportunity to share their perspective and then from there, I think, working together to come up with a solution. ... My perspective would be it's important to have a diverse group involved, so they can have again the diversity of thought. I think [that] leads to better outcomes.

Ashley's response to the scenario she was presented with demonstrates several key aspects of collaboration and why it is so important for sustainability initiatives. She brings up how facilitating these "diverse perspectives" is beneficial and how "working together" to reach a solution will lead to "better outcomes." This is similar to the literature on sustainability leadership, which also suggests that a collaborative approach leads to improved outcomes when it comes to sustainability. Her response also echoes the link between a collaborative approach and innovation, which will be further explored below. Ashley emphasizes how "diversity of thought" generates "better outcomes" much how the literature on innovative leadership emphasizes how gender diversity leads to increased cognitive conflict and improved group performance (Pellegrino et al., 2011, p. 10; Torchia et al., 2018, p. 215).

Even though all participants, regardless of gender identity, demonstrated a collaborative style of leadership in their responses to scenarios, in direct questioning, many participants indicated that they perceived women leaders to be more collaborative than men leaders. This theme was identified in the responses to direct questioning of 50\% of women participants (seven women) and $100 \%$ of male participants (four men). For example, Mary, who works in the renewable energy sector, emphasized the more collaborative approach that she perceived in women leaders, stating that "I think men authority figures sometimes tend to have a bit of my way or the highway type of 
approach... again, some men, not all men. But I think women tend to rely more on their teams, generally speaking, and so again taking input from others." Mary's response supports the field of literature on women's leadership suggesting that women leaders tend towards a more collaborative approach through increased teamwork and being open to others' input (Gould \& Hosey, 2007, p. 3).

These findings stemming from direct question present an interesting contradiction: while all men and women participants demonstrated a collaborative style of leadership in scenarios, many participants also indicated that they perceived women's leadership to be more collaborative than men's. There are a number of reasons why this may be. It was previously discussed how a movement away from the traditional hierarchical leadership structure is theoretically underway, but in practice is yet to become a reality (Höpfl \& Matilal, 2007, p. 200). It may be that the men participants therefore recognize the importance of collaboration and bring this knowledge to their leadership roles. However, perhaps they still do not actually implement this collaborative approach to the same extent as women; meaning that even though they may respond to a theoretical scenario with a collaborative approach, they would not do so in real life. The fact that all men participants indicated that they perceived women's leadership to be more collaborative than men's, despite the fact that they had all previously responded to a scenario with collaborative leadership, supports this theory. Another reason for this distinction may be that this is simply the result of inaccurate stereotypes, namely, the stereotype that women are inherently more collaborative more than men. One piece of evidence pointing to this is the fact that while all men indicated that they believed women to be more collaborative than men, only half of women participants indicated that they perceived this to be the case. Thus, more men than women indicated that they perceived women leaders as being more collaborative. 
More research is needed in order to further scrutinize this link between women's leadership in Canadian energy sector firms and collaborative leadership, particularly this distinction between the gendered nature of revealed leadership attributes and stated leadership attributes (i.e., how scenarios revealed no gendered distinction, but direct questioning responses indicated a perception of women's leadership as more collaborative). However, considering the magnitude of research indicating that women leaders tend towards a more collaborative leadership style, the first explanation presented for this distinction is more likely. Namely, that men's responses to the theoretical scenarios are not necessarily reflective of how they would respond in real life. This means that though men participants did respond to a theoretical scenario in a collaborative way, they may not do so when actually faced with the same scenario in their workplaces. ${ }^{30}$ Therefore, this research suggests that women leaders do have a more collaborative approach to leadership, supporting the main argument of this thesis. Specifically, these findings suggest that promoting women's leadership in energy sector firms may serve to facilitate Canada's transition towards a sustainable energy future because women leaders tend to demonstrate a collaborative leadership style, which is the first of the eight leadership attributes which research has shown to be key to sustainability leadership.

\subsubsection{Innovation}

The second leadership attribute that this research found to be key to sustainability leadership and is also associated with women's leadership is that of innovative leadership. As discussed in section 3.1, this form of leadership consists of two aspects: bringing new ideas to the table as an

\footnotetext{
${ }^{30}$ It is important to note that men leaders face barriers stemming from their gender just like how women leaders do. For example, much like how women leaders who display stereotypically masculine leadership attributes such as assertiveness are often less well-liked (Fiske, 2012; Shinbrot et al., 2019), men who display stereotypically feminine leadership attributes (such as collaboration) may face backlash. Though I was unable to find any research studying this leadership attribute specifically, there is ample research demonstrating that men face backlash in the workplace when they stray from traditionally masculine gender norms (Arthrell et al., 2019, p. 7; Mayer, 2018).
} 
individual and facilitating discussion and collaboration in order to encourage group innovation (Adams \& Funk, 2012; Torchia et al., 2018). For example, women and their unique perspective on issues not only bring novel ideas, but women's more collaborative approach to leadership also encourages people to speak up and share their own novel ideas, question the status quo, and promote positive change. Thus, this theme is inexorably intertwined with that of a collaborative style of leadership, as is exemplified in Ashley's response to a scenario above. However, the two themes are distinct in that collaborative leadership is not only about innovation. Rather, collaborative leadership is also linked to increased productivity (Torchio, 2019), workplace satisfaction (Perkins-Gough, 2010), and company performance in an increasingly globalized world (Maalouf, 2019). Bringing new ideas to the table as an individual is also different than cultivating innovation within teams.

An innovative style of leadership was identified as a theme across the two forms of questioning. In scenario responses, $91 \%$ of women participants (ten women) demonstrated an innovative leadership style and $25 \%$ of men did (one man). For example, Samantha demonstrated an innovative style of leadership both personally and in terms of group dynamics in her response to a scenario:

I think I have some different perspectives and I'll bring them to the table and come up with some ideas, but I also recognize that my viewpoint isn't wholesome and so holistic, so if I can go out and get other perspectives, you'll make that idea better. And sometimes people come to you with a new idea and then it's a matter of how do you...how do you run with that? How do you... how do you support it if you think it's a good idea? So, I mean, I think you know if you run things purely as an individual, you're going to have much less success in getting change and positive change. Because you need support and you know the more support and then... And the more ..... and sometimes that means you know you might change, you might tweak your idea. You might change your idea a bit because somebody brings up an issue like I hadn't thought of that. Good point, right? And that just is going to make the solution better and also give it more chance of being adopted or endorsed. 
Samantha's response demonstrates several important aspects of innovative leadership. At a personal level, she recognizes that she brings "different perspectives," but Samantha also recognizes the limitations of her own perspective and indicates that she believes that achieving a "holistic" and "success[ful]" outcome can be achieved through incorporating input from others. Samantha's response also brings up the idea of needing "support" from others to not only further develop and improve the solution, but also to promote its adoption. This idea is more related to the theme of collaborative leadership than innovation, but this link that Samantha makes once again points to the interconnectedness of these two themes.

Direct questioning addressed women's leadership and its association with innovation in a much more direct manner. Fifty-four percent (54\%) of women participants (seven women) and $75 \%$ of men participants (three men) indicated that they believed that more diverse leadership (namely, including more women) would better facilitate innovation. For example, one male participant working in the renewable energy sector, Michael, emphasized how each individual comes from distinct lived experiences, which all impact people's opinions. He suggested that bringing these people with distinct lived experiences together can lead to improved outcomes and new ideas:

What I like to see personally is a great combination of male and female, and a diverse crew to work with. Because I think that that strengthens the viewpoints because lived experience, cultural experience, gender identity all of those play into what your thoughts on certain things are.

Another male participant, Andrew, had a similar response to direct questioning.

A lot of companies hire people based on fit and it seems great and it seems like it works. But if you're hiring someone that fits within your organization, you're really not diversifying your organization much. You need almost someone who doesn't fit who's got a new perspective or a different way of doing things to really force your company to evolve or get out of its comfort zone ... You don't want anymore of that groupthink, which can be really dangerous in terms of everyone just nodding and saying, yeah, it's a great project without considering. Well, maybe there's another project. Or maybe there's another thing we should think about within this project. 
He therefore also emphasized how diversity brings "new perspective[s]" and encourages companies to "get out of [their] comfort zone." Andrew also brought up the concept of "groupthink" and how damaging the phenomenon can be for company performance. This idea echoes the literature on women's leadership and innovation, and how homogenous groups can actually hamper innovation through a lack of critical evaluation of alternatives and points of view (Janis, 1972).

These insights from both the scenarios (revealed leadership attributes) and direct questioning (stated leadership attributes) both support the main argument of this thesis. This research indicates that women leaders do promote innovation, both as a personal attribute and as a style of leadership. Sustainable energy transition requires movement away from the status quo and the production of novel ideas and approaches, meaning that innovation is a key leadership attribute for the successful attainment of sustainability goals and initiatives. Since this research suggests that women leaders do promote innovation, this also suggests that the promotion of women's leadership in energy sector firms may facilitate Canada's sustainable energy transition.

\subsubsection{Transformational leadership}

The third theme addressed in this research is concerned with transformational leadership, which includes looser hierarchies, fostering employee loyalty, and inspirational leadership (Cherry, 2020). For example, a transformation leader will not micro-manage, but rather will set a vision for their team, make sure everyone understands the importance of the vision and how it will be achieved, and support each member of the team so everyone can be successful (Lee, 2020). Transformational leadership did not emerge as a theme in scenario responses but did emerge in direct questioning. In their responses, the theme of transformational leadership being characteristic of women's leadership was identified in $29 \%$ of women participants (four women) and $25 \%$ of 
men participants (one man). For example, Andrew, who works in the oil and gas sector, indicated that he perceived women's leadership as better able to facilitate loyalty and shared commitment, both of which are key aspects of a transformational style of leadership:

And so, you're back to building teams. I think that's the important part in that you know, I've seen some fantastic teams be built based on loyalty and that kind of shared commitment. And so, if leaders can express that and get that buy-in then I think that really helps. And for one reason or another, I think you know females can do that a little bit better.

Andrew's response to direct questioning therefore describes women's leadership as more transformational, but also ties in aspects of collaborative leadership ("building teams"). Other participants had similar responses in direct questioning, emphasizing how they perceived women's leadership as "more inspiring" (Sarah) and "more passion[ate]" (Tracy) and women leaders as more "compelling speakers," and more "engag[ing]" (Allison). These aspects of inspiration, passion, and being compelling and engaging leaders are all characteristic of transformational leadership.

Though this theme appeared only in direct questioning and not in scenario responses and was therefore less common than the previous themes of innovation and collaboration, the fact that women as transformational leaders was brought up in direct questioning indicates that there may be more to this. The form of direct questioning used was completely open-ended, and left participants free to come up with whatever ideas and perceptions they may have about different genders in leadership positions. Therefore, the fact that a total of five participants still indicated that they believed women to be more transformational leaders, even with no prompts or foreshadowing earlier in the interviews, is compelling. Previous research has also indicated that women tend to be more transformational leaders (Eagly et al., 2003). This suggests that this research supports the main argument of this thesis: since women tend to display transformational 
leadership, and transformational leadership is key to sustainability leadership, the promotion of women leaders may serve to facilitate a transition towards sustainability.

\subsubsection{Ethical and transparent leadership}

The fourth theme that this research explored is that of ethical and transparent leadership. Leaders demonstrating this attribute will push for more honest and transparent business practices, such as increased disclosure of risks to stakeholders. Unlike transformational leadership, this theme was only identified in scenario questioning and not direct questioning. Both gender identities demonstrated this attribute, though a slightly higher percentage of women did than men (100\% versus $75 \%$ respectively). For example, Mary, who works in the renewable energy sector, expressed her personal integrity and pride as an engineer:

Well, you know, I pride myself as an engineer, you take an oath right, to, above all, have some professional integrity and if, and I've been in a similar situation before and if I feel like there's a risk there that hasn't been fully or appropriately addressed, I would $100 \%$ express my concern to that superior. Probably not just the concern, but also a plan on how to mitigate the concern and confirm if it's actually a concern or if it is ...how we could navigate it. But yeah, no I would hands down say something - at the end of the day if it's, you know found to be a true concern and they still move forward and it backfires. It could affect their reputation, you know?

This personal conviction and concern for firm reputation that Mary expressed are both key aspects of ethical and transparent leadership. The scenario responses of other women participants reiterated these same components of the theme of ethical and transparent leadership. For example, Harper's response to a scenario with an ethical dilemma reflected her personal conviction: "[I would] scream like hell from my lungs throughout the company and I have no qualms and going above my manager or my leader to say something's wrong." Other women participants emphasized the second aspect of this theme, reiterating "the importance of reputation" (Charlotte) and how unethical behaviour can lead to "brand damage" (Sarah). Men's responses to scenarios also demonstrated ethical and transparent leadership, though a slightly smaller percentage of men did 
then women. However, their responses included the same key aspects of this theme, emphasizing how unethical behaviour can lead to “community push back or damaging [the company's] ESG score by a rating agency" (Andrew).

Previous research suggests that women leaders tend to be more ethical and transparent than their male counterparts (Boulouta, 2013, p. 193). However, in this research this theme was identified in the scenario responses of only a slightly higher percentage of women than men and the theme did not emerge in direct questioning. This research into the theme of ethical and transparent leadership therefore provides little evidence to support the main argument of this thesis. Though women leaders who participated in this research did demonstrated ethical and transparent leadership, men leaders did as well (though they did so to a slightly lesser degree). Nonetheless, even this slight gendered distinction indicates that women may be more ethical and transparent in leadership positions. Since ethical and transparent leadership is key to attaining sustainability, women therefore also may be more effective sustainability leaders.

\subsubsection{Long-term orientation}

The fifth theme this research is exploring is that of having a long-term orientation as a leadership attribute. Since achieving sustainability requires a long-term perspective and prioritizing the future over short-term costs and benefits, sustainability leadership literature suggests that this orientation is key to the attainment of sustainability initiatives (Campbell et al., 2018). Like the theme of transformational leadership, this theme only emerged in direct questioning and not in scenario responses. Only a few participants indicated that they perceived women to have this leadership attribute to a greater extent than men: $14 \%$ of women (two women) and $25 \%$ of men (one man). However, as mentioned previously, the fact that participants brought up this attribute with no prompts indicates that there may be more to this. For example, one 
participant who indicated that she perceived women to have more of a long-term orientation was Charlotte, who works in the oil and gas sector:

I think women are more futuristic... they are always thinking more about their future. And when you look at sustainability it's very much about the future, so don't think about the here and now, think about the future. So just the ability to be able to think about the future and the sustainability of it.

This excerpt from Charlotte's interview is extremely similar to the interviews of the other two participants who indicated a perception that women's leadership is more long-term focused. Both of these participants stated how women "contemplate future impacts better" (Andrew) and "trend towards long term thinking" (Sarah). Though this requires further research, these findings support the small amount of research indicating that women may have a longer-term orientation than men (Adams \& Ferreira, 2009; McElhaney \& Mobasseri, 2012; Silverman, 2003). This research therefore also supports the main argument of this research: if women leaders think long-term, they also may be more effective sustainability leaders.

\subsubsection{Inclusive leadership}

The sixth theme which this research identified as being key to sustainability leadership is that of inclusive leadership. Inclusive leaders are those promote better working conditions for employees and work to create a more welcoming environment. They are also more concerned with impacts a project can have on local communities and stakeholders. Inclusive leadership as a theme was identified across scenario responses and direct questioning and across gender identities. In responding to scenarios, women's responses had a higher incidence of demonstrating inclusive leadership then men's ( $91 \%$ of women [ten women] compared of $50 \%$ of men [two men]). This theme of inclusive leadership can be seen in the excerpt from Katherine's interview below, where she demonstrates a concern for the wellbeing of her team when responding to a scenario:

The thing I don't do is driving people harder because if there's anything I've discovered in in the years of leading teams it's that when people have a really clear idea of what they're trying 
to deliver, and they believe in that outcome, they work like dogs. And you do not need to do anything to push them more. And in fact for mental health and all that other stuff...It's giving them the space to do the work that they do exceptionally well and not increase the pressure because they already have enough pressure on themselves.

Katherine's concern for her team, their "mental health", and "not increase[ing] the pressure" are all key aspects of inclusive leadership. Other participants had similar responses to scenarios, echoing concern for their teams' "mental health" in a hypothetical high-pressure scenario (Stephanie, James) and a desire to "add more capacity" (Andrew) or "bring in other people" (Ashley) to relieve team stress.

The theme of inclusive leadership was also identified in direct questioning: both women ( $57 \%$ or eight women) and men ( $25 \%$ or one man) indicated that they perceived women to be more inclusive leaders. Many participants indicated this through describing women as having a more inclusive and compassionate approach to leading their teams. One such example is Sarah, who stated: "I find that women trend towards ... inclusivity is my experience. So being inclusive of those introverts of diverse folks. And creating a space where they can communicate."

A keyword within with this theme of inclusive leadership which emerged a total of 17 times throughout the interviews in direct questioning was "empathy." Interestingly, though no men raised the attribute of empathy as being a valuable asset associated with women's leadership, 50\% of women (seven women) did. For example, Hannah expressed how she has come realize how important this quality of caring and empathy is in leadership positions:

I think women just inherently have a more of a... whether it's like a tendency or a capacity for kind of like that empathy, caring, thinking about people aspect ... and I think that's important for a leader, because you know, obviously, you know there's nothing without having strong team and being behind you, so I think kind of that the people caring aspect is so important.

This research therefore supports previous literature which suggests that women are more inclusive leaders (McElhaney \& Mobasseri, 2012). Since a sustainable energy transition will require the 
engagement and inclusion of people across all walks of life and around the world, inclusive leadership is also key to sustainability leadership (Campbell et al., 2018; Knight \& Paterson, 2017; Visser \& Courtice, 2011). This research therefore also supports the main argument of this research and indicates that gender matters when it comes to Canada's sustainable energy transition since women may be sustainable energy transition leaders.

\subsubsection{The ability to manage complexity}

The final theme that this research explored is the ability of leaders to manage complexity. Energy system transitions are extremely complex, occurring across a variety of spheres (political, economic, technical, social) and progressing in a non-linear fashion. Because of their complexity, existing literature suggests that leadership within this complexity is particularly challenging but important for the achievement of sustainability (Hull et al., 2018; Metcalf and Benn, 2013; Sørensen \& Handcock, 2020; Visser and Courtice, 2011; WBCSD, 2011). Much like transformational leadership and having a long-term orientation, this research only identified the theme of managing complexity in direct questioning and not in scenario responses. In total, $43 \%$ of women (six women) and 50\% of men (two men) indicated that they perceived women leaders

to be better able to manage complexity than leaders who are men. For example, Charlotte emphasized how women leaders are more "multi-dimensional", whereas men tend to have a more "linear perspective." Similarly, Mark described women's leadership as "more multi-faceted" and "more encompassing," once again demonstrating the perception that women leaders are better able to manage complexity.

As was previously discussed, even though this theme was not present in scenario responses, the fact that participants brought up this theme with no prompting suggests that this may be a stronger trend than this research initially indicates. Furthermore, there is previous research 
suggesting that women may be better able to manage complexity due to their unique approach leadership, which can be characterized as having looser hierarchies, encouraging innovation and creativity, and challenging the status-quo (Uhl-Bien et al., 2007). Therefore, this research supports once again supports the main argument of this research. Specifically, these findings indicate that women may be sustainable energy transition leaders and the promotion of women's leadership in Canadian energy sector firms may serve to facilitate Canada's sustainable energy transition.

\subsubsection{Bringing it all together}

Though the evidence for some themes was much stronger than evidence for others, almost all of the thematic findings of this analysis support the main argument of this research (with the exception of the theme of environmental management). This research found evidence that women leaders in Canadian energy sector firms demonstrate seven of the eight sustainability leadership attributes to a greater extent than their male counterparts. This suggests that women may be the sustainable energy transition leaders that Canada needs to address the many sustainability challenges it is facing and that promoting women's leadership in energy sector firms will serve to facilitate Canada's transition towards a sustainable energy future. A summary of findings organized by theme can be found in Table 3 below. 
Table 3: Summary of Findings

\begin{tabular}{|l|l|l|}
\hline Theme & Result & $\begin{array}{l}\text { Strength of } \\
\text { evidence }\end{array}$ \\
\hline Collaboration & $\begin{array}{l}\text { Findings support literature suggesting women are more } \\
\text { collaborative leaders. }\end{array}$ & Strong \\
\hline Innovation & $\begin{array}{l}\text { Findings support previous research indicating that } \\
\text { women leaders promote innovation. }\end{array}$ & Strong \\
\hline $\begin{array}{l}\text { Transformational } \\
\text { leadership }\end{array}$ & $\begin{array}{l}\text { Findings support research suggesting women leaders } \\
\text { are transformational leaders. }\end{array}$ & Medium \\
\hline $\begin{array}{l}\text { Ethical and } \\
\text { transparent leadership }\end{array}$ & $\begin{array}{l}\text { Findings support literature demonstrating a link } \\
\text { between women's leadership and ethical and } \\
\text { transparent leadership. }\end{array}$ & Weak \\
\hline $\begin{array}{l}\text { Environmental } \\
\text { management }\end{array}$ & $\begin{array}{l}\text { Findings were unable to provide insight into whether } \\
\text { or not women perform better in terms of } \\
\text { environmental management, though previous research } \\
\text { suggests that they do. }\end{array}$ & None \\
\hline $\begin{array}{l}\text { Long-term orientation } \\
\text { Findings support literature suggesting women leaders } \\
\text { have a long-term perspective. }\end{array}$ & Medium \\
\hline $\begin{array}{l}\text { Inclusive leadership } \\
\text { complexity }\end{array}$ & $\begin{array}{l}\text { Findings support research indicating that women } \\
\text { leaders are inclusive leaders. }\end{array}$ & Strong \\
\hline
\end{tabular}

Beyond this evidence linking nearly all themes of sustainability leadership attributes to women's leadership, this research uncovered one other theme supporting this main argument. Nearly all participants (16 out of 18) indicated that women's distinct leadership attributes make them better suited for sustainability leadership within the Canadian energy sector. Though two participants were unsure, stating that "you'd think so, but I haven't borne witness to it" (James) and "I think the honest answer is I don't know" (Katherine), the rest indicated that they believed women demonstrated a style of leadership better suited to sustainability. Participants gave a variety

\footnotetext{
${ }^{31}$ Evidence was considered strong if it was found in responses to both avenues of questioning and medium if it was found only through direct questioning. Evidence for ethical and transparent leadership was considered weak because it was found only through scenarios and the difference between genders was small.
} 
of reasons as to why they believed this to be the case, many referring to one or more of the eight attributes discussed above. Some reasons given by participants as to why they believed this to be the case were because women "have an ability to build teams" (Andrew), think in a more "multidimensional" way (Charlotte) and are less "narrow minded" (Mark), or simply because women bring "different perspectives, different approaches, [and] different ways of thinking" (Hailey). Thus, though additional research is needed to further interrogate these finding, this research suggests that encouraging women leaders can facilitate a transition towards sustainability within Canadian energy sector firms.

The following section will turn away from the primary research question of this thesis and return to the secondary research question. Namely, it will expand on the literature presented in section 3.2 through revisiting the barriers and recommendations for women leaders within Canadian energy sector firms. Rather than exploring the question of why women's leadership matters, as this section did, section 5.2 will explore how it can be promoted. This will include a discussion of the barriers and recommendations put forward by participants in this research and compare these findings to existing literature on women's leadership in private energy sector firms.

\subsection{Revisiting Barriers and Recommendations for Women Leaders}

If women are sustainable energy transition leaders, as previous research and the analysis above suggests, then Canadian energy sector firms should work to promote more women into leadership positions within the industry. However, this will not be as simple as it may seem. Women are currently vastly underrepresented in leadership roles in the sector, and they face a variety of barriers in the workplace. As discussed in section 3.2, research shows that prominent barriers include cultural and social norms, unfair and biased practices, a lack of flexibility, and limited support and role models. The literature review in section 3.2 also provided 
recommendations to address these barriers. These recommendations include the initiation of a cultural shift through initiatives like unconscious bias training, changing recruitment and promotion practices, and improving human resource policies (see Table 2 for a full list).

One goal of the primary research component of this thesis was to explore the barriers that participants believed women in the sector face and ask for their recommendations regarding how to make Canadian energy sector firms more welcoming for women and women leaders (i.e., my secondary research question). Unlike the analysis presented in section 5.1 above, this primary research was done through only one avenue of questioning: direct questioning. These questions were also asked near the end of interviews, ensuring that participants were already thinking about women's leadership and their experiences in the sector. This section will therefore examine participants' responses to the question of what barriers exist for women leaders and provide further Canada-specific insights regarding how women leaders can be better supported in the energy sector firms.

All 18 participants indicated that they believed that women face barriers in Canadian energy sector firms. For example, Tracy emphasized her experiences in the sector as often being "a huge sausage party" and Stephanie reminisced how she used to be referred to as "just a mindless girl," or "JAMG," a phrase she heard when she first entered the energy sector. However, nearly half (seven, 39\%) of participants considered barriers to advancement in the sector to be more of a concern than barriers to entry. For example, Hannah expressed this sentiment; while she acknowledged that entry can be an issue for women, she emphasized how women tend to leave the sector and are not advancing to leadership positions:

I think the two things for me that are interesting is you look at the number of women that enter the sector versus how long they stick around for, and you know that number is not great, we see them leaving the sector after 4, 5, 10 years kind of thing ... [one reason why is that] women that aren't advancing into either management or leadership positions, that's not 
happening at the same rate as men ... I guess, maybe like for entry it's probably not as much of a barrier, I think it's maybe once you get in there, and if you have the unfortunate luck of getting into a company that does have more of that old boy's mentality... um then you're going to see those barriers pretty quickly.

This sentiment that women may be able to enter the sector but often leave echoes research on women in STEM (see section 3.2.9), which also suggests that women leave the field in much higher rates than men due to the variety of barriers and biases that they face in the workplace (Frank, 2019). This is also reflected in the barriers discussed in the literature (section 3.2), many of which focus on barriers related to advancement in the sector rather than entry. For example, cultural and social norms, unfair practices, and limited support for women in the workplace may all lead to a woman leaving the sector rather than remaining and advancing to a leadership position.

Hannah's response points to another theme which emerged in the interviews: the heterogeneity of companies within the sector. Her response suggests that though some companies may have an "old boy's mentality," not all do. This theme emerged in many of the interviews. For example, Mary emphasized how women are "very well represented" at the company she works at but recognized that "you don't really see that" at other companies. Similarly, Charlotte celebrated her company's commitment to "ensuring that leadership is 50/50" and how not all companies "see the value of bringing different voices" into leadership roles like her place of work does. This trend of participants perceiving their place of work as more egalitarian likely emerged at least in part due to self-selection: for the most part, only companies who were already thinking about and prioritizing these issues responded to my inquiry. ${ }^{32}$ However, it is interesting to note that though many companies therefore do need to make significant improvements to their practices, culture, and policies in order to better facilitate the advancement of women leaders, not all may have to.

\footnotetext{
${ }^{32}$ When emailing a company directly, I emailed the general information address provided on the company's website. This typically went to an administrative staff member, who would either ignore the inquiry, respond asking for further details, or forward the research inquiry to leaders within the company.
} 
Rather, there are companies within the Canadian energy sector that are already acting on the issue of gender inequality. In such cases, encouraging the promotion of women into leadership positions may be much easier.

This points to yet another theme which emerged in the interviews: participants believed that, though further action is needed, things are better now than they used to be for women in the sector. Almost half of participants (seven, 39\%) suggested that they believed this to be the case. For example, Anna stated that "even the past 20 years that I've been in the workforce I definitely see a difference, which is nice [but] I think we still have a long way to go.” Other participants indicated that they "think it's gotten better" (Samantha) and that "things have changed, and it is more positive now" (Victoria).

However, despite the heterogeneity of the sector and the positive change that has occurred in parts of the sector, participants indicated that barriers remain for women and women leaders in Canadian energy sector firms. A summary of the barriers and recommendations put forward by participants is presented below in Figures 10 and 11. Both Figures present participant responses according to the barriers and recommendations found in the literature review (section 3.2). As a result, there are a few gaps: not all barriers and recommendations discussed in the literature were brought up by participants. This does not mean that the conclusions of existing literature are necessarily inaccurate, but rather reflects the positions of these individuals. For example, even though it is often discussed in the literature (Barua \& Gaudet, 2018; Pearl-Martinez \& Stephens, 2016, p. 2; Smet, 2018), no participants presented the lack of gender-disaggregated data on employment within the sector as a barrier. However, this is not surprising since this is a high-level issue more concerned with governance of the sector rather than individual experiences. Similarly, the fact that no participants discussed sexual harassment as a barrier for women in the sector may 
be the result of the fact that, as discussed above, things have improved in the sector. As expressed by Victoria, now women "get less of the overt harassment" (emphasis added).

The frequency of each barrier and recommendation is also not very high, with each theme rarely being identified in the responses of even half of the 18 participants. However, this is also not surprising. In the interviews, questions regarding barriers and recommendations were left completely open-ended, leaving it up to participants to reflect on their experiences and perceptions. This approach is distinct from much of the previous research on barriers and recommendations for women in the energy sector, which has often provided more guidance for participants. For example, in the research study conducted by IRENA (2019), participants were asked to select what they perceived to be the most important barriers and solutions for women in the renewable energy sector from a pre-determined list (p. 84). A more open-ended ended approach was selected to avoid leading participants to certain conclusions, facilitate more discussion, and encourage participants to bring up new ideas. As can be seen by the variety of other themes identified in the responses to these questions discussed above, this approach succeeded in doing this: many conclusions beyond how frequently participants pointed to each barrier and recommendation emerged from this part of the interviews. 


\section{Barriers}

$(n=18)$

$$
8
$$

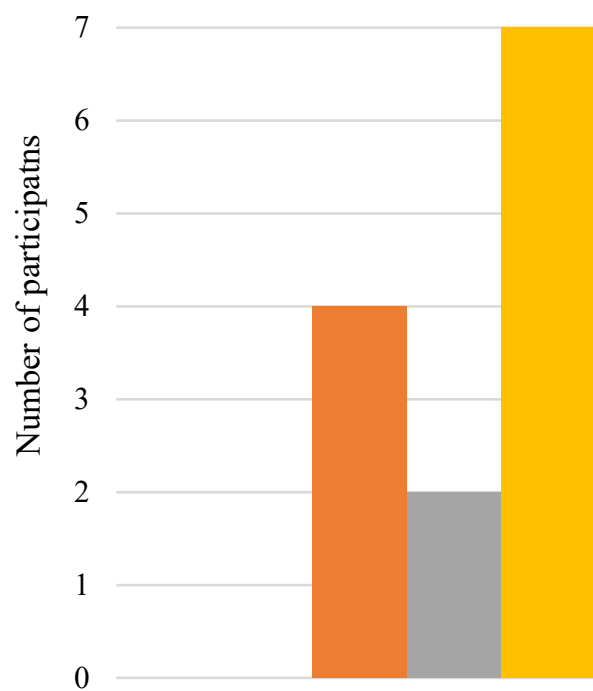

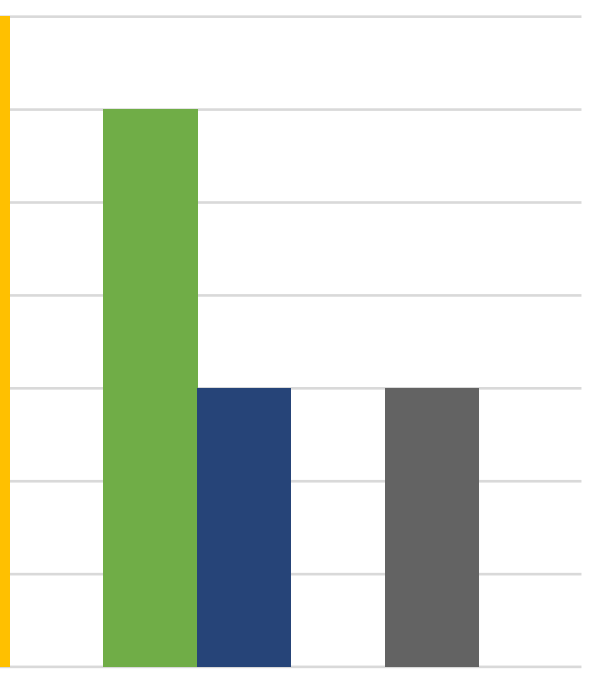

- A lack of gender-disaggregated data

- Cultural and social norms

- Unfair practices

$\square$ A lack of flexibility and accommodation in the workplace

- Sexual harassment

- Limited support and role models

- Low levels of confidence

- A lack of understanding of jobs and opportunities within the energy sector

- Insufficient and/or improper backgrounds/education

Figure 10: Barriers Women Face in Canadian Energy Sector Firms

\section{Recommendations}

$$
(\mathrm{n}=18)
$$

12

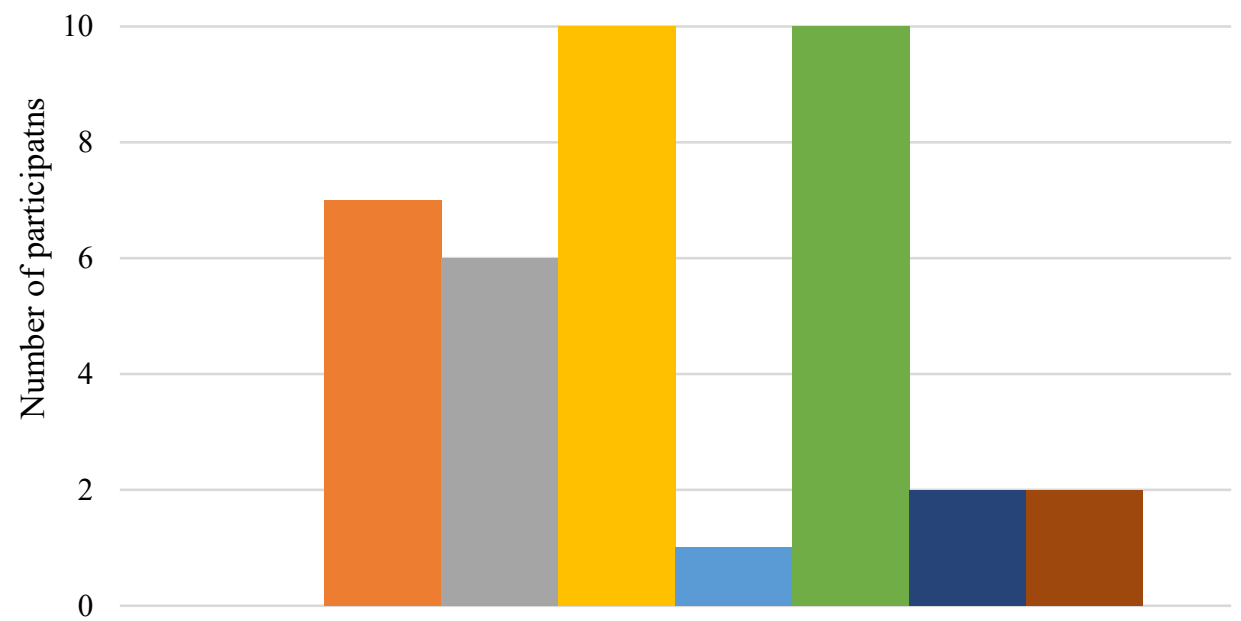

- Collect gender-disaggregated data

- Initiate a cultural shift

Change recruitment and promotion practices

Increase the flexibility in the workplace

Improve human resource policies

Encourage mentorship and sponsorship programs and highlight women in the energy sector

- Spread awareness of the energy sector and its wide range of jobs

- Promote women in STEM

Figure 11: Recommendations to Better Support Women in Canadian Energy Sector Firms 


\subsubsection{A lack of flexibility and accommodation}

In this research, a lack of flexibility and accommodation in the workplace emerged as the most commonly-referenced barrier for women in Canadian energy sector firms (seven participants). In their responses, participants almost all focused on pregnancy and maternity leave, and how companies and higher-ups often do not make it easy for women to go through a pregnancy, go on maternity leave, and raise their children. Instead, participants pointed to this time in a woman's life (around a woman's 30s) as a critical time for advancement, and discussed how going on maternity leave at this critical time can lead to discriminatory practices:

Women [often]... have to take a couple of years [off] in their career for maternity leave and whatnot. And it's usually unfortunately right smack in your 30s when you know you've started to establish your position. By then you would probably be considered for advancement, but you're leaving for a year and [bosses sometimes think] 'oh don't give it to her, she's probably going to go again for a couple years, you know, for another maternity leave.' (Mary)

It's kind of crazy like bosses will say out loud like, 'I don't want to hire a woman because they're going to get pregnant'. So, they want either a really young one or a really old one. They don't want to hire one in their 30s, because they're worried that they're going to go on mat leave, which is such a stupid barrier. (Sarah)

Both Mary and Sarah therefore expressed similar concerns regarding the reactions of higher-ups to a woman taking maternity leave. They both suggested that going on maternity leave may mean that a woman would not be considered in advancement and hiring decisions. These responses also tie in other barriers that women face, such as unfair practices and cultural and social norms.

The solution many participants (ten) suggested to address this barrier is to increase the flexibility of the workplace. This includes initiatives such as mandatory parental leave, leave for caring for family, more flexible scheduling, more work-life balance, and on-site childcare. Katherine's recommendation regarding how to make the sector more inclusive included several of these components: 
I had a guy [colleague]... who had a baby, and I begged him to take parental leave because accepting that women take maternity leave is different than saying that all people have parental leave at some point in their lives. And if you make it normal for everybody then it's not going to be this big barrier for women and this big choice point to say I have to choose family or career, which everybody who's married to somebody who doesn't take parental leave does. So I think that there's lots of ways that we need to look at how we [can] encourage advancement of women and not through ... not encouraging advancement by pushing women to play the same games that are required in the current system, but by actually changing the system and not by you know saying 'okay well I guess it's the same thing, yeah you have to play the same game as men, work all these hours that nobody really needs to work all that other junk'.

Katherine's response therefore includes key aspects of increasing flexibility in the workplace, such as parental leave and encouraging more widespread change though "changing the system" and improving work-life balance for everyone. This is a key point: a more flexible workplace would support a wide range of diverse employees beyond women. One participant in this research, Sarah, noted that this flexibility would also support people with disabilities, transgender people, and those suffering from chronic ailments like irritable bowel syndrome (IBS) and Crohn's disease. These individuals may feel uncomfortable using the workplace washrooms or simply require more flexible schedules. Thus, through having a more flexible and supportive workplace, a company can better attract and retain these individuals who may be top-tier and extremely good at their jobs, but simply struggle to adhere to a regimented and uncompromising work schedule.

\subsubsection{Limited support and role models}

The second most-frequently referenced barrier for women and women leaders in the Canadian energy sector was that of limited support and role models. Many participants (six) pointed to this lack of role models that women have as being a barrier that women in the energy sector face. For example, Hannah expressed concern for the fact that the leadership teams in the sector are still predominantly men, so women entering the sector don't see themselves in those roles: “....and that's important, because I think if you're going to go for something you need sort of 
a role model and say 'oh yeah she did it, I can do it too." Participants also reiterated other aspects

of this barrier that the literature identified, namely, that the lack of networks available to women hinders their ability to enter and advance within the sector. For example, Charlotte pointed out how the "tight-knit industry" tends to support men in lieu of women:

It's often males in these positions of power and the issue is that women often haven't built up enough momentum in terms of the socioeconomics and creating that value [networks] that they can actually use to advance each other. Whereas men have been in it for a long time. So their advancement is much more easier than for females.

Addressing this barrier through encouraging mentorship and sponsorship programs for women in the energy sector as well as highlighting women in the sector was one of the most suggested recommendations (ten participants). Much like how existing literature pointed to this as being important, many participants in this research pointed to these kinds of initiatives as being key to promoting women in the energy sector. For example, many pointed to the importance of "seeing yourself" in senior leadership positions, which can be extremely difficult if all leaders are men (Anna, Ashley, Hannah, Mary, Samantha).

\subsubsection{Cultural and social norms}

In this research, cultural and social norms were the third most referenced barrier for women and women leaders in Canadian energy sector firms (four participants). Participants mentioned how some companies in the sector are "old boy's club[s]" (Hannah) and how many men in the sector have "blind spots" when it comes to the challenges that women face (James). Samantha's discussion of this barrier includes several other aspects of how cultural and social norms limit women's success and advancement:

I think there are probably barriers because the cultures [in the energy sector] aren't necessarily ... haven't always been inclusive, and maybe still aren't inclusive, and so you see women, [or] people who demonstrate other diverse traits, who might say 'I don't see that as a friendly place for me to be', or 'how am I going to advance there?' Because, you know, until recently, well even now I mean, you can still look around [and] a lot of companies today and in the energy sector you'll look at boards and executives that are, you know, white 
and male, and so sometimes it's hard to imagine what your pathway is there, or if it's a culture you want to be in.

Samantha therefore brings in not only how the cultures at some companies in the sector are not inclusive of women and other forms of diversity, but also ties in this barrier with the lack of representation of women in leadership positions in the sector, and how this can discourage women from even trying. These quotes from participants tie in the key aspects of the barrier of cultural and social norms: the lack of awareness of the challenges that women face, and conscious and unconscious bias.

The recommendation of initiating a cultural shift in order to address this barrier was also the third most referenced recommendation (seven participants). Participants pointed to the fact that many men "are just unaware" of the issues that women face, and how addressing this requires "programs" and "training" regarding women's issues, diversity, and how to become more aware of "unconscious bias" and how it impacts one's actions (Charlotte, Sarah, Victoria). Anna also brought up how companies should "have a deliberate gender strategy" in order to promote more systematic change in the company. These suggestions made by participants are similar to many of those presented in the literature. For example, previous research also emphasizes how providing unconscious bias and diversity training can facilitate a cultural shift in an organization towards greater inclusivity (Boyd et al., 2019, p. 66; Equal by 30, 2021).

\subsubsection{Low levels of confidence}

In participants' responses, low levels of confidence among women tied with improper/insufficient backgrounds and/or education as the fourth most frequently referenced barrier for women in the sector. As discussed in the literature review (section 3.2), these low levels of confidence are endemic to women across the workforce. A few participants echoed these conclusions, expressing concern for women's reticence to advocate for themselves and be 
confident in their knowledge and abilities. For example, both Ashley and Tracy brought up the same example of how men are more likely to apply for a job even if they do not have all of the listed qualifications, while women will often wait until they can check off all qualifications before applying. Mary brought up a more comical real-life example of this phenomenon:

I remember being at a conference [and] somebody asked the room 'who here is an expert on breastfeeding?' And the room was full of women and men and like essentially no women raised their hands, some of them being mothers, some of them having breast fed in the past. And there was one guy that raised his hand and the person asked, 'so why do you think that you're an expert on breastfeeding?' And the guy is like 'oh I watched my wife do it a couple times.' And you know what's interesting in that is that men tend to put their hand up when they really don't know exactly what they're doing or where they're going. But you know, they're like, yeah, I'm going to figure it out. I'm putting my hand up, I can do this. Whereas women ... if in contrast, if I'm given a project and I'm not $100 \%$ familiar with it. My instinct is to say, okay, I don't know this, this, this and this. I'll do my best, but I just want to put it out there that I'm not an expert right off the bat. We're [women are] more comfortable disclaiming all of those things.

This example that Mary provided points to another conclusion of the literature review: that there are two sides to this barrier. While it is true that women are often not confident enough and do not apply or raise their hands when maybe they should, men tend to apply and raise their hands when maybe they should not. Because this barrier is therefore two-sided, the literature review suggested an approach which addressed both women and men and their respective shortcomings in situations such as the one Mary presented. To bolter women's confidence, mentorship and sponsorship programs were recommended as well as highlighting more women in the energy sector. However, more systematic change is also needed so that companies no longer prioritize the promotion of people who are extremely vocal and (over)confident over those who may be quieter but equally or even more competent (Chamorro-Premuzic \& Gallop, 2020). This includes changing recruitment and promotion practices to be more inclusive and less biased.

The recommendation of mentorship and sponsorship programs was already discussed as one of the top recommendations stemming from this research, but this second recommendation, 
changing recruitment and promotion practices, was also suggested by several participants (six). Participant responses pointed to several key elements of changing recruitment and promotion practices to make them more inclusive and better able to facilitate the advancement of women. These include the importance of using inclusive language (Harper), targets for the number of women in an organization's leadership and/or the number of women candidates solicited to fill a role (Samantha, Andrew, James), and using blind applications to avoid conscious and unconscious bias (Michael, Victoria). For example, Samantha recommended setting a target for women's representation in leadership roles, and discussed how well this strategy worked at her place of work:

We set we set a target, have $30 \%$ of our board and our executive female ... [and] I don't think that intentional effort has resulted in a lower quality of leadership, and I think that's really important because I think sometimes people [that] ... you're going to take a less qualified candidate, because you're may not select based on merit, you're going to select based on some other element of diversity and I just don't think that's true.

Thus, in her response, Samantha refuted the main argument against policies like targets and quotas, arguing that it does not lead to "a lower quality of leadership," but rather that these women "add a lot of value." This is similar to existing research which suggest that quotas often support rather than undermine a meritocracy (Besley et al., 2017).

\subsubsection{Improper/insufficient backgrounds and/or education}

The barrier of women having improper/insufficient backgrounds and/or education (whether perceived or real) also appeared in the responses of a total of three participants. Interestingly, all of these participants who pointed to this as a barrier were men. For example, Andrew pointed to how "attracting women to the STEM programs" was a problem and was limiting women's ability to advance and succeed in the energy sector. No participants pointed to the fact that this phenomenon is often perceived rather than real (due to the fact that people often are not aware of 
the wide range of jobs in the sector) or discussed the phenomenon of women leaving the sector and/or their technical fields in droves.

The literature review recommended several actions to address this barrier, including encouraging mentorship and sponsorship programs, highlighting women in the energy sector, changing recruitment and promotion practices, and promoting women in STEM. All recommendations except for the fourth have already been discussed so only evidence for this last recommendation will be presented here. Two participants (both men) suggested that encouraging women to enter STEM programs would improve their prospects in the energy sector. For example, Andrew suggested "breaking down those stereotypes that math and science are only for boys and engineering is only for boys and then also kind of dropping the breadcrumbs of these are the potential careers that you could do." His response therefore not only includes how important the promotion of women in STEM is, but also brings in a different recommendation: spread awareness of the energy sector and its wide range of jobs.

\subsubsection{Other barriers and recommendations}

Due to the limited availability of data for the rest of the barriers and recommendations, those remaining are simply listed below in Table 4 with key evidence from participants. The final barrier discussed by a total of two participants was that of unfair practices. The last two recommendations put forward by a few participants were improving human resource policies and spreading awareness of the energy sector and its range of jobs. 
Table 4: Other Barriers and Recommendations Put Forward by Participants

\begin{tabular}{|c|c|}
\hline Barrier & Evidence \\
\hline $\begin{array}{l}\text { Unfair practices } \\
\text { Recruitment/promotion } \\
\text { practices which } \\
\text { perpetuate the } \\
\text { predominance of men } \\
\text { in the energy sector }\end{array}$ & $\begin{array}{l}(\mathrm{n}=2) \\
\text { "I find that because the entrenched leadership is mostly white men, } \\
\text { they want to groom another person who looks like them... And so, I } \\
\text { find a lot of the times they're, they're kind of progressing people who } \\
\text { look like them. And so, it's going to keep that one male-dominated } \\
\text { leadership style." (Sarah) }\end{array}$ \\
\hline Recommendation & Evidence \\
\hline $\begin{array}{l}\text { Improve human resource } \\
\text { policies to be more inclusive } \\
\text { - Zero-tolerance for } \\
\text { sexual harassment }\end{array}$ & $\begin{array}{l}\text { (n=1) } \\
\text { "A harassment policy... [my company] always just went off of } \\
\text { Canadian you know gender equality in the workforce kind of thing and } \\
\text { [my company] now has one [a harassment policy] specifically in place } \\
\text { to add to that Canadian policy and add protections, and I think that was } \\
\text { an important step." (Harper) }\end{array}$ \\
\hline $\begin{array}{l}\text { Spread awareness of the energy } \\
\text { sector and its wide range of } \\
\text { jobs }\end{array}$ & $\begin{array}{l}(\mathrm{n}=2) \\
\text { "But I think there's a number of things that we could be doing to get } \\
\text { more females in the sector. One is just to really highlight the roles that } \\
\text { women can play, rather than trying to convince women to do } \\
\text { something that they don't really want to do (like maybe the physical } \\
\text { labour part of it), there's a lot of things like women can do like own } \\
\text { their own business ... they can do the HR, the payroll, and all the } \\
\text { advertising, and like essentially running their own business. So I think } \\
\text { we need to do more of that to highlight women that are already doing } \\
\text { that and also show them that this is this is a career this is a job for } \\
\text { you." (Anna) }\end{array}$ \\
\hline
\end{tabular}

This primary research therefore reiterated many of the conclusions of previous research discussed in the literature review (3.2). While not all barriers and recommendations discussed in the literature were brought up by participants, the majority were. These barriers and recommendations stemming from the responses of participants are listed below. They are listed according to how frequently each was suggested by participants. 


\section{Barriers:}

1. A lack of flexibility and accommodation in the workplace

2. Limited support and role models for women in the energy sector

3. Cultural and social norms

4. Low levels of confidence

5. Insufficient and/or improper backgrounds/education (perceived or real)

6. Unfair practices

\section{Recommendations:}

1. Increase flexibility and accommodation in the workplace

2. Encourage mentorship and sponsorship programs and highlight women in the energy sector

3. Initiate a cultural shift

4. Change recruitment and promotion practices

5. Spread awareness of the energy sector and its wide range of jobs

6. Promote women in STEM

7. Improve human resource policies

Actors across government bodies, advocacy groups, and energy sector firms will play a role in implementing these recommendations. For example, all three of these groups could play a role in implementing the first recommendation: increasing flexibility and accommodations in the workplace. At the government level, federal and/or municipal legislation could be altered to encourage shared parental leave. Though the Canadian Federal Government currently allows parents to share parental leave, it is not mandatory. ${ }^{33}$ However, as of 2019, sharing parental leave to care for a child means that parents can claim benefits for an extra five weeks under standard benefits (Government of Canada, 2019). While this is definitely a step in the right direction, further support would bolster the benefits of this change.

Advocacy groups could also play a role in increasing flexibility in the workplace. For example, a group could do further research into the flexibility-related barriers that women in the

\footnotetext{
${ }^{33}$ Research done in response to Norway's 2018 change to its parental leave legislation indicates that giving men nontransferable paternal leave (meaning they cannot transfer the time to their partner) can significantly increase the percent of men taking parental leave. In fact, now $90 \%$ of men take parental leave to care for their children (Apolitical, 2018).
} 
workforce face and use that information to pressure the government and/or companies to change. Lastly, companies within the energy sector have a crucial role to play in increasing the level of flexibility and accommodation in the workplace. Changes at the company-level could take the form of new human resource policies which support people of all gender identities in taking time off to care for children or aging parents. Companies could also work to create a culture in which work-life balance is encouraged.

\subsection{Chapter Five Conclusion}

Chapter Five has provided further insights into the two research questions guiding this research. Building on the literature review in section 3.1, section 5.1 explored the primary research question of this thesis and provided evidence which supports literature suggesting that women leaders tend to have the attributes key to sustainability leadership. This suggests that women are sustainable energy transition leaders and promoting women's leadership in energy sector firms will serve to facilitate Canada's sustainable energy transition. Section 5.2 scrutinized the secondary research question and built on existing research through exploring participants' descriptions of the barriers that women and women leaders face as well as their recommendations for improving the situation. Findings once again supported much of the existing literature.

The following chapter will review these finding once more and explore the implications of these findings. Chapter Six will also return to the discussion of how gender can be situated within sociotechnical transitions which was started in section 4.2. Lastly, the final chapter of this thesis

will provide a discussion of future avenues for research which were uncovered in the course of performing this primary and secondary research. 


\section{Chapter Six: Conclusion and Implications of Findings}

Addressing Canada's contemporary crisis of sustainability will require widespread and systematic change, particularly in energy sector firms. This research demonstrated how women leaders may be well-suited to guide this change and usher in a new era of sustainability. Building on a small amount of existing literature which suggests that women are sustainability leaders (Campbell et al., 2018; Marshall, 2011), this thesis combined primary and secondary research in order to respond to the following main research question: will promoting women's leadership in energy sector firms serve to facilitate Canada's sustainable energy transition?

Based on a review of existing literature, eight leadership attributes were identified as being crucial for sustainability leadership. These eight leadership attributes are: collaboration, innovation, transformational leadership, ethical and transparent leadership, environmental management, long-term orientation, inclusive leadership, and the ability to manage complexity. To see if women leaders tend to demonstrate these sustainability leadership attributes to a greater extent than men, literature on women's leadership was then scrutinized. Though the amount of research varies between leadership attributes, this literature review tied all sustainability leadership attributes to women's leadership. For example, research suggests that having a long-term orientation is key to sustainability leadership (Campbell et al, 2018; Sørensen \& Handcock, 2020; Visser \& Courtice, 2011) and that women leaders tend to prioritize longer-term rewards (Adams \& Ferreira, 2009) and value future costs and benefits more than men (Coller \& Williams, 1999; Kirby \& Marakovic, 1996).

These conclusions from secondary research led to the creation of framework by which to further explore these issues. Since existing research on the role that gender plays in shaping leadership attributes is dominated by dated studies and/or research not specific to Canada and/or 
the energy sector, primary research in the form of interviews was undertaken. This research complements the existing literature, which is dominated by large-scale quantitative studies, by providing in-depth qualitative and Canada-specific insights. Ultimately, results from analysis of these interviews supported the conclusions of previous studies, suggesting that women leaders perform gender in way that more effectively addresses sustainability problems. Through thematic analysis using NVivo, seven of the eight sustainability leadership attributes identified in the literature review were tied to women's leadership in participant responses. Strong evidence linking women leaders in Canadian energy sector firms to collaborative leadership, innovative leadership, and inclusive leadership was found. Medium-strength evidence was found linking these women's leadership with transformational leadership, having a long-term orientation, and the ability to manage complexity. Lastly, this research provided only weak evidence linking women leaders in Canadian energy sector firms to ethical and transparent leadership. No evidence was found regarding how gender may influence the eighth and final leadership attribute, environmental management. These findings suggest that the answer to my primary research question is yes, promoting women's leadership in Canadian energy sector firms will serve to facilitate Canada's sustainable energy transition.

However, regardless of women leaders' ability to usher in this transition, the fact is that women are currently vastly underrepresented in leadership positions in Canadian energy sector firms. Thus, though the primary research question asked why women's leadership is important, this thesis also explored a secondary research question: how can this current scenario be changed? In other words, what barriers do women leaders in Canadian energy sector firms face and how can they be overcome? 
This thesis approached this secondary research question in much the same manner as the primary question, first exploring existing research and then expanding on this secondary research with primary research. Chapter Three (3.2) reviewed literature on the barriers that women in the energy sector face and how these barriers can be overcome. Interviews with men and women leaders in the sector were then used to verify and expand on these findings. For example, both previous research and the primary research conducted for this thesis concluded that the lack of mentorship and sponsorship opportunities for women in the sector poses a barrier for women and women's leadership in Canadian energy sector firms (Catalyst, 2020; IRENA, 2019, p. 12; MacDougall et al., 2020). Other barriers mentioned frequently by participants and echoed by previous research include a lack of flexibility and accommodation in the workplace, cultural and social norms, and low levels of confidence among women. The top recommendations put forward by participants in order to overcome these barriers are to increase the level of flexibility and accommodation in the workplace, encourage mentorship and sponsorship programs, highlight women in the energy sector, and to initiate a cultural shift. With a greater awareness of these barriers and action regarding these recommendations, this research can help facilitate women's advancement in Canadian energy sector firms, ultimately serving to also facilitate a national sustainable energy transition.

This thesis therefore provides both a reason why women's leadership should be supported in the sector and a roadmap for how this can be achieved. However, the research and analysis presented above primarily focuses on the micro level: how gender influences leadership at individual companies in Canada. In concluding this thesis, it is worth returning to the broader discussion of how these gendered influences impact sociotechnical transitions, a discussion which was started in Chapter Four. Figure 6 in Chapter Four provided a visual representation of how 
women leaders can impact Canada's sociotechnical energy transition. The model presented suggests that the sustainability crisis that Canada is facing could serve as a shock to trigger change in Canada's energy system. ${ }^{34}$ According to the Multi-Level Perspective (MLP), the model of sociotechnical change this thesis has adopted, a shock is one means by which a sociotechnical transition can be initiated. Thus, Canada's sustainability crisis could serve to trigger a sociotechnical sustainable energy transition.

The adapted MLP model displayed in Figure 6 explains this transition as follows. The sustainability crisis is putting pressure on the existing dominant energy system (the regime) characterized by male leadership and a lack of sustainability, destabilizing it. Women leaders (niche actors) can capitalize upon this instability and promote a sociotechnical transition to a more sustainable energy system using their innovations (sustainability leadership attributes). In this way, through promoting women's leadership in Canadian energy sector firms, sustainability and a sustainable energy transition can be facilitated. The theoretical foundations of this model stem from not only the MLP, but also from research suggesting that since women are external to the dominant energy system, they may be more willing to challenge the status quo and facilitate transition (Halpern, 2019; Lieu et al., 2020; Marshall, 2011). The adapted MLP framework represented in Figure 6 therefore provides a novel representation of how Canada's sustainable energy transition can be facilitated.

The focus of the MLP model and this research was therefore on sociotechnical transitions themselves, rather than their results. Thus, the model described above says nothing of what the resulting energy system will look like. As a result, the conclusions of this model and the primary research that I conducted in this thesis in order to further explore it were conclusions surrounding

\footnotetext{
${ }^{34}$ As discussed in section 1.2, Canada's sustainability crisis includes the effects of climate change, land and water consumption and pollution, a deterioration of habitats, and wildlife morbidity and mortality.
} 
how this sociotechnical sustainable energy transition can occur and be facilitated. While this adapted MLP model does indicate that the resulting energy system will be more sustainable and will include a greater representation of women leaders, other characteristics of the post-transition energy system remain unclear. Since facilitating the sustainable energy transition itself was the focus of this research, the model of the MLP worked well. However, in concluding this thesis it is worth discussing what the energy system resulting from the transition described above and in Figure 6 would look like.

A key takeaway from the literature discussed in Chapter Four was that energy transition does not just change the technologies we use to produce and consume energy; rather, energy transitions can be harbingers for a new era in global human history (Miller et al., 2013, p. 146). Thus, a sustainable energy transition will lead to new livelihoods, new building designs, new methods of manufacturing, new policies, and will change economic and social structures across Canada and the world. At this time, it is impossible to say what exact characteristics an energy system produced by a women's-leadership-induced sustainable energy transition would have, but I believe that there is reason for optimism.

First off, it is important to note that while transitioning towards a more sustainable energy system is crucial to address contemporary sustainability problems like climate change and having more women in leadership positions is more likely to bring about this transition, it may not lead to a more inclusive or just energy system beyond increasing gender equality (e.g., it may not change racial issues or income inequality concerns). Rather, even though the sociotechnical energy transition discussed will change a variety of socio-economic and technical processes and ways of life, it will not necessarily address the structural power dynamics embedded within the system. Instead, existing power asymmetries and the inequality embedded in our energy system may 
"simply be replicated and transferred over into [the] new energy [system]" (Johnson et al., 2020, p. 1). If this happens, social issues in the energy sector such as poverty and social vulnerability, widening inequalities, poor working conditions, unemployment, and financial volatility will not be changed by the energy transition (Savaget et al., 2019, p. 879). Thus, other systemic power asymmetries may remain, to the detriment of energy justice and energy democracy. ${ }^{35}$

However, there is reason to believe that women's leadership in the energy sector will not only help facilitate a transition to a more sustainable energy system, but also will help ensure that the resulting energy system is more equitable. For example, research by Allen and colleagues (2019) found that women leaders are more likely to promote a conception of energy transition that advocates for energy justice and energy democracy. Connections can also be drawn to previously discussed literature, such as research demonstrating that women leaders tend to be more inclusive leaders. This means that women leaders often are more concerned with their employees' working conditions, creating a welcoming environment, and providing benefits to the local communities where the given company operates, all of which are key to creating a more equitable energy system as well as a more sustainable one (McElhaney \& Mobasseri, 2012, p. 4). This means that is likely that the energy system resulting from the sociotechnical energy transition described in this thesis will work to reduce power asymmetries and promote energy justice and democracy, though to what extent remains unknown.

The epigraph at the beginning of Chapter One of this thesis signalled the theme of this research. To reiterate: "in the haste to save the planet it seems tempting to avoid gendered wars

\footnotetext{
${ }^{35}$ Energy justice and energy democracy are concepts becoming increasingly popular in several factions of society and scholarship, particularly grassroots organizations and their supporters. The concepts are focused on "connect[ing] energy infrastructural change with the possibilities for deep political, economic and social change" (Burke \& Stephens, 2017, p. 35). In short, both have the goal of creating equitable participation in the energy system, affordable and equal access to energy, and remediating the harms inflicted by the dominant energy system which have, historically, disproportionately impacted marginalized communities (Allen et al., 2019, p. 2).
} 
and potential misunderstandings. We do not have the time. But perhaps we have no other option" (Marshall, 2011, p. 279). This quote points to an important conclusion of this thesis. Though sustainability problems stemming from Canada's energy sector abound and both governmental and non-governmental actors are rushing to act, it is worth taking a step back and considering all resources available. Gender issues may initially appear frivolous next to the stories of impending doom dominating the media, something to be dealt with later, after the crisis is averted. However, upon closer inspection, it becomes clear that this is not the case. Instead, this research demonstrated that gender matters, and women leaders could be the sustainable energy transition leaders that Canada needs to address its contemporary sustainability crisis. Thus, rather than being a frivolous concern to be dealt with later, gender issues should be at the very heart of Canada's efforts to address its sustainability crisis.

\subsection{Avenues for Future Research}

This thesis sought to fill a gap in the literature on sociotechnical transitions through considering the role that gender plays in leading Canada's sustainable energy transition. However, this research also uncovered many gaps in the existing literature that it was unable to fill. Many of these were mentioned throughout previous chapters, such as the dearth of gender-disaggregated data mentioned in Chapter Three. In short, since it is currently not clear how many women are employed in the Canadian energy sector and what roles they have, it is difficult to determine a baseline and advocate for change. Research on this topic could therefore play a key role in triggering action on the issue of gender inequality in the energy sector.

Another topic which requires further research is the exact nature of the connection between women's leadership and collaborative leadership in Canadian energy sector firms. While the analysis presented in Chapter Five did uncover a connection, it also revealed a discrepancy between revealed and stated leadership attributes. In other words, while scenarios (revealed 
leadership attributes) uncovered no difference between men and women leaders' level of collaboration, direct questioning (stated leadership attributes) did, finding that women are more collaborative than their male counterparts. While I was able to justify this discrepancy through assuming that men's responses to scenarios may not be reflective of how they would act in real life, more research is needed to further explore this issue.

Lastly, the analysis in Chapter Five uncovered only a weak link between women's leadership and ethical and transparent leadership in Canadian energy sector firms. This theme was only identified in scenario questioning and not direct questioning and was identified in the responses of only a slightly higher percentage of women participants than men participants. Thus, though this research suggests that women in Canadian energy sector firms may be more ethical and transparent leaders, additional research is needed to further bolster these findings.

Beyond these three gaps which were uncovered over the course of this research, another important topic which requires further research is the role of intersectionality and individuals with other marginalized identities in Canada's energy transition. In order to maintain focus and keep this thesis manageable, this research focused only on women and men. This ignores the multitude of other factors that impact a person's identity and leadership attributes, such as race, age, socioeconomic status, or background. It also ignores other gender identities and the role that they can play in Canada's energy transition. While it was important to focus this research, this is a notable gap in existing literature that this thesis did not address. However, the conclusions of this thesis do suggest that filling this gap may be important. This is because this research presented women as playing a unique and beneficial role in Canada's energy transition due in large part to the fact that they are currently a minority and marginalized in Canada's private energy sector. This implies that individuals who are even more external to the regime may have even more 
contributions. For example, a leader who is a middle-aged white woman who grew up and was educated in Canada may have a different impact on Canada's sustainable energy transition than, for example, a recent immigrant who is a person of colour and in their early twenties. Future research should further explore the exact nature of how these different identities affect individuals' roles in sociotechnical transitions. 


\section{References}

Adams, R. B., \& Ferreira, D. (2009). Women in the boardroom and their impact on governance and performance. Journal of Financial Economics, 94(2): 291-309. https://doi.org/10.1016/j.jfineco.2008.10.007

Adams, R.B., \& Funk, P. (2012). Beyond the Glass Ceiling: Does Gender Matter? Management Science, 58(2), 219-235. https://doi.org/10.1287/mnsc.1110.1452

Aĭkhenval'd, A. (2016). How gender shapes the world (First edition.). Oxford University Press.

Airswift \& Energy Jobline. (2019). The global energy talent index report. Global Energy Talent Index (GETI). https://www.getireport.com/reports/2019/

Albaum, G., \& Peterson, R. (2006). Ethical Attitudes of Future Business Leaders: Do They Vary by Gender and Religiosity? Business \& Society, 45(3), 300-321. https://doi.org/10.1177/0007650306289388

Ali, B. (2018). Forecasting model for water-energy nexus in Alberta, Canada. WaterEnergy Nexus, 1(2), 104-115. https://doi.org/10.1016/j.wen.2018.08.002

Allen, E., Lyons, H., \& Stephens, J. C. (2019). Women's leadership in renewable transformation, energy justice and energy democracy: Redistributing power. Energy Research \& Social Science, 57, 101233-. https://doi.org/10.1016/j.erss.2019.101233

Alston, M., \& Whittenbury, K. (2013). Research, Action and Policy: Addressing the Gendered Impacts of Climate Change (1st ed. 2013.). Springer Netherlands. https://doi.org/10.1007/978-94-007-5518-5

Amnesty International. (2016). Out of sight, out of mind: Gender, Indigenous rights, and energy development in northeast British Columbia, Canada. https://www.amnesty.ca/outofsight

Andersen, A. J., \& Hansson, P. H. (2011). At the end of the road? On differences between women and men in leadership behaviour. Leadership \& Organization Development Journal, 32(5), 428-441. https://doi.org/10.1108/01437731111146550

Antonakis, J., Cianciolo, A., \& Sternberg, R. (2004). The nature of leadership. Thousand Oaks, CA: Sage Publications.

Apolitical. (2018). Norway's "daddy quota" means 90\% of fathers take parental leave. https://apolitical.co/solution-articles/en/norways-daddy-quota-means-90-of-fathers-take-parentalleave

Arbogast, G., \& Thornton, B. (2010). A global corporate sustainability model. Journal of Sustainability and Green Business. https://www.aabri.com/manuscripts/10732.pdf

Arthrell, E., Lawrence, C., Calamai, J. B., \& Morris, A. (2019). The design of everyday men. Deloitte. https://www2.deloitte.com/content/dam/insights/us/articles/ca1671_design-ofeveryday-men/DI_The-design-of-everyday-men.pdf 
Baruah, B., \& Biskupski-Mujanovic, S. (2018). Identifying promising policies and practices for promoting gender equity in global green employment. Clean economy working paper series.

https://institute.smartprosperity.ca/sites/default/files/baruahfinalgloballandscapegenderandgreene conomyreport-kss.pdf

Baruah, B., \& Gaudet, C. (2018). Creating and Optimizing Employment Opportunities for Women in the Clean Energy Sector in Canada. Clean economy working paper series. https://institute.smartprosperity.ca/sites/default/files/baruahksgfinalreportmay2018-kss.pdf

Bass, B., \& Avolio, B. (1994). Shatter the glass ceiling: Women may make better managers. Human Resource Management, 33(4), 549-560. https://doi.org/10.1002/hrm.3930330405

Bear, S., Rahman, N., \& Post, C. (2010). The impact of board diversity and gender composition on corporate social responsibility and firm reputation. Journal of Business Ethics, 97(2), 207-221. https://doi.org/10.1007/s10551-010-0505-2

Beauvoir, S. (1973). The second sex. New York: Vintage Books.

Becker, S. O., Fernandes, A., \& Weichselbaumer, D. (2019). Discrimination in hiring based on potential and realized fertility: Evidence from a large-scale field experiment. Labour Economics, 59, 139-152. https://doi.org/10.1016/j.labeco.2019.04.009

Bell, S., Daggett, C., \& Labuski, C. (2020). Toward feminist energy systems: Why adding women and solar panels is not enough. Energy Research \& Social Science, 68, 101557-. https://doi.org/10.1016/j.erss.2020.101557

Benko, C., \& Pelster, B. (2013). How women decide. Harvard Business Review. https://hbr.org/2013/09/how-women-decide

Besley, T., Folke, O., Persson, T., \& Rickne, J. (2017). Gender quotas and the crisis of the mediocre man: Theory and evidence from Sweden. The American Economic Review, 107(8), 2204-2242. https://doi.org/10.1257/aer.20160080

Biswas, D. (2016). Book review: Competition law and the European Union. Christ University Law Journal, 5(1), 99-103.

https://proxy.library.carleton.ca/login?url=https:/www.proquest.com/scholarly-journals/bookreview-competition-law-european-union/docview/2501457296/se-2?accountid=9894

Bolwig, S., Bolkesjø, T., Klitkou, A., Lund, P., Bergaentzlé, C., Borch, K., Olsen, O., Kirkerud, J., Chen, Y., Gunkel, P., \& Skytte, K. (2020). Climate-friendly but socially rejected energy-transition pathways: The integration of techno-economic and socio-technical approaches in the Nordic-Baltic region. Energy Research \& Social Science, 67, 101559-. https://doi.org/10.1016/j.erss.2020.101559

Bord, R., \& O'Connor, R. (1997). The gender gap in environmental attitudes: The case of perceived vulnerability to risk. Social Science Quarterly, 78(4), 830-840.

Borkowski, S., \& Ugras, Y. (1998). Business students and ethics: A meta-analysis. Journal of Business Ethics, 17(11), 1117-1127. https://doi.org/10.1023/A:1005748725174 
Boulouta, I. (2013). Hidden connections: the link between board gender diversity and corporate social performance. Journal of Business Ethics, 113(2), 185-197.

https://doi.org/10.1007/s10551-012-1293-7

Boyd, A., Nobelius, A., \& Stands, S. (2019). Women for sustainable energy: Strategies to foster women's talent for transformational change. Global Women's Network for the Energy Transition. https://www.globalwomennet.org/wp-content/uploads/2020/02/Gwnet-study.pdf

Brammer, S., Millington, A., \& Pavelin, S. (2007). Gender and ethnic diversity among UK corporate boards. Corporate Governance : An International Review, 15(2), 393-403. https://doi.org/10.1111/j.1467-8683.2007.00569.x

Brander, M. (2012). Greenhouse gases, CO2, CO2e, and carbon: What do all these terms mean? Ecometrica. https://ecometrica.com/assets/GHGs-CO2-CO2e-and-Carbon-What-DoThese-Mean-v2.1.pdf

Bridle, R., Sharma, S., Mostafa, M., \& Geddes, A. (2019). Fossil fuel to clean energy subsidy swaps: How to pay for an energy revolution. International Institute for Sustainable Development. https://www.iisd.org/library/fossil-fuel-clean-energy-subsidy-swap

Brown, D. A. H., Brown, D. L., \& Anastasopoulos V. (2002). Women on boards: not just the right thing . . . but the "bright" thing. Conference Board of Canada. https://utsc.utoronto.ca/ phanira/WebResearchMethods/women-bod\&fpconference $\% 20$ board.pdf

Brunell, A. B., Gentry, W. A., Campbell, W. K., Hoffman, B. J., Kuhnert, K. W., \& DeMarree, K. G. (2008). Leader Emergence: The Case of the Narcissistic Leader. Personality \& Social Psychology Bulletin, 34(12), 1663-1676. https://doi.org/10.1177/0146167208324101

Burke, M. J., \& Stephens, J. C. (2017). Energy democracy: Goals and policy instruments for sociotechnical transitions. Energy Research \& Social Science, 33, 35-48. https://doi.org/10.1016/j.erss.2017.09.024

Burton, B., \& Hegarty, W. (1999). Some determinants of student corporate social responsibility orientation. Business \& Society, 38(2), 188-205. https://doi.org/10.1177/000765039903800204

Butler, J. (1988). Performative acts and gender constitution: An essay in phenomenology and feminist theory. Theatre Journal, 40(4), 519-531. https://doi.org/10.2307/3207893

Campbell, G., Dienel, E., Deleuze, M. G., Klintworth, G., Learned, A., Oh, G., \& Oppenheim, J. (2018). Better leadership, better world: Women leading for the global goals. Business and Sustainable Development Commission. https://sdghub.com/project/betterleadership-better-world-women-leading-for-the-global-goals/

Campbell, W. K., \& Crist, C. (2020). How narcissism and leadership go hand-in-hand. Psychology Today. https://www.psychologytoday.com/ca/blog/new-sciencenarcissism/202010/how-narcissism-and-leadership-go-hand-in-hand

Canada Energy Regulator. (2019). Market Snapshot: Wind turbines in Canada have increased in both size and production capacity. Government of Canada. https://www.cer- 
rec.gc.ca/en/data-analysis/energy-markets/market-snapshots/2019/market-snapshot-windturbines-in-canada-have-increased-in-both-size-production -capacity.html

Canada Energy Regulator. (2020a). Provincial and Territorial energy profiles - Canada. Government of Canada. https://www.cer-rec.gc.ca/en/data-analysis/energy-markets/provincialterritorial-energy-profiles/provincial-territorial-energy-profiles-canada.html

Canada Energy Regulator. (2020b). Canada's energy future 2020. Government of Canada. https://www.cer-rec.gc.ca/en/data-analysis/canada-energy-future/2020/index.html

Canada Energy Regulator. (2020c). Canada's energy transition: Historical and future changes to energy systems - update - an energy market assessment. Government of Canada. https://www.cer-rec.gc.ca/en/data-analysis/energy-markets/canadas-energy-transition/canadasenergy-transition-historical-future-changes-energy-systems-update-energy-market-assessmentintroduction.html

Canada Energy Regulator. (2020d). Canada's energy transition: Historical and future changes to energy systems. Government of Canada. https://www.cer-rec.gc.ca/en/dataanalysis/energy-markets/canadas-energy-transition/canadas-energy-transition-historical-futurechanges-energy-systems-update-energy-market-assessment-future-pathways.html

Carter, N., \& Wagner, H. (2011). The bottom line: corporate performance and women's representation on boards (2004-2008). Catalyst. https://www.catalyst.org/research/the-bottomline-corporate-performance-and-womens-representation-on-boards-2004-2008/

Catalyst. (2019). Quick take: Women in energy - gas, mining, and oil. https://www.catalyst.org/research/women-in-energy-gas-mining-oil/

Catalyst. (2020). Women in male-dominated industries and occupations (quick take). https://www.catalyst.org/research/women-in-male-dominated-industries-and-occupations/

Chamorro-Premuzic, T., \& Gallop, C. (2020). 7 leadership lessons men can learn from women. Harvard Business Review. https://hbr.org/2020/04/7-leadership-lessons-men-can-learnfrom-women

Chan, D. (2021). Benevolent Sexism: How Well-Meaning Stereotypes Hurt Women in the Workplace. Orange Grove Consulting. https://orangegroveconsulting.com/benevolent-sexismhow-well-meaning-stereotypes-hurt-women-in-the-workplace/

Chen, G., Crossland, C., \& Huang, S. (2016). Female board representation and corporate acquisition intensity: female board representation and M\&A. Strategic Management Journal, 37(2), 303-313. https://doi.org/10.1002/smj.2323

Chen, J. (2021). Environmental, Social, and Governance (ESG) criteria. Investopedia. https://www.investopedia.com/terms/e/environmental-social-and-governance-esg-criteria.asp

Cherry, K. (2020). A closer look at the effects of transformational leadership. Very Well Mind. https://www.verywellmind.com/what-is-transformational-leadership-2795313

Cision. (2021). Equal by 30 survey reveals women under-represented in global energy sector. https://www.newswire.ca/news-releases/equal-by-30-survey-reveals-women-underrepresented-in-global-energy-sector-860417728.html 
Clean Energy, Education, and Empowerment (C3E) initiative. (2019). Status report on gender equality in the energy sector.

https://www.cleanenergyministerial.org/sites/default/files/2019-

06/Status\%20Report\%20on\%20Gender\%20Equality\%20in\%20the\%20Energy\%20Sector_0.pdf

CleanBC. (2021). Energy conservation assistance program.

https://betterhomesbc.ca/rebates/free-upgrades-bc-hydro-fortisbc-energy-conservationassistance-program/

Climate Action Network. (2013). Climate change adaptation and the role of the private sector. https://europa.eu/capacity4dev/file/14313/download?token=1waP-

Q5z\&usg=AOvVaw1Mw90jEupF2bCAieJRr2pB

Coller, M., \& Williams, M. (1999). Eliciting individual discount rates. Experimental Economics : A Journal of the Economic Science Association, 2(2), 107-127.

https://doi.org/10.1007/BF01673482

Corbley, A. (2021). World's largest wind turbine manufacturer says all its blades will soon be fully recycled. Good News Network. https://www.goodnewsnetwork.org/vestas-announcesfully-recyclable-wind-turbine-blades/

Corkal, V., Levin, J, \& Gass, P. (2020). Canada's federal fossil fuel subsidies in 2020. International Institute for Sustainable Development.

https://www.iisd.org/system/files/publications/canada-fossil-fuel-subsidies-2020-en.pdf

Crutchfield, A., \& Asghar, K. (2020). Canada's energy investors are embracing ESG. It's time for industry to respond accordingly. PricewaterhouseCoopers.

https://www.pwc.com/ca/en/industries/energy/environmental-social-governance.html

Davenport, T. H. (2001). Knowledge work and the future of management. In W. G. Bennis G. M. Spreitzer \& T. G. Cummings (Eds.), The future of leadership: Today's top leadership thinkers speak to tomorrow's leaders (pp. 41-58). 2001 San Francisco: Jossey-Bass.

Deloitte. (2011). Leadership: Do men and women do it differently? Deloitte point of view. https://www2.deloitte.com/content/dam/Deloitte/au/Documents/human-capital/deloitte-au-hcleadership-men-women-differently-130516.pdf

Deloitte. (2019). Leading the social enterprise: Reinvent with a human focus. 2019 Deloitte Global Human Capital Trends. https://www2.deloitte.com/content/dam/insights/us/articles/5136_HC-Trends-2019/DI_HCTrends-2019.pdf

Devillard., S., Bonin, G., Madgavkar, A., Krishnan, M., Pan, T., Zhang, H., \& Ng, M. (2019). The present and future of women at work in Canada. McKinsey and Company. https://www.mckinsey.com/ /media/mckinsey/featured\%20insights/gender\%20equality/the $\% 20$ present $\% 20$ and $\% 20$ future $\% 20$ of $\% 20$ women $\% 20$ at $\% 20$ work $\% 20$ in $\% 20$ canada/the-present-andfuture-of-women-at-work-in-canada-vf.ashx

Dezsö C.L., \& Ross, D.G. (2012). Does female representation in top management improve firm performance? A panel data investigation. Strategic Management Journal, 33(9): 10721089. https://doi.org/10.1002/smj.1955 
Dorber, M., May, R., \& Verones, F. (2018). Modeling Net Land Occupation of Hydropower Reservoirs in Norway for Use in Life Cycle Assessment. Environmental Science \& Technology, 52(4), 2375-2384. https://doi.org/10.1021/acs.est.7b05125

Dutta, S., Kooijman, A., \& Cecelski, E. (2017). Energy access and gender: Getting the right balance. The World Bank.

http://documents.worldbank.org/curated/en/463071494925985630/pdf/115066-BRI-P148200PUBLICFINALSEARSFGenderweb.pdf

Eagly, A. H., \& Carli, L. L. (2003). The female leadership advantage: An evaluation of the evidence. The Leadership Quarterly, 14(6), 807-834.

Eagly, A., Johannesen-Schmidt, M., \& Van Engen, M. (2003). Transformational, Transactional, and Laissez-Faire Leadership Styles: A Meta-Analysis Comparing Women and Men. Psychological Bulletin, 129(4), 569-591. https://doi.org/10.1037/0033-2909.129.4.569

Editors of Salem Press (Eds.). (2011). Sociology reference guide: Gender roles and equality. Salem Press.

Eisler, D. (2016). Energy Literacy in Canada: A summary. The School of Public Policy Publications (SPPP), 9(1), 1-25. https://doi.org/10.11575/sppp.v9i0.42561

Electricity Human Resources Canada. (2017). Profile of women working in the clean energy sector in Canada. https://electricityhr.ca/resources/women-in-clean-energy/

Environmental Defence. (2013). Reality check: Water and the tar sands. https://environmentaldefence.ca/report/report-reality-check-water-and-the-tar-sands/

Equal by 30. (2021). Reporting framework. https://www.equalby30.org/sites/default/files/pictures/equalby30/pdf/the_equal_by_30_reporting framework.pdf

Ercetin, S. (2016). Women leaders in chaotic environments : examinations of leadership using complexity theory (1st ed. 2016.). Springer. https://doi.org/10.1007/978-3-319-44758-2

Eschner, K. (2019). Canada: extreme floods show climate threat as experts warn of further tumult. The Guardian. https://www.theguardian.com/world/2019/apr/30/canada-floodingquebec-montreal-justin-trudeau-climate-change

Exxonmobil. (2021). Landing page. Retrieved May 21, 2021, from https://corporate.exxonmobil.com/

Felter, C., \& Robinson, K. (2021). Water stress: A global problem that's getting worse. Council on Foreign Relations. https://www.cfr.org/backgrounder/water-stress-global-problemthats-gettingworse\#: :text $=$ Water $\% 20$ scarcity $\% 20$ threatens $\% 20$ the $\% 20$ health $\% 20$ and $\% 20$ development $\% 20$ o f $\% 20$ communities $\% 20$ around $\% 20$ the $\% 20$ globe.\&text $=$ Climate $\% 20$ change $\% 20$ will $\% 201$ ikely $\% 2$ 0exacerbate,events $\% 2 \mathrm{C} \% 20$ including\%20floods\%20and $\% 20$ droughts.

Fernandez-Feijoo, B., Romero, S., \& Ruiz-Blanco, S. (2014). Women on boards: Do they affect sustainability reporting? Corporate Social-Responsibility and Environmental Management, 21(6), 351-364. https://doi.org/10.1002/csr.1329 
Fiske, S. T. (2012). Managing ambivalent prejudices: The smart-but-cold, and the warmbut dumb stereotypes. The Annals of the American Academy of Political and Social Science, 639(1), 33-48. https://doi.org/10.1177/0002716211418444

Fluker, S. (2019). Energy development wins when it's pitted against endangered species. The Conversation. https://theconversation.com/energy-development-wins-when-its-pittedagainst-endangered-species-117961

Folk, E. (2019). How the energy industry contributes to water pollution. Renewable Energy Magazine. https://www.renewableenergymagazine.com/emily-folk/how-the-energy-industrycontributes-to-water-20191213

Forte, A. (2004). Antecedents of managers moral reasoning. Journal of Business Ethics, 51(4), 315-347. https://doi.org/10.1023/B:BUSI.0000032501.59580.33

Frank, K. (2019). A gender analysis of the occupational pathways of STEM graduates in Canada. Statistics Canada. https://www150.statcan.gc.ca/n1/pub/11f0019m/11f0019m2019017eng.htm

Franke, G., Crown, D., \& Spake, D. (1997). Gender differences in ethical perceptions of business practices: A social role theory perspective. Journal of Applied Psychology, 82(6), 920934. https://doi.org/10.1037/0021-9010.82.6.920

Frias-Aceituno, J., Rodriguez-Ariza, L., \& Garcia-Sanchez, I. (2013). The role of the board in the dissemination of integrated corporate social reporting. Corporate Social-Responsibility and Environmental Management, 20(4), 219-233. https://doi.org/10.1002/csr.1294

Furst, S., \& Reeves, M. (2008). Queens of the hill: Creative destruction and the emergence of executive leadership of women. The Leadership Quarterly, 19(3), 372-384. https://doi.org/10.1016/j.leaqua.2008.03.001

Garikipati, S., \& Kambhampati, U. (2021). Leading the Fight Against the Pandemic: Does Gender Really Matter? Feminist Economics, 27(1-2), 401-418.

https://doi.org/10.1080/13545701.2021.1874614

Geels, F. W., \& Schot, J. (2007). Typology of sociotechnical transition pathways. Research Policy, 36(3), 399-417. https://doi.org/10.1016/j.respol.2007.01.003

Geels, F. W. (2019). Socio-technical transitions to sustainability: a review of criticisms and elaborations of the Multi-Level Perspective. Current Opinion in Environmental Sustainability, 39, 187-201. https://doi.org/10.1016/j.cosust.2019.06.009

Geels, F. W. (2005). The dynamics of transitions in socio-technical systems: A multilevel analysis of the transition pathway from horse-drawn carriages to automobiles (1860-1930). Technology Analysis \& Strategic Management, 17(4), 445-476.

https://doi.org/10.1080/09537320500357319

Geels, F. W., Sovacool, B. K., Schwanen, T., \& Sorrell, S. (2017). Sociotechnical transitions for deep decarbonization. Science (American Association for the Advancement of Science), 357(6357), 1242-1244. https://doi.org/10.1126/science.aao3760 
Geotab. (2021). Barriers to EV adoption. https:/www.geotab.com/white-paper/barriers-toev-adoption/

Gill, R. (2006). Theory and practice of leadership. Thousand Oaks, CA: Sage Publications.

Gilligan, C. (1982). In a different voice: Psychological theory and women's development. Harvard University Press.

Glass, C., Cook, A., \& Ingersoll, A. (2016). Do women leaders promote sustainability? Analyzing the effect of corporate governance composition on environmental performance. Business Strategy and the Environment, 25(7), 495-511. https://doi.org/10.1002/bse.1879

Global Women's Network for the Energy Transition. (2021). Landing page. Retrieved May 21, 2021, from https://www.globalwomennet.org/

Goodfellow, L., Hanania, J., Stenhouse, K., \& Donev, J. (2018). Water quality degradation from hydropower. Energy Education.

https://energyeducation.ca/encyclopedia/Water_quality_degradation_from_hydropower

Gould, K., \& Hosey, L. (2007). Women in green: Voices of sustainable design. BookBaby.

Government of Canada. (2017). Sources of air pollution.

https://www.canada.ca/en/environment-climate-change/services/air-pollution/sources.html

Government of Canada. (2019). More choice for parents.

https:/www.canada.ca/en/employment-social-development/campaigns/eiimprovements/parental-choice.html

Groot, J., Mohlakoana, N., Knox, A., \& Bressers, H. (2017). Fuelling women's empowerment? An exploration of the linkages between gender, entrepreneurship and access to energy in the informal food sector. Energy Research \& Social Science, 28, 86-97. https://doi.org/10.1016/j.erss.2017.04.004

Haipeng, Z., \& Xuxuan, X. (2012). Combining Stated Preference and Revealed Preference Methods for the Valuation of Non-market Goods. Chinese Journal of Population Resources and Environment, 10(4), 121-126. https://doi.org/10.1080/10042857.2012.10685119

Halpern, M. (2019). Feminist standpoint theory and science communication. Journal of Science Communication, 18(4). https://doi.org/10.22323/2.18040302

Hammer, M., \& Champy, J. (1994). Reengineering the corporation: A manifesto for business revolution. New York: Harper Business.

Harjoto, M., Laksmana, I., \& Lee, R. (2015). Board diversity and corporate social responsibility. Journal of Business Ethics, 132(4), 641-660. https://doi.org/10.1007/s10551-0142343-0

Harrison, J.S., \& Coombs, J.E. (2012). The moderating effects from corporate governance characteristics on the relationship between available slack and community-based firm performance. Journal of Business Ethics, 107(4), 409-422. https://doi.org/10.1007/s10551-0111046-z 
Harvey, F. (2021). Third of global food production at risk from climate crisis. The Guardian. https:/www.theguardian.com/environment/2021/may/14/third-of-global-foodproduction-at-risk-from-climate-crisis

Hawthorne, M. (2011). Industry resists newer technology that protects Great Lakes species. Chicago Tribune.

https://www.sej.org/sites/default/files/webform/AwardsWinners2012/PowerPlantsKillMillionsof LakeFish.pdf

Hennig, M., \& Jardim, A. (1977). The managerial woman (1st ed.). Anchor Press/Doubleday.

Hesselbein, F., Goldsmith, M., Beckhard, R. and Schubert, R.F. (Eds.). (1998). The community of the future. Jossey-Bass.

Hewlett, S.A., Marshall, M., \& Sherbin, L. (2013). How diversity can drive innovation. Harvard Business Review. https://hbr.org/2013/12/how-diversity-can-drive-innovation

Hirschorn, L. (1997). Reworking authority: leading and following in the post-modern organization. MIT Press.

Höpfl, H., \& Matilal, S. (2007). "The lady vanishes": some thoughts on women and leadership. Journal of Organizational Change Management, 20(2), 198-208. https://doi.org/10.1108/09534810710724757

Hopkins, M. M., \& O’Neil, D. A. (2015). Authentic leadership: application to women leaders. Frontiers in Psychology, 6, 959-959. https://doi.org/10.3389/fpsyg.2015.00959

Huang, J., \& Kisgen, D. (2013). Gender and corporate finance: Are male executives overconfident relative to female executives? Journal of Financial Economics, 108(3), 822-839. https://doi.org/10.1016/j.jfineco.2012.12.005

Huberty, M., \& Zysman, J. (2010). An energy system transformation: Framing research choices for the climate challenge. Research Policy, 39(8), 1027-1029. https://doi.org/10.1016/j.respol.2010.05.010

Huey, J. (1994). The new post-heroic leadership. Fortune, 129(4), 42-50.

Hull, B., Robertson, D., \& Mortimer, M. (2018). wicked leadership competencies for sustainability professionals: Definition, pedagogy, and assessment. Sustainability, 11(4), 171177. http://doi.org/10.1089/sus.2018.0008

Insurance Board of Canada. (2019). Eastern Canada Spring Flooding Caused Close to $\$ 208$ million in Insured Damage. http://www.ibc.ca/on/resources/media-centre/mediareleases/eastern-canada-spring-flooding-caused-close-to-208-million-in-insured-damage

International Energy Agency. (2016). Energy and air pollution. https://www.iea.org/reports/energy-and-air-pollution

International Energy Agency (IEA). (2020). World energy investment 2020. https://www.iea.org/reports/world-energy-investment-2020 
Intergovernmental Panel on Climate Change. (2018). Global warming of 1.5 $5^{\circ} \mathrm{C}$ : An IPCC special report on the impacts of global warming of $1.5^{\circ} \mathrm{C}$ above pre-industrial levels and related global greenhouse gas emission pathways, in the context of strengthening the global response to the threat of climate change, sustainable development, and efforts to eradicate poverty. https://www.ipcc.ch/sr15/

International Renewable Energy Agency. (2019). Renewable energy: A gender perspective. https://www.irena.org/publications/2019/Jan/Renewable-Energy-A-Gender-Perspective

International Renewable Energy Agency. (2020). Energy transition. https://www.irena.org/energytransition

Janis, I. L. (1972). Groupthink. Boston: Houghton-Mifflin.

Jensen, S. M., \& Luthans, F. (2006). Entrepreneurs as authentic leaders: impact on employees' attitudes. Leadership \& Organization Development Journal, 27(8), 646-666. https://doi.org/10.1108/01437730610709273

Joecks, J., Pull, K., \& Vetter, K. (2013). Gender diversity in the boardroom and firm performance: what exactly constitutes a "critical mass?". Journal of Business Ethics, 118 (1), 6172 .

Johnson, O., Gerber, V., \& Muhoza, C. (2019). Gender, culture and energy transitions in rural Africa. Energy Research \& Social Science, 49, 169-179. https://doi.org/10.1016/j.erss.2018.11.004

Johnson, O. W., Han, J. Y.-C., Knight, A.-L., Mortensen, S., Aung, M. T., Boyland, M., \& Resurrección, B. P. (2020). Intersectionality and energy transitions: A review of gender, social equity and low-carbon energy. Energy Research \& Social Science, 70, 101774-. https://doi.org/10.1016/j.erss.2020.101774

Johnstone, N., \& Silva, M. (2020). Gender diversity in energy: what we know and what we don't know. International Energy Agency. https://www.iea.org/commentaries/gender-diversityin-energy-what-we-know-and-what-we-dont-know

Jones, N. F., Pejchar, L., \& Kiesecker, J. M. (2015). The Energy Footprint: How Oil, Natural Gas, and Wind Energy Affect Land for Biodiversity and the Flow of Ecosystem Services. Bioscience, 65(3), 290-301. https://doi.org/10.1093/biosci/biu224

Kabat-Farr, D., \& Cortina, L. M. (2014). Sex-Based Harassment in Employment: New Insights into Gender and Context. Law and Human Behavior, 38(1), 58-72. https://doi.org/10.1037/lhb0000045

Kassinis, G., Panayiotou, A., Dimou, A., \& Katsifaraki, G. (2016). Gender and environmental sustainability: A longitudinal analysis: gender and environmental sustainability. Corporate Social-Responsibility and Environmental Management, 23(6), 399-412. https://doi.org/10.1002/csr.1386

Kelley, R. (2017). Retiring worn-out wind turbines could cost billions that nobody has. Energy Central. https://energycentral.com/news/retiring-worn-out-wind-turbines-could-costbillions-nobodyhas\#: :text=Estimates\%20put\%20the\%20tear\%2Ddown,above\%20the \%20ground $\% 2 \mathrm{C} \% 20$ at $\% 2$ 
0\%24200\%2C000\%20.\&text=Decommissioning $\% 20$ these $\% 20$ turbines $\% 20$ could $\% 20$ cost $\% 20$ as $\% 20$ much $\% 20$ as\%20\%242.3\%20billion\%20.

Kennedy, E., \& Dzialo, L. (2015). Locating gender in environmental sociology. Sociology Compass, 9(10), 920-929. https://doi.org/10.1111/soc4.12303

Kinver, M. (2020). Black turbine blade 'can cut bird deaths'. BBC News. https://www.bbc.com/news/science-environment-53909825

Kirby, K., \& Marakovic, N. (1996). Delay-discounting probabilistic rewards: Rates decrease as amounts increase. Psychonomic Bulletin \& Review, 3(1), 100-104. https://doi.org/10.3758/BF03210748

Knight, B., \& Paterson, F. (2017). Behavioural competencies of sustainability leaders: an empirical investigation. Journal of Organizational Change Management, 31(3), 557-580. https://doi.org/10.1108/JOCM-02-2017-0035

Koenig, A. M., Eagly, A. H., Mitchell, A. A., \& Ristikari, T. (2011). Are leader stereotypes masculine? A meta-analysis of three research paradigms. Psychological Bulletin, 137(4), 616642.

Konrad, A. M., Kramer, V. W., \& Erkut, S. (2008). The impact of three or more women on corporate boards. Organizational Dynamics, 37, 145-164.

Laan, T., \& Corkal, V. (2020). International best practices: Estimating tax subsidies for fossil fuels in Canada. International Institute for Sustainable Development. https://www.iisd.org/publications/tax-subsidies-canada

Lafleur, C. (2019). Are wind farms a threat to wildlife? Let's talk science. https://letstalkscience.ca/educational-resources/stem-in-context/are-wind-farms-a-threat-wildlife

Lahiri, G., Schwartz, J., \& Volini, E. (2018). The symphonic C-suite: Teams leading teams. Deloitte insights. https:/www2.deloitte.com/us/en/insights/focus/human-capitaltrends/2018/senior-leadership-c-suite-collaboration.html

Landry, E. E., Bernardi, R. A., \& Bosco, S. M. (2016). Recognition for sustained corporate social responsibility: Female directors make a difference. Corporate Social Responsibility and Environmental Management, 23(1), 27-36. https://doi.org/10.1002/csr.1358

Larkin, M., Bernardi, R., \& Bosco, S. (2013). Does female representation on boards of directors associate with increased transparency and ethical behavior? Accounting and the Public Interest, 13(1), 132-150. https://doi.org/10.2308/apin-10374

Lee, S. (2020). What is transformational leadership? Torch blog. https://torch.io/blog/whatis-transformational-leadership/

Lee, U., Han, J., \& Elgowainy, A. (2016). Water consumption factors for electricity production in the United States. Energy Systems Division, Argonne National Laboratory. https://greet.es.anl.gov/files/wcf-2016

Levi, M., Li, K., \& Zhang, F. (2014). Director gender and mergers and acquisitions. Journal of Corporate Finance 28, 185-200. 10.1016/j.jcorpfin.2013.11.005 
Lieu, J., Sorman, A., Johnson, O., Virla, L., \& Resurrección, B. (2020). Three sides to every story: Gender perspectives in energy transition pathways in Canada, Kenya and Spain. Energy Research \& Social Science, 68, 101550-. https://doi.org/10.1016/j.erss.2020.101550

Lipman-Blumen, J. (1996). The connective edge: Leading in an interdependent world. San Francisco: Jossey- Bass.

Liu, C. (2018). Are women greener? Corporate gender diversity and environmental violations. Journal of Corporate Finance (Amsterdam, Netherlands), 52, 118-142. https://doi.org/10.1016/j.jcorpfin.2018.08.004

Lundvall, B. A., Joseph, K., Chaminade, C., \& Vang, J. (2009). Handbook of Innovation Systems and Developing Countries: Building Domestic Capabilities in a Global Setting. Edward Elgar.

Lyngsie, J., \& Foss, N. J. (2017). The more, the merrier? Women in top-management teams and entrepreneurship in established firms. Strategic Management Journal, 38(3), 487-505. https://doi.org/10.1002/smj.2510

Maalouf, G. (2019). Effects of collaborative leadership on organizational performance. International Journal of Multidisciplinary Research and Development, 6(1), 138-144. https://doi.org/10.22271/ijmrd.2019.v6.i1.25

MacDougall, A., Valley, J., \& Jeffrey, J. (2020). 2020 diversity disclosure practices diversity and leadership at Canadian public companies. Osler. https://www.osler.com/en/resources/governance/2020/report-2020-diversity-disclosure-practicesdiversity-and-leadership-at-canadian-public-companies

Markard, J., Raven, R., \& Truffer, B. (2012). Sustainability transitions: An emerging field of research and its prospects. Research Policy, 41(6), 955-967. https://doi.org/10.1016/j.respol.2012.02.013

MacGregor, S. (2009). A stranger silence still: The need for feminist social research on climate change. The Sociological Review, 57, 124-140. https://doi.org/10.1111/j.1467954X.2010.01889.x

MacNeill, J. (2007). Leadership for sustainable development. In Institutionalizing sustainable development, 19-23. Paris: Organisation for Economic Cooperation and Development.

Marshall, J. (2007). The gendering of leadership in corporate social responsibility. Journal of Organizational Change Management, 20(2), 165-181. https://doi.org/10.1108/09534810710724739

Marshall, J. (2011). En-gendering notions of leadership for sustainability. Gender, Work \& Organization, 18(3), 263-281. https://doi.org/10.1111/j.1468-0432.2011.00559.x

Mayer, D. M. (2018). How men get penalized for straying from masculine norms. Harvard Business Review. https://hbr.org/2018/10/how-men-get-penalized-for-straying-from-masculinenorms 
McCright, A., \& Xiao, C. (2014). Gender and environmental concern: Insights from recent work and for future research. Society \& Natural Resources, 27(10), 1109-1113.

https://doi.org/10.1080/08941920.2014.918235

McElhaney, K. A., \& Mobasseri S. (2012). Women create a sustainable future. UC Berkeley Haas School of Business. https://www.eticanews.it/wpcontent/uploads/2012/11/Report-Women_Create_Sustainable_Value.pdf

McFarland, L.J., Senn, L.E. and Childress, J.R. (1994). 21st century leadership: Dialogues with 100 top leaders. The Leadership Press.

McGuinness, P. B., Vieito, J. P., \& Wang, M. (2017). The role of board gender and foreign ownership in the CSR performance of Chinese listed firms. Journal of Corporate Finance, 42, 75-99. https://doi.org/10.1016/j.jcorpfin.2016.11.001

McKelvey, B., \& Boisot, M. H. (2003). Transcendental organizational foresight in nonlinear contexts. Paper presented at the INSEAD Conference on Expanding Perspectives on Strategy Processes, Fontainebleau, France.

Merrill, D. (2021). The U.S. will need a lot of land for a zero-carbon economy. Bloomberg. https:/www.bloomberg.com/graphics/2021-energy-land-use-economy/

Metcalf, L., \& Benn, S. (2013). Leadership for sustainability: An evolution of leadership ability. Journal of Business Ethics, 112(3), 369-384. https://doi.org/10.1007/s10551-012-1278-6

Mikkola, M. (2017). Feminist perspectives on sex and gender. Stanford Encyclopedia of Philosophy. https://plato.stanford.edu/entries/feminism-gender/

Millard, R. (2021). World running out of time to tackle the climate crisis: UN. CTV News. https://www.ctvnews.ca/climate-and-environment/world-running-out-of-time-to-tackle-climatecrisis-un- 1.5393242

Miller, C., Iles, A., \& Jones, C. (2013). The social dimensions of energy transitions. Science as Culture, 22(2), 135-148. https://doi.org/10.1080/09505431.2013.786989

Miller, T., \& Triana, M. (2009). Demographic diversity in the boardroom: Mediators of the board diversity-firm performance relationship. Journal of Management Studies, 46(5), 755-786. https://doi.org/10.1111/j.1467-6486.2009.00839.x

Milne, W. (2003). Women, energy and sustainability: making links, taking action. Canadian Woman Studies, 23(1), 55-60.

Miner, J. B. (1993). Role motivation theories. New York: Routledge.

Mohnen, P. (2019). R\&D, innovation and productivity. MERIT Working Papers. https://ideas.repec.org/p/unm/unumer/2019016.html

Moldoveanu, M., \& Narayandas, D. (2019). The future of leadership development. Harvard Business Review. https://hbr.org/2019/03/the-future-of-leadership-development

Morrison, A. M., \& Von Glinow, M. A. (1990). Women and Minorities in Management. The American Psychologist, 45(2), 200-208. https://doi.org/10.1037/0003-066X.45.2.200 
Murray, J. (2020). Which major oil companies have set net-zero emissions targets? NS Energy. https://www.nsenergybusiness.com/features/oil-companies-net-zero/\#

Natural Resources Canada. (2020a). Energy and greenhouse gas emissions (GHGs). Government of Canada. https://www.nrcan.gc.ca/science-data/data-analysis/energy-dataanalysis/energy-facts/energy-and-greenhouse-gas-emissions-ghgs/20063

Natural Resources Canada. (2020b). Energy and the economy. Government of Canada. https://www.nrcan.gc.ca/science-data/data-analysis/energy-data-analysis/energy-facts/energyand-economy/20062

Natural Resources Canada. (2020c). Renewable energy facts. Government of Canada. https://www.nrcan.gc.ca/science-data/data-analysis/energy-data-analysis/energy-facts/renewableenergy-facts/20069

Noland, M., Moran, T., \& Kotschwar, B. (2016). Is gender diversity profitable? Evidence from a global survey. In Policy File. Peterson Institute for International Economics.

Oparaocha, S., \& Dutta, S. (2011). Gender and energy for sustainable development. Current Opinion in Environmental Sustainability, 3(4), 265-271. https://doi.org/10.1016/j.cosust.2011.07.003

Orr, E., \& Stevenson, J. E. (2017). We interviewed 57 female CEOs to find out how more women can get to the top. Harvard Business Review. https://hbr.org/2017/11/we-interviewed57female-ceos-to-find-out-how-more-women-can-get-to-the-top

Osborn, R., Hunt, J., \& Jauch, L. (2002). Toward a contextual theory of leadership. The Leadership Quarterly, 13 (6), 797-837.

Park, R., Metzger, B., \& Foreman, L. (2019). Promoting gender diversity and inclusion in the oil, gas and mining extractive industries. A Women's Human Rights Report. https://unece.org/DAM/energy/images/CMM/CMM_CE/AHR_gender_diversity_report_FINAL. pdf

Pate, R. C., Hightower, M. M., Cameron, C. P., \& Einfeld, W. (2007). Overview of Energy-Water Interdependencies and the Emerging Energy Demands on Water Resources. http://www.circleofblue.org/wp-content/uploads/2010/09/SANDIA-research.pdf

Pearl-Martinez, R., \& Stephens, J. (2016). Toward a gender diverse workforce in the renewable energy transition. Sustainability: Science, Practice and Policy, 12(1), 8-15. https://doi.org/10.1080/15487733.2016.11908149

Pellegrino, G., D’Amato, S., \& Weisberg, A. (2011). The gender dividend: making the business case for investing in women. Deloitte.

https://www2.deloitte.com/content/dam/Deloitte/ru/Documents/public-sector/gender-dividenden.pdf

Perkins-Gough, D. (2010). Special report / METLIFE survey: Collaboration improves job satisfaction. http://www.ascd.org/publications/educationalleadership/summer10/vol67/num09/MetLife-Survey@-Collaboration-Improves-JobSatisfaction.aspx 
Petit, V. (2014). Male stereotype of a leader persists. Financial Times. https://www.ft.com/content/7fa182cc-7ebd-11e3-8642-00144feabdc0

Pineda, A. C., \& Faria, P. (2019). Towards a science-based approach to climate neutrality in the corporate sector. https://sciencebasedtargets.org/resources/files/Towards-a-science-basedapproach-to-climate-neutrality-in-the-corporate-sector-Draft-for-comments.pdf

Posca, E. (2018). [Review of book Gender relations in Canada: Intersectionalities and social changes, by J. Siltanen, \& A. Doucet]. Canadian Woman Studies, 33(1-2), 240-243.

Post, C., Rahman, N., \& Rubow, E. (2011). Green governance: Boards of directors' composition and environmental corporate social responsibility. Business \& Society, 50(1), 189223. https://doi.org/10.1177/0007650310394642

Powell, G. N. (Ed.). (1999). Handbook of gender and work. Thousand Oaks: Sage

Prasad, S., Sheetal, K. R., Venkatramanan, V., Kumar, S., \& Kannojia, S. (2019). Sustainable Energy: Challenges and Perspectives. In Sustainable Green Technologies for Environmental Management (pp. 175-197). Springer Singapore. https://doi.org/10.1007/978981-13-2772-8_9

Pueyo, A., \& Maestre, M. (2019). Linking energy access, gender and poverty: A review of the literature on productive uses of energy. Energy Research \& Social Science, 53, 170-181. https://doi.org/10.1016/j.erss.2019.02.019

Ramirez, R., Mukherjee, M., Vezzoli, S., \& Kramer, A. (2015). Scenarios as a scholarly methodology to produce "interesting research." Futures : The Journal of Policy, Planning and Futures Studies, 71, 70-87. https://doi.org/10.1016/j.futures.2015.06.006

Rapier, R. (2020). Renewable energy growth continues at a blistering pace. Forbes. https://www.forbes.com/sites/rrapier/2020/08/02/renewable-energy-growth-continues-at-ablistering-pace/?sh=647ae88576b6

Redekop, B. W., \& Olson, S. (Eds.). (2010). Leadership for environmental sustainability. ProQuest Ebook Central https://ebookcentral-proquest-com.proxy.library.carleton.ca

Richardson, L. (2007). The oil sands: Toward sustainable development. Report of the Standing Committee on Natural Resources. https://www.ourcommons.ca/Content/Committee/391/RNNR/Reports/RP2614277/rnnrrp04/rnnr 04-e.pdf

Rogers, A.L., Manwell, J.F., \& Wright, S. (2006). Wind turbine acoustic noise (amended). Renewable Energy Research Laboratory, Department of Mechanical and Industrial Engineering, University of Massachusetts at Amherst. https://docs.wind-watch.org/rogerswindturbinenoise_rev2006.pdf

Rosener, J. B. (1995). America's competitive secret: Utilizing women as management strategy. New York: Oxford University Press.

Rost, J. (1991). Leadership for the twenty-first century. New York: Praeger. 
Sandmann, L.R., \& Vandenberg, L. (1995). A framework for 21st century leadership. Journal of Extension, 33 (6).

Savaget, P., Geissdoerfer, M., Kharrazi, A., \& Evans, S. (2019). The theoretical foundations of sociotechnical systems change for sustainability: A systematic literature review. Journal of Cleaner Production, 206, 878-892. https://doi.org/10.1016/j.jclepro.2018.09.208

Scorsese, M. (Director). (2013). The Wolf of Wall Street [Film]. United States: Paramount Pictures.

Senge, P. M. (1994). The fifth discipline: The art and practice of the learning organization. New York: Doubleday Currency.

Shinbrot, X. A., Wilkins, K., Gretzel, U., \& Bowser, G. (2019). Unlocking women's sustainability leadership potential: Perceptions of contributions and challenges for women in sustainable development. World Development, 119, 120-132. https://doi.org/10.1016/j.worlddev.2019.03.009

Siltanen, J., \& Doucet, A. (2008). Gender relations in Canada : Intersectionalities and social change (First edition.). Oxford University Press.

Silverman, I. (2003). Gender differences in delay of gratification: A meta-analysis. Sex Roles, 49(9), 451-463. https://doi.org/10.1023/A:1025872421115

Smet, K. (2018). Gender and the Clean Economy: Moving beyond "just add women and stir". University of Ottawa, blog. https://www.uottawa.ca/environnement/blogue/gender-andclean-economy-moving-beyond-just-add-women-and-stir

Smith, A., \& Rogers, V. (2000). Ethics-related responses to specific situation vignettes: Evidence of gender-based differences and occupational socialization. Journal of Business Ethics, 28(1), 73-86. https://doi.org/10.1023/A:1006388923834

Smith, M., \& Coady, L. (2018). Canada's energy transition: Getting to our energy future, together. Production Energy Council Report. https://www.nrcan.gc.ca/sites/www.nrcan.gc.ca/files/energy/CoucilReport_june27_English_Web .pdf

Sørensen, I., \& Handcock, T. (2020). Leadership for the decade of action. Report by United Nations Global Compact-Russell Reynolds Associates. https://www.russellreynolds.com/insights/thoughtleadership/Documents/Leadership\%20for\%20the\%20Decade\%20of\%20Action.pdf

Spillias, S., Kareiva, P., Ruckelshaus, M., \& McDonald-Madden, E. (2020). Renewable energy targets may undermine their sustainability. Nature Climate Change, 2020; DOI: $10.1038 / \mathrm{s} 41558-020-00939-\mathrm{x}$

Starbucks. (2020). Global social impact report. https://stories.starbucks.com/uploads/2020/06/2019-Starbucks-Global-Social-Impact-Report.pdf

Sweezy, P. M. (1938). Monopoly and competition in the English coal trade, 1550-1850. Harvard university press. 
Swigonski, M. E., \& Raheim, S. (2011). Feminist Contributions to Understanding Women's Lives and the Social Environment. Affilia, 26(1), 10-21.

https://doi.org/10.1177/0886109910392517

Tardif, P., \& Stanley, J. P. (2020). ESG disclosure requirements and implications for Canadian reporting issuers. Borden Ladner Gervais LLP insights.

https://www.blg.com/en/insights/2020/03/esg-disclosure-requirements-and-implications-forcanadian-reporting-issuers

30\% Club. (2021). Retrieved January 12, 2021, from https://30percentclub.org/

Thurton, D. (2021). New York state pension fund says it's selling off a \$7M stake in oilsands. $C B C$ News. https://www.cbc.ca/news/politics/new-york-state-pension-oilsandsdivestment-1.5983730

Torchia, M., Calabrò, A., \& Huse, M. (2011). Women directors on corporate boards: From tokenism to critical mass. Journal of Business Ethics, 102(2), 299-317. https://doi.org/10.1007/s10551-011-0815-z

Torchia, M., Calabrò, A., Gabaldon, P., \& Kanadli, S. (2018). Women directors contribution to organizational innovation: A behavioral approach. Scandinavian Journal of Management, 34(2), 215-224. https://doi.org/10.1016/j.scaman.2018.02.001

Torchio. (2019). How \& why collaborative leadership works. Torch blog. https://torch.io/blog/how-why-collaborative-leadership-works/

Turcotte, A., Moore, M. C., \& Winter, J. (2012). Energy Literacy in Canada. The School of Public Policy Publications (SPPP), 5(32), 1-47. https://doi.org/10.11575/sppp.v5i0.42402

Uhl-Bien, M., Marion, R., \& McKelvey, B. (2007). Complexity leadership theory: Shifting leadership from the industrial age to the knowledge era. The Leadership Quarterly, 18(4), 298318. https://doi.org/10.1016/j.leaqua.2007.04.002

United Nations. (2021). The 17 goals. https://sdgs.un.org/goals

Upham, P., Dütschke, E., Schneider, U., Oltra, C., Sala, R., Lores, M., Klapper, R., \& Bögel, P. (2018). Agency and structure in a sociotechnical transition: Hydrogen fuel cells, conjunctural knowledge and structuration in Europe. Energy Research \& Social Science, 37, 163-174. https://doi.org/10.1016/j.erss.2017.09.040

U.S. Fish and Wildlife Service. (2018). Entrapment, entanglement \& drowning. https://www.fws.gov/birds/bird-enthusiasts/threats-to-birds/entrapment-entanglementdrowning.php

Verbong, G., \& Geels, F. (2007). The ongoing energy transition: Lessons from a sociotechnical, multi-level analysis of the Dutch electricity system (1960-2004). Energy Policy, 35(2), 1025-1037. https://doi.org/10.1016/j.enpol.2006.02.010

Visser, W., \& Courtice, P. (2011). Sustainability leadership: Linking theory and practice. SSRN Electronic Journal. https://dx.doi.org/10.2139/ssrn.1947221 
Wall, K. (2019). Persistence and representation of women in STEM programs. Statistics Canada. https://www150.statcan.gc.ca/n1/pub/75-006-x/2019001/article/00006-eng.htm

Winther, T., Ulsrud, K., \& Saini, A. (2018). Solar powered electricity access: Implications for women's empowerment in rural Kenya. Energy Research \& Social Science, 44, 61-74. https://doi.org/10.1016/j.erss.2018.04.017

Women's Initiative. (2018). Gender matters - Women disproportionately report sexual harassment in male-dominated industries. Center for American Progress. https://www.americanprogress.org/issues/women/news/2018/08/06/454376/gender-matters/

Woolley, A.W., Chabris, C.F., Pentland, A., Hashmi, N., \& Malone, T.W. (2010). evidence for a collective intelligence factor in the performance of human groups. Science (American Association for the Advancement of Science), 330(6004), 686-688. https://doi.org/10.1126/science.1193147

World Business Council for Sustainable Development. (2011). Enabling leadership for sustainability. http://wbcsdservers.org/wbcsdpublications/cd_files/datas/capacity_building/people_matter/pdf/P eopleMatterLead.pdf

World Nuclear Association. (2011). Comparison of Lifecycle Greenhouse Gas Emissions of Various Electricity. http://www.worldnuclear.org/uploadedFiles/org/WNA/Publications/Working_Group_Reports/comparison_of_lifec ycle.pdf

World Wildlife Fund (WWF). (2016). Habitat-friendly renewable energy. https://www.nrcan.gc.ca/sites/www.nrcan.gc.ca/files/energy/energy-resources/WWF_-_HabitatFriendly-Renewable-Energy.pdf

Xie, J., Nozawa, W., \& Managi, S. (2020). The role of women on boards in corporate environmental strategy and financial performance: A global outlook. Corporate SocialResponsibility and Environmental Management, 27(5), 2044-2059. https://doi.org/10.1002/csr.1945

Zelezny, L., Chua, P., \& Aldrich, C. (2000). elaborating on gender differences in environmentalism. Journal of Social Issues, 56(3), 443-457.

Zenger, J., \& Folkman, J. (2019). Research: Women score higher than men in most leadership skills. Harvard Business Review. https://hbr.org/2019/06/research-women-score-higherthan-men-in-most-leadership-skills 


\section{Appendix: Interview Guide}

Part 1: Review of ethics, procedures to protect participant identity, and reaffirm informed consent

Part 2: Introductory questions

1) How long have you worked in the energy sector? This company? What is your current role?

2) Approximately how many people do you lead or are you in charge of?

3) What is the gender make-up of your company? Are there many women? How many would you estimate? Is that a substantial portion of total employees? In what capacity do they work? (team leaders, administrative, engineers, CEO...etc.)

4) When I say 'sustainable energy transition' what do you think of and what kind of challenges or obstacles come to mind?

Part 3: Scenarios

I'm going to present a few scenarios to you and ask you what you would do. I understand that this may not these may not necessarily be the kind of situations you would find your self in in your current role. However, what I'm interested in is your thought process. So, in all scenarios, I'm going to ask you to 'think out loud'.

Scenario 1: You have to make a decision about your company investing in an energy project. Regardless of what kind of project this, when it comes to prioritizing outcomes when you are making your decision, what would your top 3 priorities/determining factors be? Why did you choose these? Can you talk me through your reasoning process?

Scenario 2: Someone above you in the hierarchy has made a decision and you have some concerns. Based on what you know about this decision, you think that it could have some harmful environmental consequences and these consequences have not been properly assessed and the community that lives in the area has not been made aware of them. How would you proceed? Like the previous question, can you 'think out loud' and verbalize your reasoning?

Scenario 3: You are once again making a decision relating to investment in an energy project [like scenario 1]. This time, you know that there is a good chance that in 30-40 years the project is going to have some very negative consequences on the local ecology. How do you account for this in making your decision?

Scenario 4: You and your team have an idea regarding how to proceed in addressing a problem. Another employee in your company disagrees and has a different idea. Can you talk me through how you would deal with this situation and why?

- Prompts/follow-up: What mechanisms do you currently have to facilitate new ideas? Can you give me an example?

- Prompts/follow-up: Would you say that you are the kind of person who often thinks up new ideas? Is creativity and doing this your own original way important to you? 
Scenario 5: [2 parts]

Part 1: You are leading a team on a file relating to an energy project and you have an important deadline coming up. Your team has been working hard, but you still aren't sure if, at the current pace, the project will be completed on time. What are your priorities in this situation and how would you proceed?

Part 2: Same scenario. But now I'm going to give you a bit more information. This project you're in charge of is a feasibility study for a big energy project that's going to affect a lot people and there are a lot of stakeholders involved. You're running out of time, but you haven't had the chance to have substantive public or stakeholder engagement sessions yet. How would you proceed and why?

Part 4: Moving forward

1). Based on your experiences, do you think that women face barriers to entry and/or advancement in the Canadian energy sector? If yes, why? If not, why not?

- If yes, continue to the discussion by asking what they would suggest could be done to foster the advancement of women in the Canadian energy sector.

2). Once again, based on your experiences, do you think that gender is a relevant factor in identifying leadership for a sustainable energy transition in Canada?

- If prompts are needed: Do you think gender could influence leadership characteristics? If so how? Do you think these characteristics would be of value to your institution/ business?

3). What gender do you identify as? What are your preferred pronouns?

4). Is there anything else you would like to add?

Thank you! If you know any other leaders in the Canadian energy sector who you think might be interested in participating in this study, please pass along my email address and encourage them to reach out to me. 